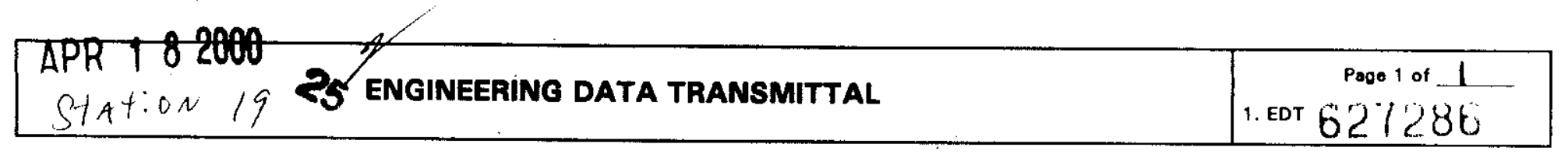

\begin{tabular}{|l|l|}
\hline $\begin{array}{l}\text { 2. To: (Receiving Organization) } \\
\text { DISTRIBUTION }\end{array}$ & $\begin{array}{l}\text { 3. From: (Originating Organization) } \\
\text { IWTS SUBPROJzCT }\end{array}$ \\
\hline $\begin{array}{l}\text { 5. Proj./Prog./Dept./Div.: } \\
\text { SNE PROJECT/A.9/IWTS SUBRROJECT }\end{array}$ & $\begin{array}{l}\text { 6. Design Authority/Design Agent/Cog. Engr.: } \\
\text { D. PRSCSCHTEL/R. DeRUSSEAU }\end{array}$ \\
\hline
\end{tabular}

8. Originator Remarks:

DRAFT KW IWTS SDD (70.3) IS SUBMITTED FOR APPROVAL

ON THE ACCELERATED SCHEDULE

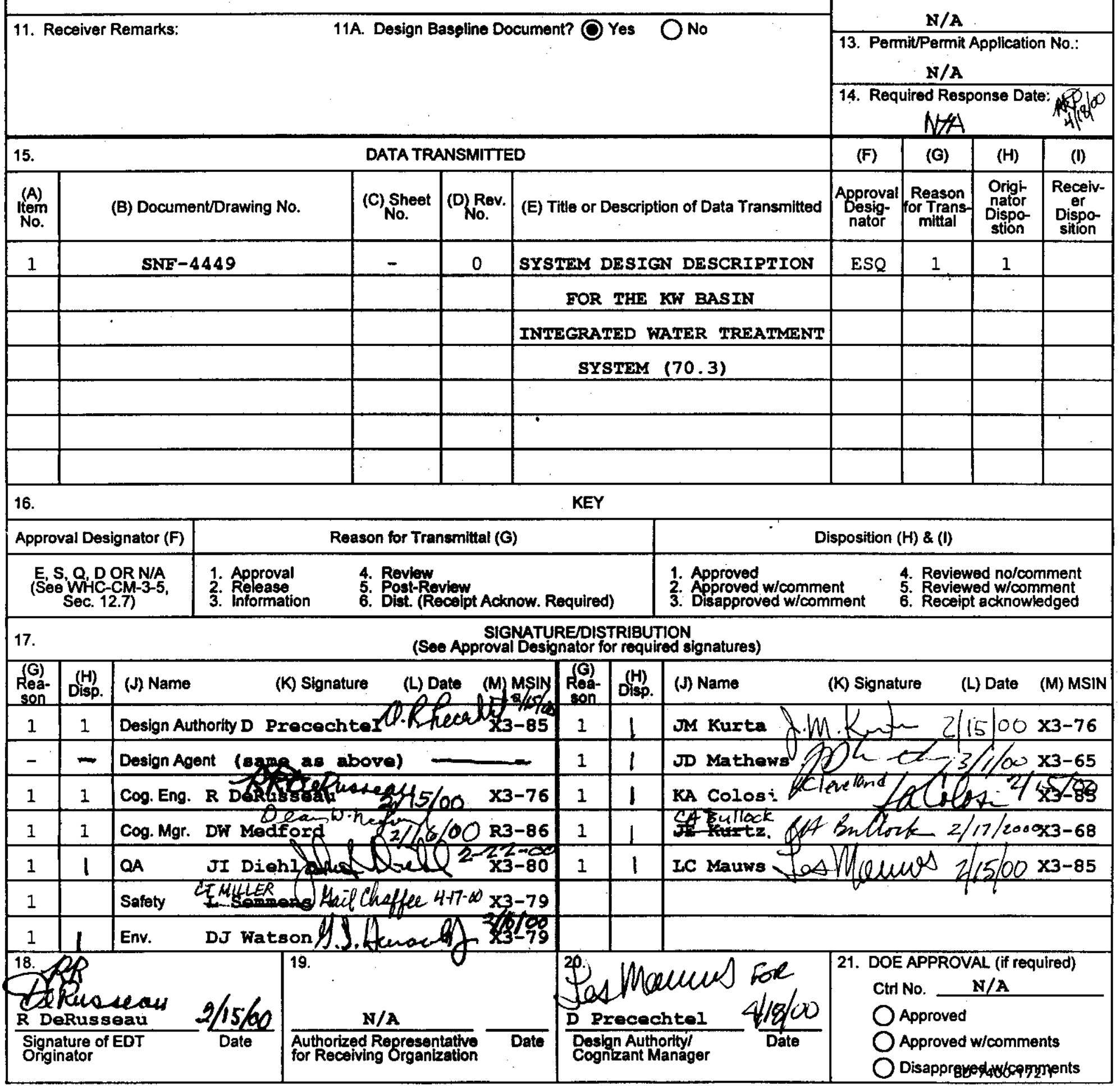


S

\section{System Description for the KW Basin Integrated Water Treatment System (70.3)}

Prepared for the U.S. Department of Energy

Assistant Secretary for Environmental Management

Project Hanford Management Contractor for the

U.S. Department of Energy under Contract DE-AC06-96RL13200

Fluor Hanford

P.O. Box 1000

Richland, Washington 
SNF-4449

Revision 0

EDT 627286

Total Pages 118

\section{System Description for the KW Basin Integrated Water Treatment System (70.3)}

RR DeRusseau

Fluor Daniel Hanford, Inc.

DR Precechtel

Fluor Daniel Hanford, Inc.

Date Published

April 2000

Prepared for the U.S. Department of Energy

Assistant Secretary for Environmental Management

Project Hanford Management Contractor for the

U.S. Department of Energy under Contract DE-AC06-96RL13200

Fluor Hanford

P.O. Box 1000

Richland, Washington
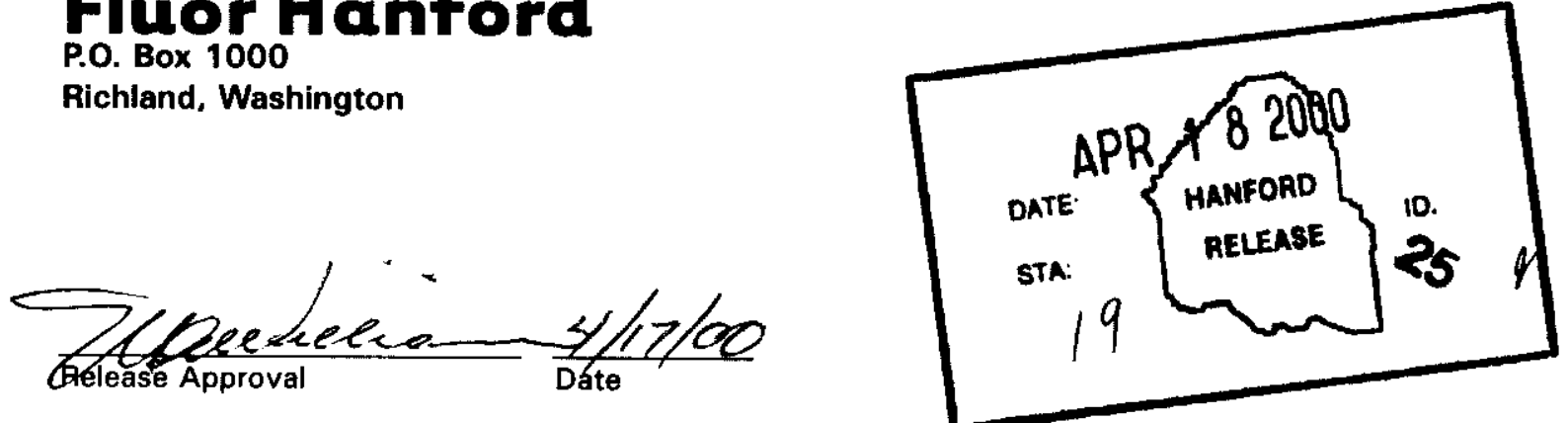
SNF-4449

Revision 0

TRADEMARK DISCLAIMER

Reference herein to any specific commercial product, process, or service by trade name, trademark, manufacturer, or otherwise, does not necessarily constitute or imply its endorsement, recommendation, or favoring by the United

States Government or any agency thereof or its contractors or subcontractors.

This report has been reproduced from the best available copy. Available in paper copy and microfiche.

Available electronically at http:/hwww.doe.gov/bridge. Available for a processing fee to the U.S. Department of Energy and its contractors, in paper, from:

U.S. Department of Energy

Office of Scientific and Technical Information

P.O. Box 62

Oak Ridge, TN 37831-0062

phone: 865-576-8401

fax: 865-576-5728

email: reports@adonis.osti.gov(423) 576-8401 
Key Words: K Basins, SDD, IWTS, Knockout Pot, Settler, Garnet Filter, IXM, Submerged Pump, Booster Pump, Water Treatment

\begin{abstract}
This is a description of the system that collects and processes the sludge and radioactive ions released by the spent nuclear fuel (SNF) processing operations conducted in the $105 \mathrm{KW}$ Basin. The system screens, settles, filters, and conditions the basin water for reuse. Sludge and most radioative ions are removed before the water is distributed back to the basin pool. This system is part of the Spent Nuclear Fuel Project (SNFP).
\end{abstract}




\section{TABLE OF CONTENTS}

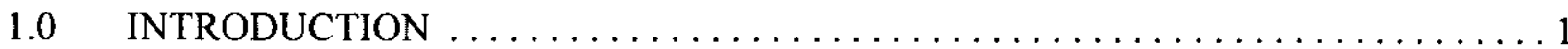

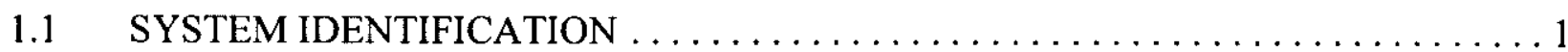

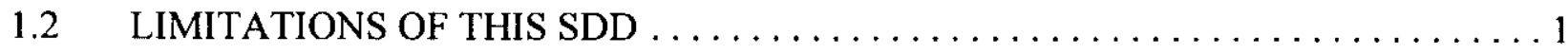

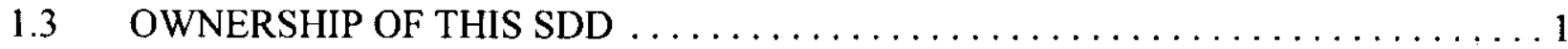

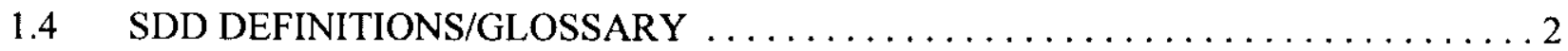

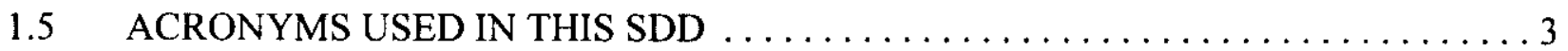

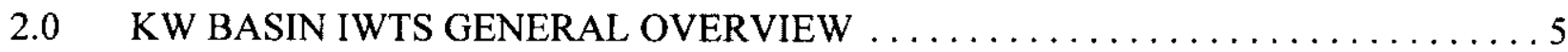

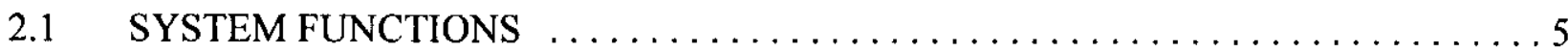

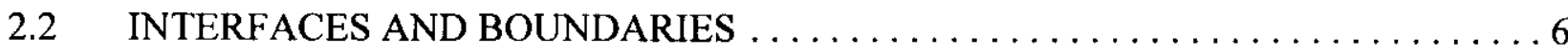

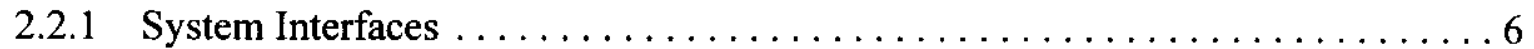

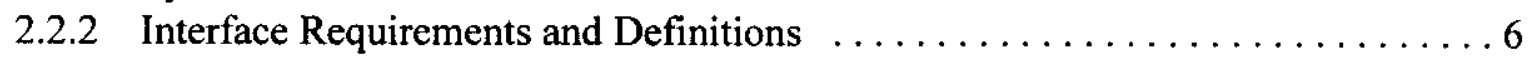

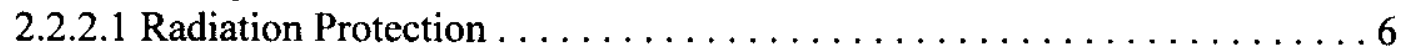

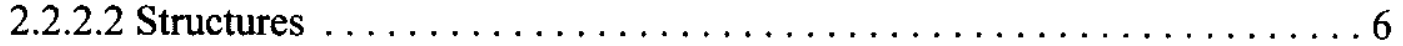

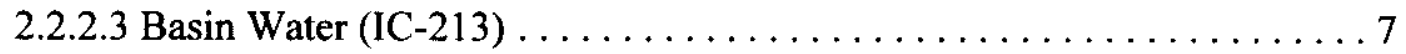

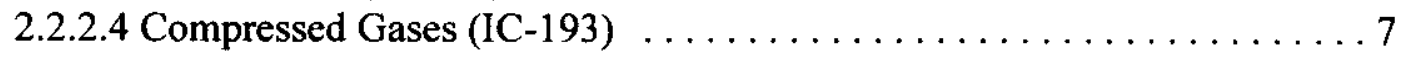

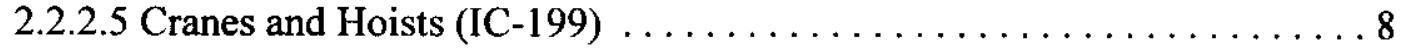

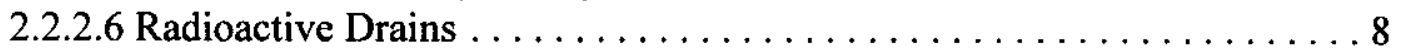

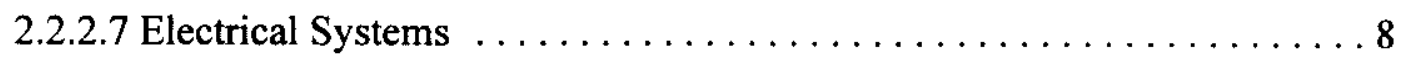

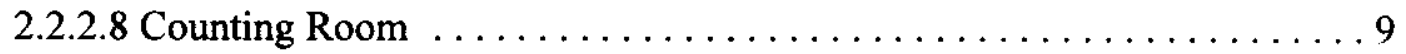

2.2.2.9 Fuel Retrieval System (ICs-016, 017, $091 \& 198) \ldots \ldots \ldots \ldots \ldots .9$

2.2.2.10 Cask Loading (ICs-046 \& 189) . .................. 10

2.2.2.11 Debris Removal (ICs-042, $051 \&$ 177) $\ldots \ldots \ldots \ldots \ldots \ldots \ldots \ldots 10$

2.2.2.12 Sludge Removal (ICs-053, $065 \& 204) \ldots \ldots \ldots \ldots \ldots \ldots \ldots \ldots 11$

2.2.2.13 CVDF Process Water Conditioning (IC-012) $\ldots \ldots \ldots \ldots \ldots \ldots 11$

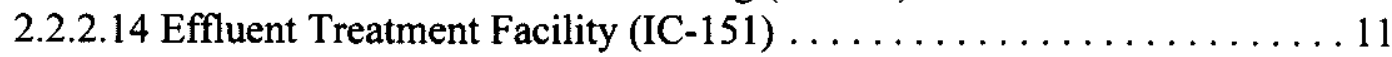

2.2.2.15 Solid Waste Disposal (ICs-146, $147 \&$ 229) . . . . . . . . . . . 12

2.2 .3 System Boundaries . . . . . . . . . . . . . . . . . . . . . . . . . . . 12

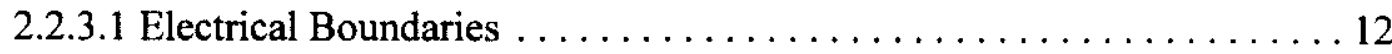

2.2.3.2 Mechanical Boundaries ........................... 13

2.3 SYSTEM SAFETY AND QUALITY CLASSIFICATIONS $\ldots \ldots \ldots \ldots \ldots \ldots \ldots \ldots$

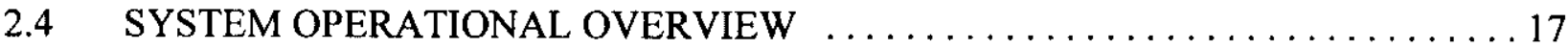

$3.0 \quad$ KW BASIN IWTS DESIGN REQUIREMENTS AND BASES $\ldots \ldots \ldots \ldots \ldots \ldots$

3.1 SYSTEM DESIGN REQUIREMENTS AND BASES $\ldots \ldots \ldots \ldots \ldots \ldots \ldots \ldots \ldots$

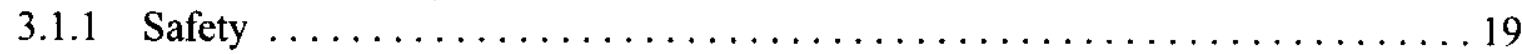

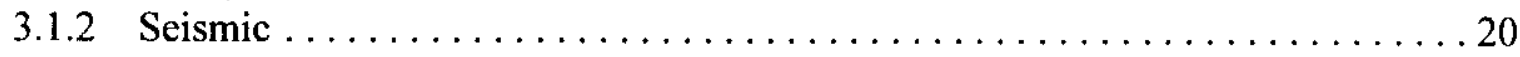

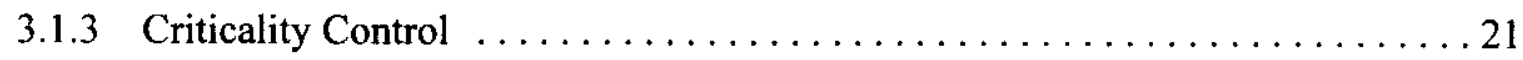

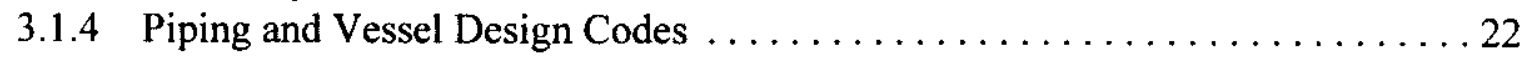

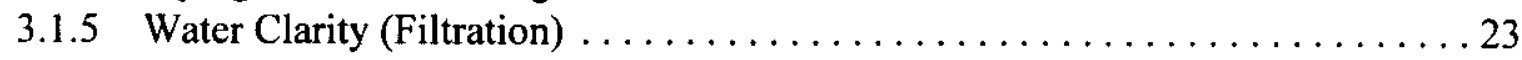

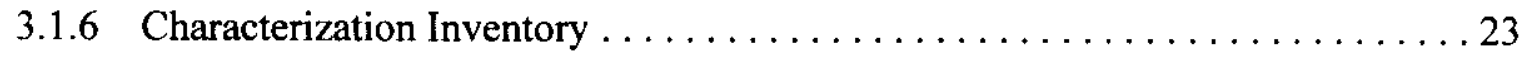

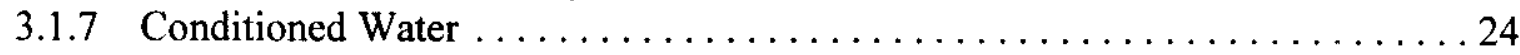




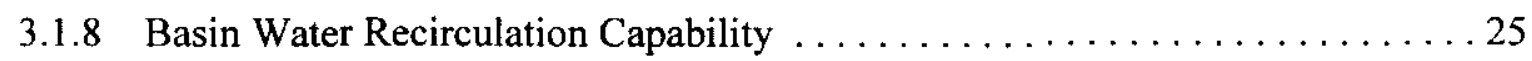

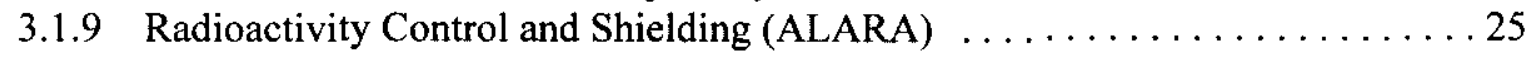

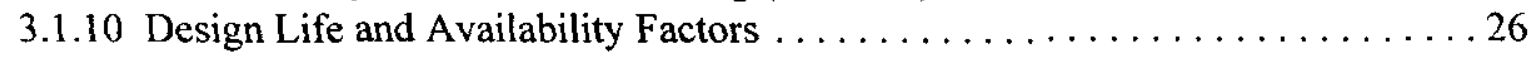

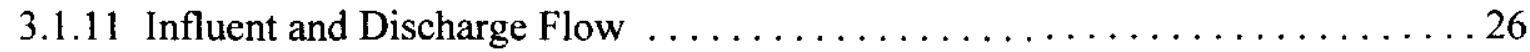

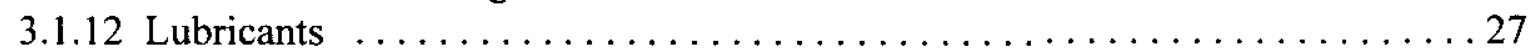

3.2 COMPONENT DESIGN REQUIREMENTS AND BASIS $\ldots \ldots \ldots \ldots \ldots \ldots \ldots 28$

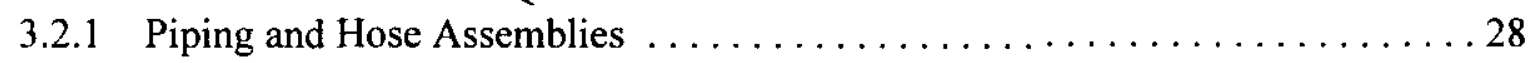

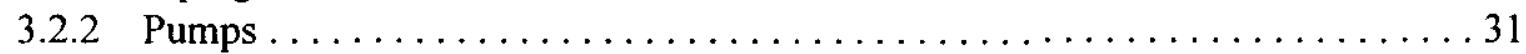

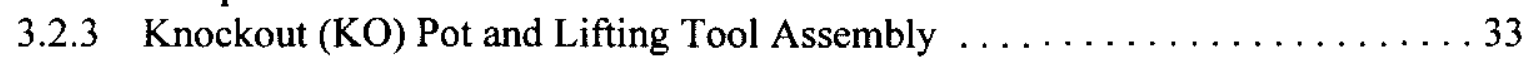

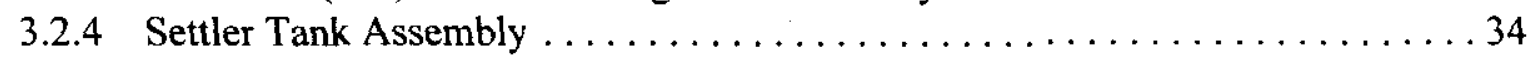

3.2.5 Garnet Filter Vessels and HEPA Subsystem $\ldots \ldots \ldots \ldots \ldots \ldots \ldots \ldots \ldots \ldots$

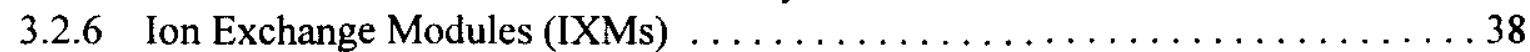

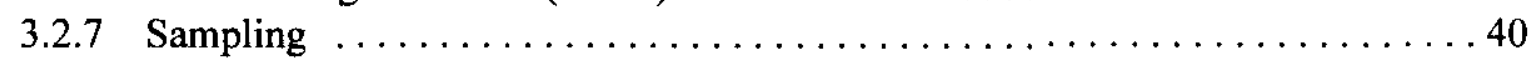

3.3 INSTRUMENTATION AND CONTROL REQUIREMENTS AND BASIS . . . . 41

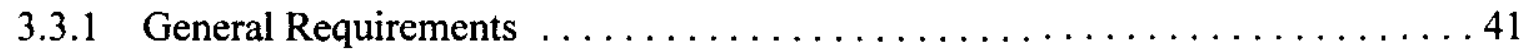

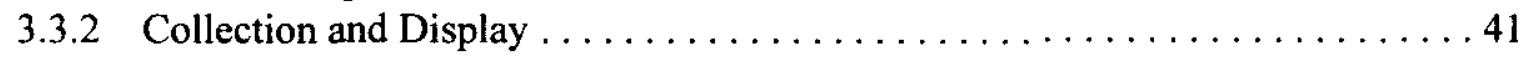

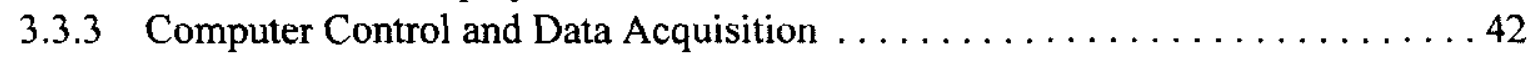

3.4 TESTING AND MAINTENANCE $\ldots \ldots \ldots \ldots \ldots \ldots \ldots \ldots \ldots \ldots \ldots \ldots \ldots \ldots$

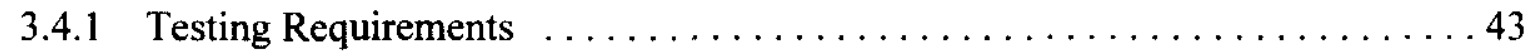

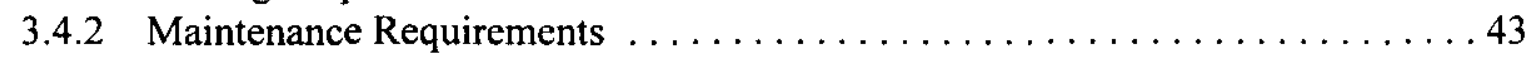

$4.0 \quad$ KW BASIN IWTS DESIGN DESCRIPTION $\ldots \ldots \ldots \ldots \ldots \ldots \ldots \ldots \ldots \ldots$

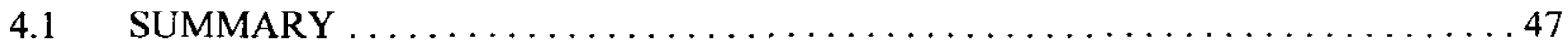

4.2 INTERFACES AND BOUNDARIES $\ldots \ldots \ldots \ldots \ldots \ldots \ldots \ldots \ldots \ldots \ldots \ldots$

4.3 PHYSICAL LOCATION AND LAYOUT $\ldots \ldots \ldots \ldots \ldots \ldots \ldots \ldots \ldots \ldots \ldots \ldots$

4.4 PRINCIPLES OF OPERATION $\ldots \ldots \ldots \ldots \ldots \ldots \ldots \ldots \ldots \ldots \ldots \ldots \ldots \ldots \ldots . \ldots 49$

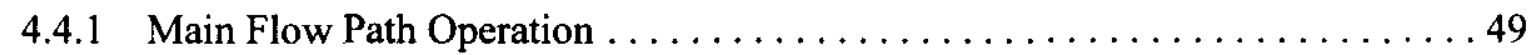

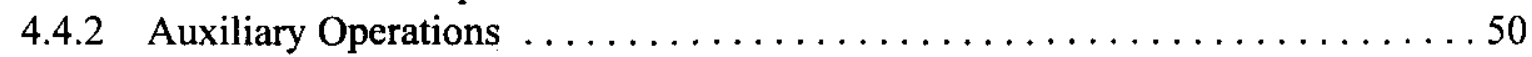

4.5 COMPONENT DESIGN DESCRIPTION $\ldots \ldots \ldots \ldots \ldots \ldots \ldots \ldots \ldots \ldots \ldots \ldots$

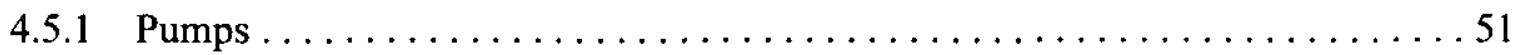

4.5.1.1 Submersible Pumps (FRW-P-1, $2 \& 3$ ) and Lifting Tool . . . . . . 51

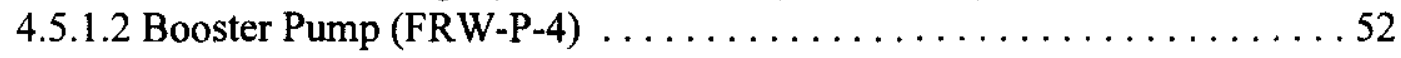

4.5.1.3 Metering Pump (FRW-P-5) and Assembly $\ldots \ldots \ldots \ldots \ldots \ldots \ldots$

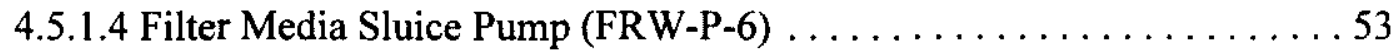

4.5.2 Knockout Pot (FRW-KOP-100) and Lifting Tool (KW-KOPH-1) . . . . . 53

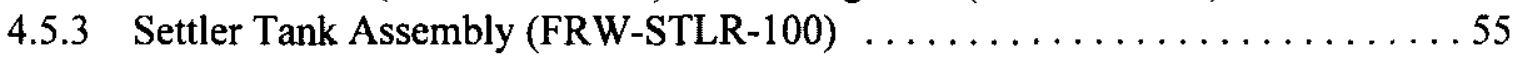

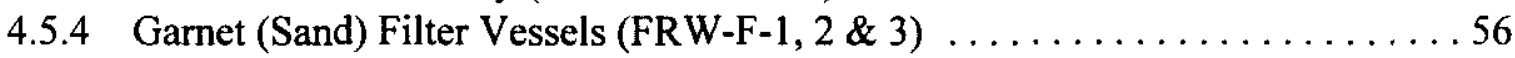

4.5.5 Ion Exchange Modules (IXM-1, $2 \& 3) \ldots \ldots \ldots \ldots \ldots \ldots \ldots \ldots \ldots$

4.5.6 Automatic Samplers (AS-420-1, 2, $3 \& 4) \ldots \ldots \ldots \ldots \ldots \ldots \ldots$

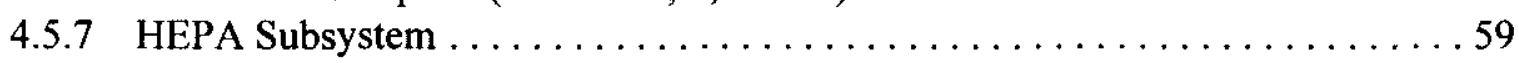

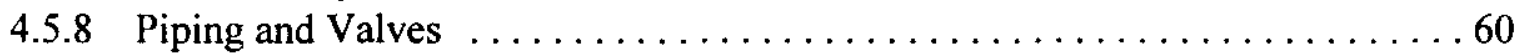

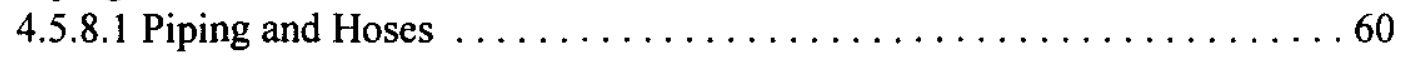

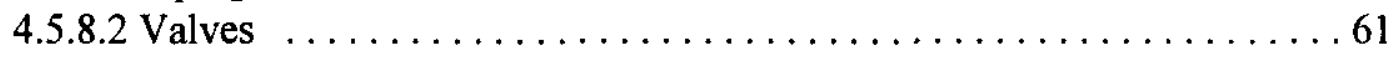

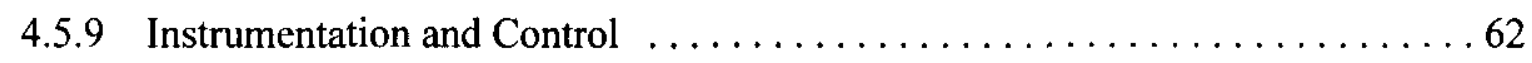




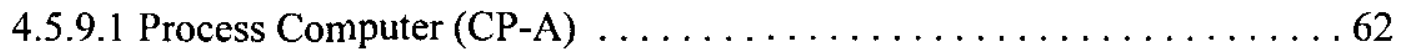

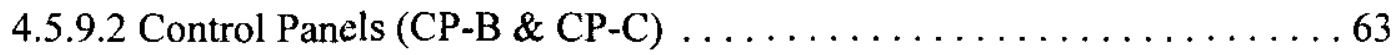

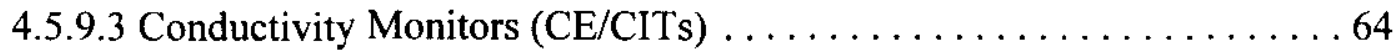

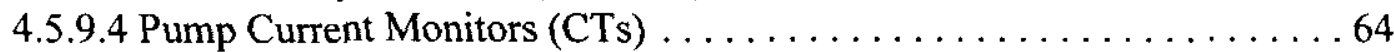

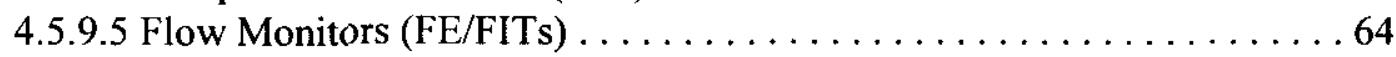

4.5.9.6 Flow Switch (FS) . . . . . . . . . . . . . . . . . . . 65

4.5.9.7 Liquid Level Detector Switch (LE) . .................... 66

4.5.9.8 Differential Pressure Indicators (DPITs and DPIs) $\ldots \ldots \ldots \ldots \ldots 66$

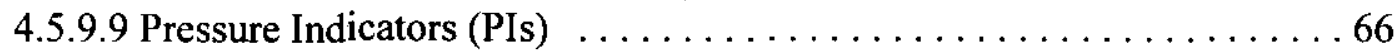

4.5.9.10 Pressure Indicator Transmitters (PITs) $\ldots \ldots \ldots \ldots \ldots \ldots \ldots 67$

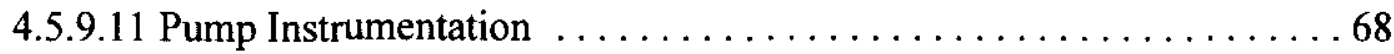

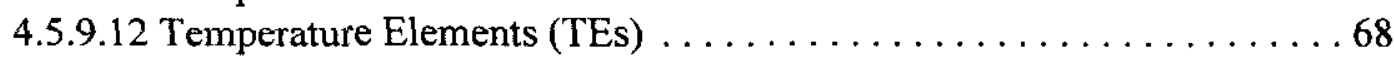

4.5.9.13 Radiation Indicators (RE/RITs) $\ldots \ldots \ldots \ldots \ldots \ldots \ldots \ldots \ldots 6$

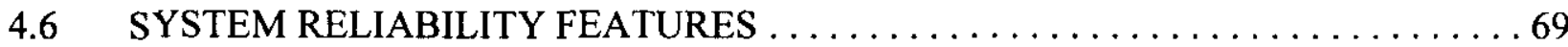

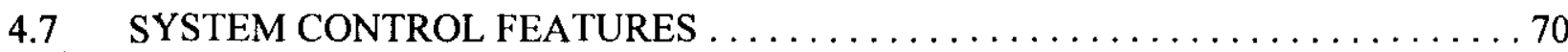

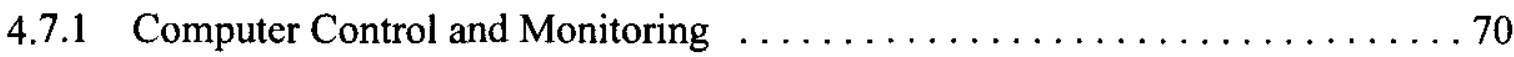

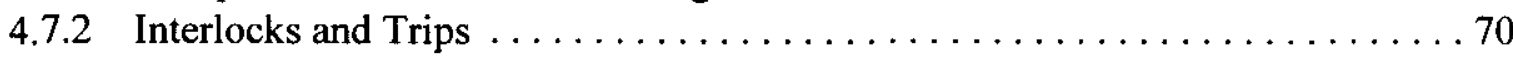

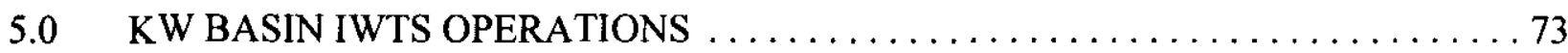

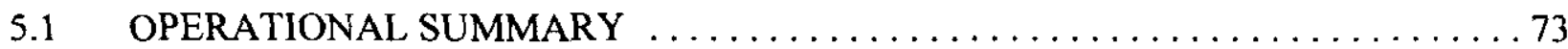

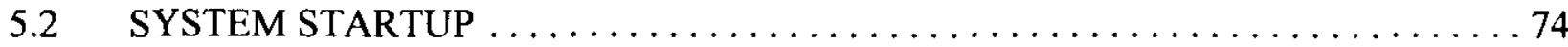

5.2.1 KO Pot and Settler Tank Assembly Fill and Vent ............... 74

5.2.2 Booster Pump and Garnet Filter Fill and Vent $\ldots \ldots \ldots \ldots \ldots \ldots \ldots . \ldots 74$

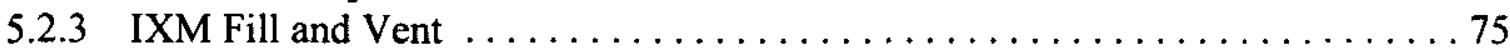

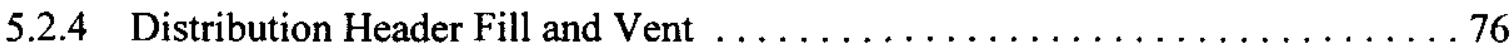

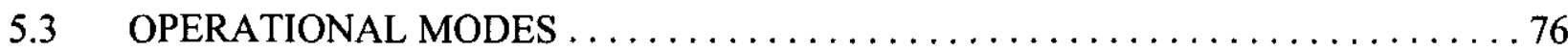

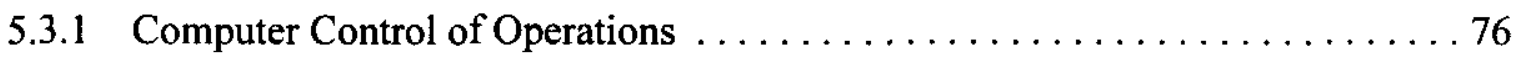

5.3 .2 FRS Shutdown (Mode 1) ................................. 77

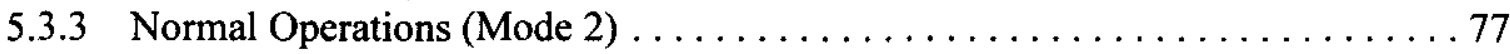

5.3.4 Garnet Filter Bed Top Sparge (Modes 3, 4\& 5) ................. 78

5.3.5 Garnet Filter Bed Backwash (Modes 6, 7 \& 8) ................. 79

5.3.6 Garnet Filter Air Sparge (Modes 9, $10 \&$ 11) .................. 79

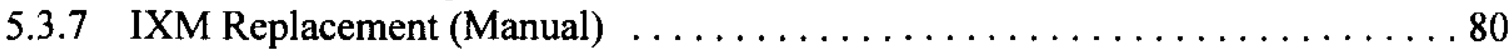

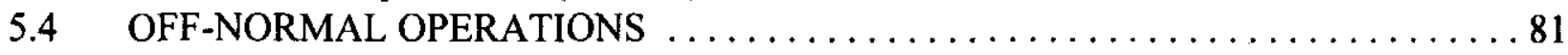

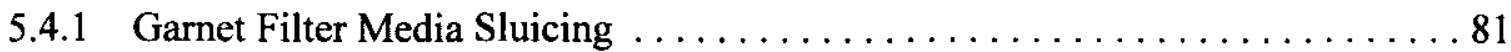

5.4 .2 Emergency Garnet Filter Backwash $\ldots \ldots \ldots \ldots \ldots \ldots \ldots \ldots \ldots \ldots . \ldots \ldots$

5.4.3 Filter Sparge or Backwash Using Recirculation Pump $\ldots \ldots \ldots \ldots \ldots \ldots . \ldots 82$

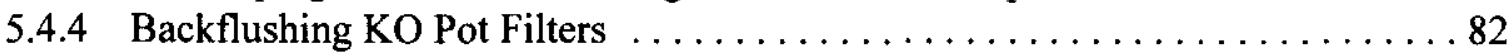

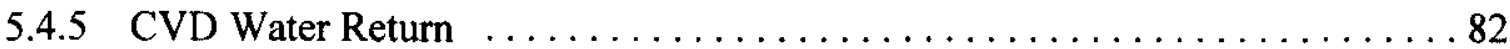

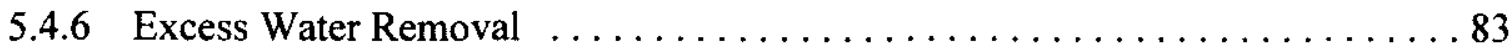

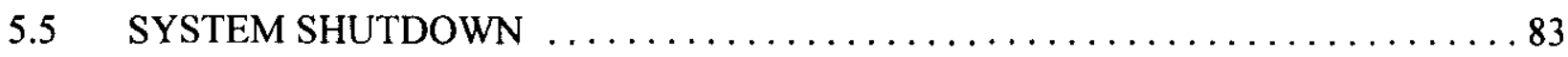

5.6 SAFETY MANAGEMENT AND ADMINISTRATIVE CONTROLS $\ldots \ldots \ldots \ldots 83$

5.7 LIMITATIONS AND PRECAUTIONS $\ldots \ldots \ldots \ldots \ldots \ldots \ldots \ldots \ldots \ldots \ldots \ldots \ldots$

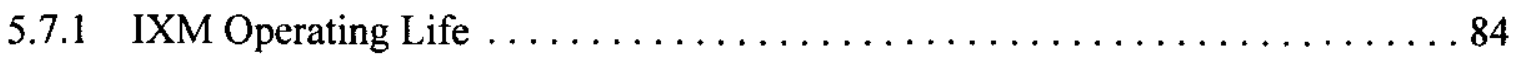




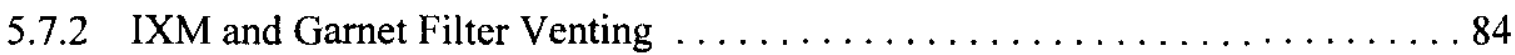

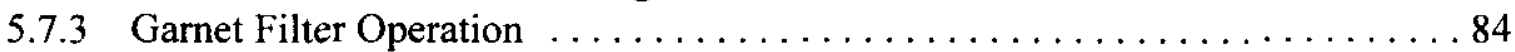

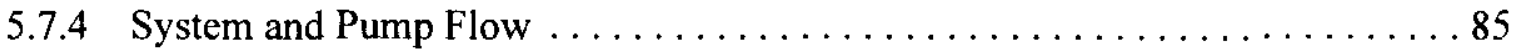

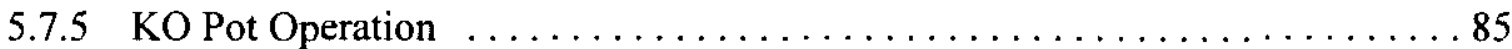

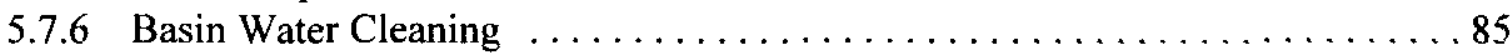

5.8 CASUALTY EVENTS AND RECOVERY PROCEDURES $\ldots \ldots \ldots \ldots \ldots \ldots$

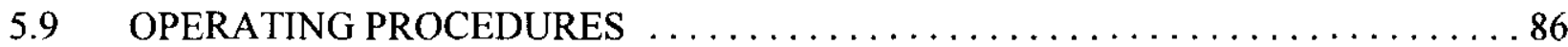

$6.0 \quad$ KW BASIN IWTS TESTING AND MAINTENANCE $\ldots \ldots \ldots \ldots \ldots \ldots \ldots . \ldots . \ldots 7$

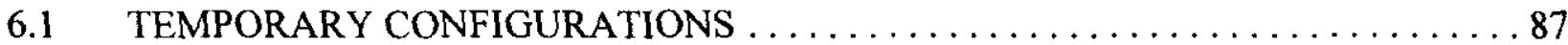

6.2 TSR-REQUIRED SURVEILLANCE $\ldots \ldots \ldots \ldots \ldots \ldots \ldots \ldots \ldots \ldots \ldots \ldots \ldots \ldots$

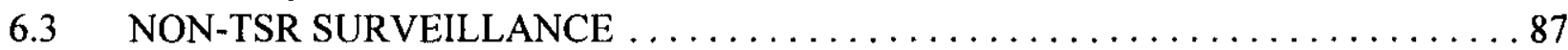

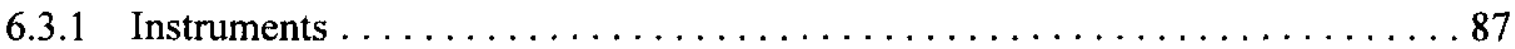

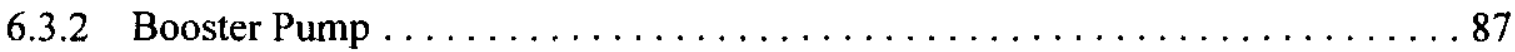

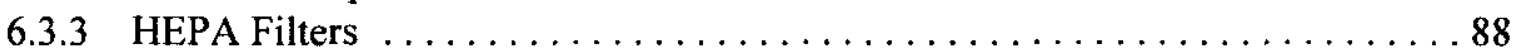

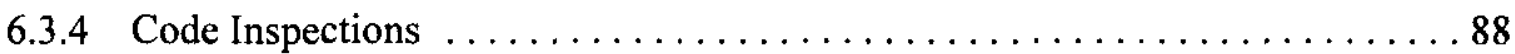

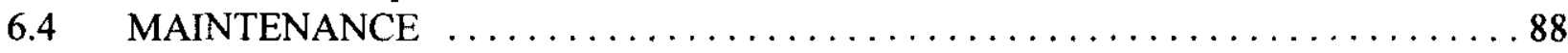

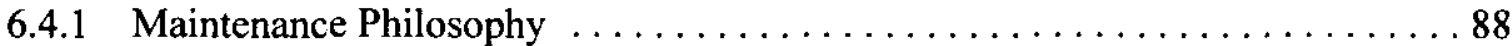

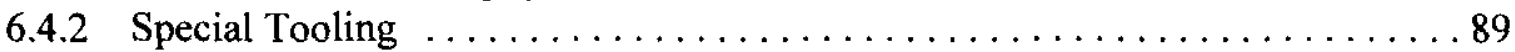

6.4.2.1 Long Reach Tools - Existing $\ldots \ldots \ldots \ldots \ldots \ldots \ldots \ldots \ldots \ldots$

6.4.2.2 Special Component Tools ........................ 89

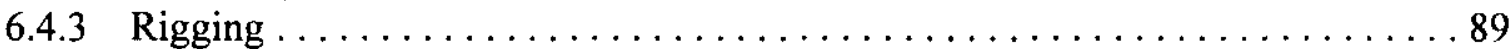

6.4.3.1 IWTS In-Pool Equipment Rigging $\ldots \ldots \ldots \ldots \ldots \ldots \ldots \ldots$

6.4.3.2 Transfer Bay Area Rigging $\ldots \ldots \ldots \ldots \ldots \ldots \ldots \ldots \ldots . \ldots \ldots$

6.5 SURVEILLANCE AND MAINTENANCE PROCEDURES $\ldots \ldots \ldots \ldots \ldots \ldots 90$

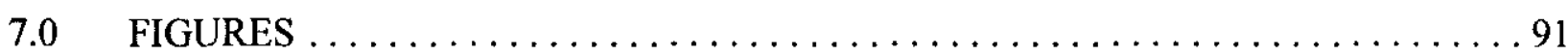

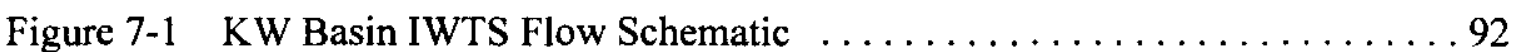

Figure 7-2 KW Basin IWTS Equipment in the Fuel Pool ............... 93

Figure 7-3 KW Basin IWTS Equipment in the Transfer Bay Area $\ldots \ldots \ldots \ldots .94$

Figure 7-4 Transfer Bay Area Equipment Isometric $\ldots \ldots \ldots \ldots \ldots \ldots \ldots . \ldots 9$

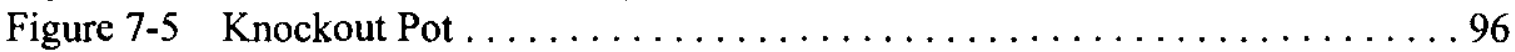

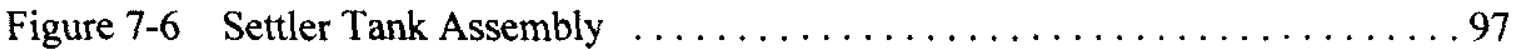

Figure 7-7 Garnet Filter Vessel Schematic . . . . . . . . . . . . . . . . . 98

Figure $7-8$ Ion Exchange Module $\ldots \ldots \ldots \ldots \ldots \ldots \ldots \ldots \ldots$

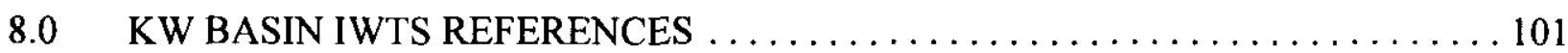

8.1 DOCUMENTS . . . . . . . . . . . . . . . . . . . . . . . . . . . . 101

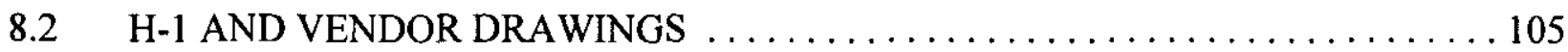

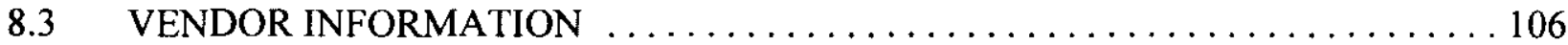

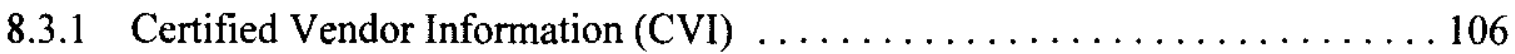

8.3.2 Trademark Data ................................... 106 



\section{$1.0 \quad$ INTRODUCTION}

\subsection{SYSTEM IDENTIFICATION}

This is a system design description (SDD) for the $105 \mathrm{KW}$ Basin Integrated Water Treatment System (IWTS), System 70.3. This IWTS is Subproject A.9 and is part of the overall Spent Nuclear Fuel Project (SNFP). The main purpose of this system is to support fuel, canister, and debris removal from the $105 \mathrm{KW}$ Basin. The system is responsible for filtering and conditioning the water from basin fuel processing activities, supplying treated water for basin activities, and supplementing the normal basin pool water filtering and conditioning system. Therefore, the major operating system interfaces of the IWTS are the portions of the Fuel Retrieval System (FRS) and the Basin Water System that are dedicated to the $105 \mathrm{KW}$ Basin.

The IWTS described in this SDD is located entirely within the $105 \mathrm{KW}$ Reactor Building. The system mechanical components are located within the basin (above and in the pool) with remote monitoring and control conducted from panels within Rooms 4 and 20A.

This system should not be confused with the Basin Water System (7.3) that is responsible for normal continuous water treatment of the $105 \mathrm{KW}$ and KE Basin pools, the similar (but much more extensive) $105 \mathrm{KE}$ Basin Integrated Water Treatment System (70.4) which supports fuel removal activities in $105 \mathrm{KE}$, and the Basin Demineralized Water System (7.4) which provides pool makeup and washdown water in $105 \mathrm{KW}$ and KE Basins. All, including the $105 \mathrm{KW}$ Basin IWTS, are sometimes called just water treatment systems (WTS).

\subsection{LIMITATIONS OF THIS SDD}

This SDD does not cover the IWTS in the 105 KE Reactor Building. The SDD text does not attempt to tabulate the equipment list, procedures, operating and alarm set points, and any other data expected to change during system operation. Instead of constantly revising the SDD to eliminate changing and possibly misleading data, the reader is referred to the centralized current data bases for this information. All data concerning the IWTS mechanical components and instruments are found in the K Basins Component Number/Master Equipment List and the Certified Vendor Information (CVI) Files. The most current alarm, administrative, compliance, emergency, facility, maintenance, operating, radiological, and surveillance procedures (AR, AP, CP, ER, FTP, MP, OP, RP, and SP procedures, respectively) can be found on the Hanford intranet under SNFP Technical Procedures Online. These SDD limitations support obtaining accurate IWTS component data and assuring procedural compliance.

\subsection{OWNERSHIP OF THIS SDD}

The IWTS Design Authority is the owner of this SDD and is ultimately responsible for the technical content, reviewing changes to the SDD, and issuing needed revisions. Any questions on the system or the content of this SDD will be resolved through the IWTS Design Authority. Questions on system design and operation should be referred to the IWTS Technical Authority. 


\subsection{SDD DEFINITIONS/GLOSSARY}

The following terms and phrases are used in this SDD:

conditioned Conditioned water has undergone anion and cation removal in the IWTS ion exchange modules (IXMs). Normally, IWTS conditioned effluent has concentrations of $\leq 0.05 \mu \mathrm{Ci} / \mathrm{L}$ of ${ }^{137} \mathrm{Cs}, \leq 0.05 \mu \mathrm{Ci} / \mathrm{L}$ of ${ }^{90} \mathrm{Sr}, \leq 0.005 \mu \mathrm{Ci} / \mathrm{L}$ of total alpha radiation emitters, and a conductance of $\leq 1 \mu \mathrm{Mho} / \mathrm{cm}$.

clear water Clear (clarified) water that has passed through a filtration system with a nominal operating rating of $5 \mu \mathrm{m}$ with the intent of providing good visibility through at least 16 feet of water for objects illuminated from the side by underwater lighting.

debris Normally, material of non-reactor origin (has never been in the reactor) that has any physical dimension $>0.25$ inch. There can be specific exceptions for other types of non-fuel, low level radioactive waste.

fuel Fuel includes any pieces of spent nuclear fuel (SNF) whose largest dimension is $>0.25$-in and includes both fuel and fuel scrap. Scrap is partial or damaged fuel elements or other reactor origin material not classified as debris, sludge, or acceptable fuel with a size $>0.25$-inch in any dimension.

garnet

Garnet is a hard, glass like material that is used as part of the IWTS filter media. The term garnet filter is used to differentiate between the new IWTS sand filters and the existing Basin Water System sand filter.

liquor Fluid within in a capped fuel canister, composed of water, potassium nitrite inhibitor, and soluble fission products. The FRS and IWTS plan to contain, capture, and process most of this fluid during canister decapping.

sludge Refers to any loose basin material having any physical dimension $<0.25$-in. This includes such items as particles of fuel, any corrosion product, dirt, and/or other material that is either reactor or non-reactor originating. Most of the sludge in the $105 \mathrm{KW}$ Basin is from the fuel in the capped canisters.

transuranic A transuranic (TRU) isotope has an atomic number $>92$ (uranium), has a half-life $>20$ years, and is an alpha emitter. TRU isotopes in the KW Basin fuel canisters are primarily ${ }^{241} \mathrm{Am}$ and ${ }^{239 / 240} \mathrm{Pu}$. TRU waste is a waste commodity containing $>100 \mathrm{nanoCi} / \mathrm{g}$ of the TRU isotopes. For example, only $30 \mathrm{~g}$ of plutonium makes an IXM, weighing $42,000 \mathrm{lb}$ dry, qualify as TRU waste.

treated Treated refers to water that has undergone particle removal, filtering (clarified), conditioning (ion exchanged), and is suitable for introduction into the basin, supplying the various interfacing users of IWTS water, and excess water disposal. 


\subsection{ACRONYMS USED IN THIS SDD}

$\begin{array}{ll}\text { ALARA } & \text { as low as reasonably achievable } \\ \text { AOV } & \text { air operated valve (remotely operated) } \\ \text { ASME } & \text { American Society of Mechanical Engineers } \\ \text { B\&PVC } & \text { Boiler and Pressure Vessel Code } \\ \text { CFR } & \text { Code of Federal Regulation } \\ \text { CSER } & \text { criticality safety evaluation report } \\ \text { CVD } & \text { cold vacuum drying } \\ \text { CVDF } & \text { Cold Vacuum Drying Facility } \\ \text { CVI } & \text { certified vendor information } \\ \text { CWC } & \text { Central Waste Complex (Hanford) } \\ \text { DESH } & \text { Duke Engineering \& Services Hanford } \\ \text { DOE } & \text { U.S. Department of Energy } \\ \text { ETF } & \text { Effluent Treatment Facility (Hanford) } \\ \text { FDH } & \text { Fluor Daniel Hanford } \\ \text { FHS } & \text { Fuel Handling System } \\ \text { FLA } & \text { full load amperage } \\ \text { FRS } & \text { Fuel Retrieval System } \\ \text { FRW } & \text { fuel retrieval water } \\ \text { HEPA } & \text { high efficiency particulate air } \\ \text { IC } & \text { interface commitment } \\ \text { IWTS } & \text { Integrated Water Treatment System } \\ \text { IXC } & \text { ion exchange column } \\ \text { IXM } & \text { ion exchange module } \\ \text { KO } & \text { knockout (pot) } \\ \text { LLW } & \text { low level waste } \\ \text { LLBG } & \text { Low Level Burial Ground (Hanford) } \\ \text { LLMW } & \text { low level mixed waste } \\ \text { MCC } & \text { motor control center } \\ \text { MCO } & \text { multi-canister overpack } \\ \text { NPSH } & \text { net positive suction head } \\ \text { OCRWM } & \text { Office of Civilian Radioactive Waste Management } \\ \text { PCM } & \text { primary cleaning machine } \\ \text { PLC } & \text { programmable logic controller } \\ \text { RTD } & \text { resistance temperature detector } \\ \text { SDD } & \text { system design description } \\ \text { SNF } & \text { spent nuclear fuel } \\ \text { SNFP } & \text { Spent Nuclear Fuel Project } \\ \text { TDH } & \text { total developed head } \\ \text { TRU } & \text { transuranic } \\ \text { WHC } & \text { Westinghouse Hanford Company } \\ \text { WIPP } & \text { Waste Isolation Pilot Project } \\ & \end{array}$


This page is intentionally left blank. 


\subsection{KW BASIN IWTS GENERAL OVERVIEW}

The intent of this section is to state the functions of the IWTS, list the interfacing systems serviced by and required for IWTS operation, describe the interfacing services and requirements, list the IWTS electrical and mechanical system boundaries, state the safety and quality classification of IWTS components, and provide a summary of the IWTS operation.

\section{$2.1 \quad$ SYSTEM FUNCTIONS}

The IWTS has the following functions:

- $\quad$ Provides treated water to support fuel retrieval and sludge removal activities

- Maintains water clarity in the spent fuel basin

- Removes radioactive particles and ions from the basin and fuel retrieval water to maintain personnel dose rates as low as reasonably achievable (ALARA)

- Reduces radioactive air emissions to levels ALARA

- Removes ionic species from the basin water to maintain water chemistry as neutral $\mathrm{pH}$, low conductivity, conditioned water

- Provides water filtering and conditioning backup for the existing basin pool cooling and treatment system

- Precludes nuclear criticality by design in any component that separates and collects particles of spent nuclear fuel

- Provides for the treatment and removal of excess water from the basin

- Accepts and performs final treatment of water collected at the Cold Vacuum Drying Facility (CVDF)

- $\quad$ Provides interim storage for sludge.

The authorization basis for construction and pre-operational testing of the IWTS, subject to the conditions of approval, is found in the Letter, CA Hansen, Department of Energy (DOE), to RD Hanson, Fluor Daniel Hanford (FDH), "Acceptance of the Safety Analysis Documents for the Fuel Retrieval System (FRS), HNF-2032, Revision (Rev.) 0, and K-West Integrated Water Treatment System (KW-IWTS), HNF-SD-SNF-SAD-002, Rev. 2," dated August 31, 1998, 98-SFD-169. The DOE letter and the attached Safety Evaluation Report (SER) are included as an attachment to HNF-SD-SNF-SAD-002 (LS Semmens, 1998). 


\subsection{INTERFACES AND BOUNDARIES}

\subsubsection{System Interfaces}

The IWTS serves or is served by the following interfacing systems and sites:

- $\quad$ Building Radiation Protection (5)

- $\quad$ Basin Structure (6.1)

- Basin Water (7.3)

- $\quad$ Compressed Gases (12)

- Cranes and Hoists (14)

- $\quad$ Radioactive Drains (18.1)

- $\quad$ Low Voltage AC Electrical Distribution (20.2)

- $\quad$ Counting Room (43.2)

- $\quad$ Fuel Retrieval (70.1)

- $\quad$ Cask Loading (70.2)

- $\quad$ Debris Removal (70.5)

- $\quad$ Sludge Removal (70.6)

- CVDF Process Water Conditioning (CVD 46-2)

- $\quad$ Effluent Treatment Facility (ETF)

- Solid Waste Disposal.

\subsubsection{Interface Requirements and Definitions}

The following information defines the services required from or supplied to each interfacing system and facility. The total of the intermittent flows of treated water supplied to the various systems by the IWTS exceeds the available water ( $320 \mathrm{GPM}$ ), but these flows are not concurrent as all activities are not performed at the same time. Agreements were made among the major interfacing basin systems, called interface commitments (ICs); and these are noted in the following subheadings and on the IWTS Drawing H-1-80550, Sheets 8 and 11.

\subsubsection{Radiation Protection}

The Building Radiation Protection System provides for the monitoring of the work area that contains the piping, components, and instrumentation of the IWTS. This system also provides for health physics services used by personnel operating the IWTS. The garnet filter enclosure radiation monitors are process monitors and are part of the IWTS.

\subsubsection{Structures}

The Basin Structures provides housing and space for the piping, components, instrumentation, and shielding for the IWTS. The major above water components are located in the northwest portion of the basin between the east/west Column Lines 13 to 16 and the north/south Column Lines A to C. This SDD will refer to this location hereafter as the Transfer Bay Area. 
The submerged pumps, the knockout $(\mathrm{KO})$ pot, and the associated piping and hoses of the IWTS are submerged in the West Bay of the basin pool. The pump stands and integral strainers are part of the FRS, but they also require space in the pool. The settler tank assembly is submerged in the east end of the Weasel Pit. The IWTS high efficiency particulate air (HEPA) filter subsystem 3 -in exhaust line penetrates the basin structure so the filtered exhaust can be released to the atmosphere.

\subsubsection{Basin Water (IC-213)}

The IWTS can serve as a backup for the Basin Water System. The IWTS has the capability to accept up to $320 \mathrm{GPM}$ of water from either the Basin Water skimmer or recirculation subsystem, to filter and condition the water, and to return this treated water to the pool. The actual skimmer pump flowrate is restricted to $<320 \mathrm{GPM}$ by the 2 -in connecting line. Recirculation water can be routed through the filters and IXMs or just the IXMs. Use of the garnet filter is optional and requires use of the IWTS booster pump to provide additional pressure and an adequate flow path. The IWTS can supply up to 30 GPM to the Basin Discharge Chute and 200 GPM to the South Loadout Pit when the treated water is available. Excess water in the basin is treated and removed by the IWTS (see Effluent Treatment Facility).

Basin water from the skimmer subsystem is used for the IWTS garnet filter backwash and top sparge. The IWTS has piping connections to use water from the recirculation subsystem as a backup for this purpose, but this would be a very rare occurrence. Information on the skimmer and recirculation pumps can be found in the System Description - The Basin Water Systems, HNF-SD-SNF-SDD-016 (JM Kurta, 1998). The Basin Water System (via the pool) accepts drains from the IXMs, their samplers, the moisture separator, water from garnet filter fill and pressure relief venting, water from IXM venting, and any water from rinsing. The Basin Water System removes pool heat from IWTS submerged components and pool circulation.

\subsubsection{Compressed Gases (IC-193)}

The Compressed Gases System provides oil-free compressed air to the IWTS for operating the IXM automatic samplers, for operating the remotely controlled air operated valves (AOVs), for providing motive power to the garnet filter sluice pump (FRW-P-6), and for garnet filter media air agitation (sparging). The air sparging for the upper sand layer in the garnet filters is supplied by a portable compressor placed outside the basin. The compressor is connected to a line that penetrates the north wall of the basin where it ends in a hose bib. When air is needed, the hose is connected to the valved and instrumented air line that extends to the filters. This connection is just to the east of the filter enclosure and above IXM-1 (see Figure 7-4). A nominal 100 SCFM will be required occasionally. Agitation frequency depends on the amount of sludge retained in the sand by the filters, and this frequency will be determined during operation after backwashing. The use of the hose instead of a permanent pipe connection prevents inadvertent water leakage into the compressed air line. 
The compressed air subsystem for the building has been reactivated to support the SNFP and to provide dry, oil free air to the rest of the IWTS components. The quantity of air used is small compared with the capacity of the compressed air subsystem.

\subsubsection{Cranes and Hoists (IC-199)}

The Basin Cranes and Hoists System provides the lifting and moving capability for installation, maintenance, and removal of the heavier IWTS equipment. Therefore, this system must ensure the proper coverage over the IWTS equipment in the pool and in the Transfer Bay Area.

A 2400 -lb hoist on Monorails 28 and 30 is required for installing, removing, and replacing the three (3) submersible pump assemblies $(\sim 950 \mathrm{lb}), \mathrm{KO}$ pots $(\sim 2100 \mathrm{lb}$ half full), and the associated hoses and pipe spools in the West Bay of the basin. All components, except the primary cleaning machine (PCM) pump, are aligned with Monorail 30. Approximately sixty (60) KO pot moves are estimated during the fuel removal process as the pots are installed and removed. Once installed in the Weasel Pit, the passive settler tank assembly should not require further service (basin removal) until after fuel processing is complete.

The 32-ton transfer bay crane and its associated 5-ton auxiliary hoist are required for installing, removing, and replacing the IWTS booster pump and skid, heavier pipe spools, and IXMs in the Transfer Bay Area. The IXMs (22-ton maximum) require periodic changeout during the SNFP fuel processing activities. It is estimated that one IWTS IXM will need to be changed out every week of operation. The IXMs are loaded into and unloaded from a tractor trailer truck in the south part of the Transfer Bay Area.

The garnet filters were installed with a mobile crane, and use of this crane is necessary to remove the filter shield wall covers to enter the shield enclosure to calibrate and maintain the filter pressure relief valves and the AOVs. Periodically, cranes and hoists may be needed to support IWTS maintenance. They will also be needed for final equipment removal from the basin.

\subsubsection{Radioactive Drains}

The Radioactive Drains System provides floor drains in the northwest Transfer Bay Area at the IXM pad and within the garnet filter shield enclosure. The floor drains are connected to a 6-in pipe that discharges into Sump C. Sump C has a capacity of 1600 gallons. Sump C has two (2) sump pumps, each capable of 40 GPM, that pump the water back to the basin pool. The drain is shown on Drawing H-1-34736.

\subsubsection{Electrical Systems}

The Low Voltage AC Electrical Distribution System provides power for all the IWTS electrical equipment, including pumps, HEPA filter heater, and instrumentation. Pumps FRW-P-1, 2, 3, and 4 use $480 \mathrm{VAC}$, three (3) phase power. The $480 \mathrm{VAC}$ is transformed to $230 \mathrm{VAC}$, single phase for FRW-P-5 and $120 \mathrm{VAC}$, single phase for FRW-H-1. The power needs are as follows: 


$\begin{array}{ll}\text { COMPONENT } & \text { LOAD } \\ \text { FRW-P-1, 2 or } 3 & \text { 480 VAC, 31 Full Load Amperage (FLA), 25.8 KVA } \\ \text { FRW-P-4 } & \text { 480 VAC, 65 FLA, 54.0 KVA } \\ \text { FRW-P-5 } & \text { 480 VAC, 0.8 FLA, 0.5 KVA } \\ \text { FRW-H-1 } & 480 \text { VAC, 1.6 FLA, 0.75 KVA } \\ \text { CP-C } & 480 \text { VAC, 1.6 FLA, 0.75 KVA }\end{array}$

\subsubsection{Counting Room}

The radiation lab analyses the water collected by the IXM autosamplers to provide data on the ${ }^{137} \mathrm{Cs}$ and alpha radiation concentration in the samples. This data is used by the IWTS to determine the cesium removal efficiency and TRU loading of the IXMs. A gamma ray spectrometer assay is periodically conducted on the "sample" HEPA filter to estimate the quantities of certain radioactive isotopes released to the atmosphere.

\subsubsection{Fuel Retrieval System (ICs-016, 017, 091 \& 198)}

The IWTS and FRS designs coordinate to prevent the pool water clarity from being degraded from canister retrieval and fuel processing operations and to maintain acceptable radiation levels in the pool and basin so that operations can continue. The fuel processing operations cause the release of particles and radioactive ions from the canisters and fuel elements. The IWTS provides pumps for drawing basin and flush water from the FRS decapping station, the PCM, and the processing table where the SNF is dumped, sorted, and loaded into multi-canister overpack (MCO) baskets. The FRS confines and strains the removed materials so that only "sludge" and water soluble ions enter the IWTS. The IWTS accepts the strained materials from up to twelve (12) canisters of fuel per day. Based on the FRS and IWTS capturing 95 to $98 \%$ canister "liquor" released during decapping, the IWTS provides sufficient circulation capacity and treatment efficiency to maintain the pool's monthly average ${ }^{137} \mathrm{Cs}$ concentration $\leq 0.05$ $\mu \mathrm{Ci} / \mathrm{L}$. The IWTS maintains the general pool water quality $\leq 0.04 \mu \mathrm{Ci} / \mathrm{L}$ alpha contamination so that basin work activities can be conducted without respirators (unmasked). The FRS and IWTS have a joint goal to maintain water clarity and visibility of $z 15 \mathrm{ft}$ to ensure FRS activities can be conducted in the pool.

The IWTS removes water from the decapping station at a minimum rate of $70 \mathrm{GPM}$ and removes water from the PCM at a minimum rate of $80 \mathrm{GPM}$. The IWTS provides factory calibrated instrumentation to provide real time flow readout with a readout accuracy of at least $\pm 5 \%$. The IWTS also removes water from the processing table at a minimum rate of $150 \mathrm{GPM}$ to support the secondary cleaning station, table activities, and vacuum wand use. The FRS provides all strainers and pump stands for the decapper pump (FRW-P-1) and the process table pump (FRW-P-3). The PCM pump (FRW-P-2) is integral to the PCM assembly that contains the 
strainer. Refer to Drawing H-1-83326 and vendor Drawings DW-213, DAG-330, and DAG-356 for pump interface details.

The IWTS provides treated water and pump suction to the FRS. The IWTS provides 80 GPM of treated water at a minimum pressure of 20 PSIG and at a nominal pressure of 35 PSIG.

The water is used for supplying the decapper flushing nozzles, the PCM cleaning nozzles, and the FRS hose bibs. The FRS may have to share the available IWTS water with other basin users, and only water to the PCM (50 GPM) is guaranteed continuously. FRS requirements, equipment, and planned operations are discussed in the System Design Description for the Fuel Retrieval System, SNF-4331 (BD Groth, 1999).

The FRS has been limited to the use of Houghto-Safe $\otimes$ hydraulic fluid that is free of microbial contamination. The maximum allowed leakage of this fluid has been limited to $50 \mathrm{ml} /$ day and to 5 gal catastrophic by design per Section 3.2.8.4 of Fuel Retrieval Subproject, Specification for Design of the SNF Project, HNF-S-0461 (BD Groth, 1998). The IWTS anticipates a small release of hydraulic fluid during basin operations, and the resin mix in the IXMs will remove this fluid from the basin water. In case of catastrophic release, a separate resin mix is used to clean the water. See letter, S.P. Burke to E.J. Shen, "Evaluation of Houghto-Safe $(620$ Hydraulic Fluid," dated May 27, 1997, 97-SPB-017.

\subsubsection{Cask Loading (ICs-046 \& 189)}

The IWTS provides treated water at a nominal rate of 15 GPM and 5 PSIG for partially filling the MCO cavity before it enters the basin pool to offset the buoyancy effect of demineralized water in the cask annular region. The IWTS water ( $\sim 40$ gallons) is supplied to a hose bib near the South Loadout Pit. The Cask Loading System will be responsible for hoses, hose connections, etc., required beyond the hose bib. The cask sits in the South Loadout Pit while in the basin pool. The IWTS also provides treated water for pit circulation at $200 \mathrm{GPM}$ (continuously while the cask is in the pit). This IWTS water supply will connect to the existing 6-in circulation line in the pit at the flange for the 6-in valve (removed).

\subsubsection{Debris Removal (ICs-042, 051 \& 177)}

Debris is considered all non-fuel material in the basin pool $>0.25$-in. Debris is low level radioactive waste and includes such items as empty canisters, canister lids, canister gas traps, fuel inserts ("buggy springs"), etc. The IWTS provides treated water at 15 GPM to the Debris Removal System in the canister loadout area for debris rinsing. The IWTS provides a 1.5 -in, valved, capped male $\operatorname{Kamlok}(B)$ connector at the dummy elevator pit location. The Debris Removal System is responsible for the matching connector and any other water distribution equipment required. 
The IWTS also supplies treated water at $30 \mathrm{GPM}$ and $\geq 25$ PSIG to the high pressure debris

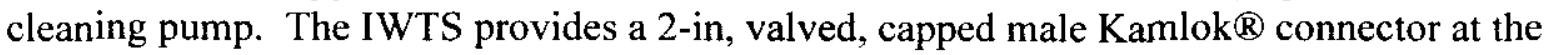
dummy elevator pit for the pump water supply. The matching connector, pump, and distribution equipment is provided by the Debris Removal System. The source of water used by the debris cleaning enclosure is the main basin, but processing the used water is considered in the design of the IWTS.

\subsubsection{Sludge Removal (ICs-053, 065 \& 204)}

The Sludge Removal System disposes of sludge accumulated in the IWTS settler tanks and KO pots. The IWTS provides four 2-in penetrations on each settler tank, two (2) at each end, with piping extensions ending in 2-in male Kamlok $\otimes$ capped connectors. All connectors are at least 4 feet below the Weasel Pit water surface and accessible by basin operators. Each KO pot has two 2 -in penetrations in the top flange for sludge removal.

The IWTS provides treated water at an intermittent nominal rate of 50 GPM to flush the piping after a sludge transfer to the transport package and/or to fill the sludge transport package.

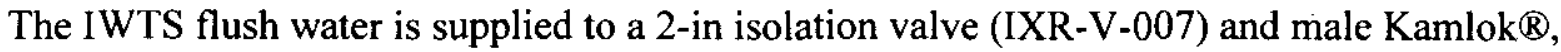
capped connector (to be opened later). The capped connector is at the southeast corner of the ion exchange column (IXC) caves. All downstream piping is provided by the Sludge Removal System. The water is used with the sludge transfer line and storage sludge removal in the Weasel Pit and West Bay. The IWTS also treats the used water that the Sludge Removal System returns to a 2 -in male Kamlok $(B)$ capped connector located underwater on the garnet filter backwash line.

\subsubsection{CVDF Process Water Conditioning (IC-012)}

Some basin water is retained by the MCO when it leaves the basin. This water is removed from the MCO fuel baskets and cask by the draining and drying activities conducted at the CVDF. The water is initially treated by the Process Water Conditioning System to reduce impurities and radioactive contamination, stored in a 5000-gal tank, and periodically returned to the IWTS by tanker truck. The water is injected into the IWTS through a 2-in male Kamlokß connector (normally capped) that is located near the west face of the IXC caves. The IWTS is designed to accept $60 \mathrm{GPM}$. Any leakage from the temporary connections will be cleaned promptly so that the work area is maintained with no radioactive contamination that can be smeared.

\subsubsection{Effluent Treatment Facility (IC-151)}

The ETF in the 200 Area is designated to receive excess water from the basin pool that accumulates from washdowns and water returned from the CVDF. The IWTS filters and conditions this water, and it is removed from a 2-in male Kamlok $\otimes$ capped loadout connection near the west face of the IXC caves. The present plans are for a tanker truck to be brought into the Transfer Bay Area, a hose connected between the truck and the loadout connection, and the required portion put into the tank. The water will then be transported to the ETF for final treatment and disposal. Tank venting and any leakage will be within the basin, and any leakage 
will be cleaned promptly so that the work area is maintained with no radioactive contamination that can be smeared. The present water disposal agreements include dedicating a tanker truck, housed and based in the $100 \mathrm{~K}$ Area, to the SNFP during operations.

\subsubsection{Solid Waste Disposal (ICs-146, $147 \&$ 229)}

Non-hazardous IWTS low level waste (LLW) will be sent to the Hanford Site Low Level Burial Ground (LLBG). Low level mixed waste (LLMW) will be transported and stored in the Hanford Site Central Waste Complex (CWC). This waste will be included in the site wide feed streams for further treatment to meet land disposal restrictions. Final disposal of this waste will also be in the LLBG. TRU and TRU-mixed waste will be stored in the CWC until it is certified to meet the Waste Isolation Pilot Project (WIPP) criteria. Then this TRU waste will be shipped to WIPP for burial.

All spent IWTS IXMs are expected to be LLW and will follow the established disposal path to the LLBG. The final characteristics of a given amount of garnet filter media are not known until the media has been sluiced from the filters, collected in a 55-gal drum, watered removed, and analyzed. Most of the drums are expected to be LLW. The selected type of 55-gal drum must meet the storage, disposal, and transportation requirements for all possible characteristics. The description of media waste, the characterization planned, and the packaging requirements for the different types of waste are contained in Letter, LG Irons, Waste Management Federal Services of Hanford, to DS Takasumi, Duke Engineering \& Services Hanford (DESH), "Revision of the Waste Disposal Plan for DE\&S Hanford, Inc. Integrated Water Treatment System Filter Media," dated March 19, 1998 (WMH-9852504).

\subsubsection{System Boundaries}

\subsubsection{Electrical Boundaries}

The IWTS electrical boundaries are at the IWTS motor control center (MCC 8) that is at the east end of Corridor 7, $105 \mathrm{KW}$ Building. MCC 8 is fed from basin Power Panel PP-105KW-9. Although MCC 8 was procured as part of the IWTS, it is considered a component of the Low Voltage AC Electrical Distribution System. The IWTS connection wiring is shown on the Wiring Diagrams H-1-83401 and H-1-83402. Refer to other drawings in that same series for conduit, cable trays, inter-connections, and garnet filter lighting.

IWTS electrical boundaries with MCC 8 are shown in the following table: 


\begin{tabular}{||l||c||c||}
\hline $\begin{array}{l}\text { ELECTRICAL BOUNDARY } \\
\text { FUNCTION }\end{array}$ & EQUIPMENT ID & BOUND $\overline{\text { ARY LOCATION }}$ \\
\hline \hline $\begin{array}{l}\text { Supplies Power for Process Table } \\
\text { Pump }\end{array}$ & FRW-P-3 & MCC 8, Compartment A1 \\
\hline Supplies Power for Booster Pump & FRW-P-4 & MCC 8, Compartment A2 \\
\hline $\begin{array}{l}\text { Supplies Power for Canister } \\
\text { Decapping Pump }\end{array}$ & FRW-P-1 & MCC 8, Compartment B1 \\
\hline $\begin{array}{l}\text { Supplies Power for Primary } \\
\text { Cleaning Pump }\end{array}$ & FRW-P-2 & MCC 8, Compartment B2 \\
\hline $\begin{array}{l}\text { Supplies Power for the PLC-2 } \\
\text { Power Distribution Cabinet }\end{array}$ & CP-C & MCC 8, Compartment B3 \\
\hline $\begin{array}{l}\text { Supplies Power for the Metering } \\
\text { Pump }\end{array}$ & FRW-P-5 & MCC 8, Compartment B4 \\
\hline $\begin{array}{l}\text { Supplies Power for the HEPA } \\
\text { Filter Heater }\end{array}$ & FRW-H-1 & MCC 8, Compartment B5 \\
\hline
\end{tabular}

\subsubsection{Mechanical Boundaries}

Certain items have no actual physical boundaries with a system as they interface with the basin atmosphere or basin pool water. The pool interfaces and their upstream isolation valves can be generalized as follows:

- Distribution header return to basin Discharge Chute (IXR-V-011)

- Distribution header return to basin South Loadout Pit (IXR-FCV-001)

- Distribution header high point fill vents and siphon breaks to the basin pool (IXR-V-012, 022, 023, and 024)

- Garnet filter relief vents to the basin pool (FRW-PRV-111, 211, and 311)

- $\quad$ HEPA filter subsystem moisture separator drain to the basin pool (FRW-V-050)

- IXM vents to the basin pool (IXV-V-100, 101, 200, 201, 300, and 301)

- IXM drains to the basin pool (IXM-V-013, 023, and 033).

The mechanical boundaries with the interfacing systems are presented in the following table. The table lists the boundary function, the designated boundary component or connector, and the approximate basin location of that boundary. 


\begin{tabular}{|c|c|c|}
\hline $\begin{array}{c}\text { MECHANICAL BOUNDARY } \\
\text { FUNCTION }\end{array}$ & EQUIPMENT ID & BOUNDARY LOCATION \\
\hline $\begin{array}{l}\text { Provide IWTS Pump Suction } \\
\text { Flows to FRS Decapping Station } \\
\text { and Process Table }\end{array}$ & $\begin{array}{l}\text { FRW-P-1 and } 3 \text { Inlets, } \\
\text { Respectively }\end{array}$ & $\begin{array}{l}\text { Pump Inlet Flanges, In-Pool at } \\
\text { Approximately Column } \\
\text { Lines D.0/12.3 }\end{array}$ \\
\hline $\begin{array}{l}\text { Provide IWTS Pump Suction } \\
\text { Flow to FRS PCM }\end{array}$ & FRW-P-2 Pump Inlet & $\begin{array}{l}\text { Pump Inlet Flange, Integral to } \\
\text { PCM Assembly, In-Pool at } \\
\text { Column Lines D.0/12.0 }\end{array}$ \\
\hline $\begin{array}{l}\text { Provide IWTS Treated Water to } \\
\text { FRS for Decapping, PCM } \\
\text { Flushing, and Hose Bibs }\end{array}$ & IXR-V-009 & $\begin{array}{l}\text { FRS Piping Connection in } \\
\text { Basin Overhead Piping, } \\
\text { Column Lines C.1/11.7 }\end{array}$ \\
\hline $\begin{array}{l}\text { Provide IWTS Treated Water for } \\
\text { MCO Fill Before Pool Entry }\end{array}$ & IXR-V-008 & $\begin{array}{l}\text { Next to the South Loadout Pit, } \\
\text { Column Lines D. } 2 / 13.4\end{array}$ \\
\hline $\begin{array}{l}\text { Provide IWTS Treated Water for } \\
\text { Water Circulation when MCO } \\
\text { Cask is in the Basin Pool }\end{array}$ & IXR-FCV-001 & $\begin{array}{l}\text { South Loadout Pit Connection } \\
\text { to Old Basin Recirc Sparge, } \\
\text { Column Lines D. } 7 / 13.5\end{array}$ \\
\hline $\begin{array}{l}\text { Provide IWTS Treated Water for } \\
\text { Sludge Removal }\end{array}$ & IXR-V-007 & $\begin{array}{l}\text { Middle Transfer Bay Area, } \\
\text { Column Lines C.1/13.4 }\end{array}$ \\
\hline $\begin{array}{l}\text { Provide IWTS Treated Water for } \\
\text { Debris Removal Cleaning Pump }\end{array}$ & IXR-V-005 & $\begin{array}{l}\text { West End of Dummy Elevator } \\
\text { Pit, Above Grating at Column } \\
\text { Lines B. } 0 / 6.9\end{array}$ \\
\hline $\begin{array}{l}\text { Provide IWTS Treated Water for } \\
\text { Debris Rinsing }\end{array}$ & IXR-V-006 & $\begin{array}{l}\text { West End of Dummy Elevator } \\
\text { Pit, Above Grating at Column } \\
\text { Lines B. } 0 / 6.9\end{array}$ \\
\hline $\begin{array}{l}\text { Provide Isolation Between IWTS } \\
\text { and the Basin Water Recirculation } \\
\text { Subsystem Inlet }\end{array}$ & FRW-V-004 & $\begin{array}{l}\text { IWTS Booster Pump Skid } \\
\text { Inlet at Approximately } \\
\text { Column Lines B.5/14.4 }\end{array}$ \\
\hline $\begin{array}{l}\text { Provide Isolation Between IWTS } \\
\text { Booster Pump Skid and the Basin } \\
\text { Water Skimmer Subsystem Inlet }\end{array}$ & FRW-V-010 & $\begin{array}{l}\text { IWTS Booster Pump Skid } \\
\text { Inlet at Approximately } \\
\text { Column Lines B.3/14.6 }\end{array}$ \\
\hline $\begin{array}{l}\text { Provide Isolation Between the } \\
\text { IWTS Inlet and the Cold Vacuum } \\
\text { Drying (CVD) Water Return }\end{array}$ & FRW-V-003 & $\begin{array}{l}\text { West of Abandoned IXCs at } \\
\text { Column Lines C. } 0 / 14.8\end{array}$ \\
\hline $\begin{array}{l}\text { Provide Isolation for IWTS } \\
\text { Treated Excess Basin Water } \\
\text { Removal (Loadout) }\end{array}$ & IXR-V-004 & $\begin{array}{l}\text { Approximately Column } \\
\text { Lines B.9/14.8 }\end{array}$ \\
\hline $\begin{array}{l}\text { Provide Isolation Between the } \\
\text { Building Compressed Air System } \\
\text { and the Autosamplers and AOVs }\end{array}$ & $\mathrm{CA}-\mathrm{V}-820$ and 821 & $\begin{array}{l}\text { Dual Compressor Header } \\
\text { Branch Connection }\end{array}$ \\
\hline $\begin{array}{l}\text { Provide Isolation Between IWTS } \\
\text { Filter Air Sparge Manifold and } \\
\text { Portable Compressor }\end{array}$ & FRW-V-014 & $\begin{array}{l}\text { Garnet Filter Inlet at } \\
\text { Approximately } \\
\text { Column Lines A.5/14.9 }\end{array}$ \\
\hline
\end{tabular}




\subsection{SYSTEM SAFETY AND QUALITY CLASSIFICATIONS}

The overall safety classification of the IWTS is general service with portions that are Safety Class. The specific IWTS equipment, or portions of them, that have a safety function and are considered Safety Class, are presented in the following equipment table. All listed components are passive. This table was derived from Table 4-1 of the Westinghouse Hanford Company (WHC) originated $K$ Basins Final Safety Analysis Report, Rev. 3L, WHC-SD-WM-SAR-062 (FDH, 1999). This revision has been updated to include the new basin systems, including IWTS. The current safety classification and quality level of each IWTS component are listed with that component in the K Basin Component Number/Master Equipment List data base.

The quality classifications of the IWTS are consistent with the safety classification and also the level of safety and project risk associated with failure of the component as defined in Section 2.0 of the Hanford procedure Graded Quality Assurance, HNF-PRO-259. The quality classifications are $1,2,3$, and 0 . The application of these quality classifications on the design, procurement, fabrication, acceptance, and document control are as described in Control of Purchased Items and Services, HNF-PRO-268. All safety class items in the following table are Quality Class 1. Safety Significant items would be Quality Class 2, but the IWTS does not have portions presently classified as Safety Significant. The remainder of the components in the IWTS are General Service and are Quality Class 3 or 0 . All General Service components that contain or could contain radioactive material or are important to the continued operation of the IWTS are Quality Class 3. Those General Service components that pose a low functional risk and have acceptable standard commercial practices can be Quality Class 0 .

Section 3.0 and Table 3-1 of the Application of the Office of Civilian Radioactive Waste Management QA Requirements to the Hanford Nuclear Fuel Project, HNF-SD-SNF-RPT-007 (RL McCormack, 1999), did not list any IWTS components and activities that required application of the DOE Office of Civilian Radioactive Waste Management (OCRWM) Quality Assurance Requirements and Description (QARD). The document specifically states in Section 4.5.3 that application to IWTS is unnecessary. 


\begin{tabular}{|c|c|c|c|}
\hline \multicolumn{4}{|c|}{ IWTS SAFETY CLASS EQUIPMENT LIST } \\
\hline EQUIPMENT & SAFETY FUNCTION & $\begin{array}{l}\text { DESIGN BASIS } \\
\text { ACCIDENTS } \\
\end{array}$ & $\begin{array}{c}\text { FUNCTIONAL } \\
\text { REQUIREMENTS }\end{array}$ \\
\hline KO Pot & $\begin{array}{l}\text { Prevents criticality by: } \\
\text { (1) ensuring that fuel is } \\
\text { contained in the pot and } \\
\text { will not spill as the result } \\
\text { of a load drop or seismic } \\
\text { event, (2) limiting SNF } \\
\text { volume and controlling pot } \\
\text { geometry, and ( } 3 \text { ) } \\
\text { controlling spacing } \\
\text { between the pots to a } \\
\text { minimum gap of } 1 \text {-in. }\end{array}$ & $\begin{array}{l}\text { Heavy load drop, } \\
\text { seismic forces, and } \\
\text { criticality }\end{array}$ & $\begin{array}{l}\text { Physical dimensions to } \\
\text { control geometry and } \\
\text { physical strength to } \\
\text { withstand load drops } \\
\text { without failure }\end{array}$ \\
\hline KO Pot Screens & $\begin{array}{l}\text { Prevents criticality in } \\
\text { downstream settler } \\
\text { assembly and garnet filters } \\
\text { by limiting SNF particle } \\
\text { size leaving KO pot to } \\
<500 \mu \mathrm{m} \text { (nominal). }\end{array}$ & $\begin{array}{l}\text { Criticality } \\
\text { analyses } \\
\text { performed with } \\
550 \mu \mathrm{m} \text { SNF to } \\
\text { provide erosion } \\
\text { margin }\end{array}$ & $\begin{array}{l}\text { Limit sludge particle } \\
\text { size in downstream } \\
\text { equipment and strength } \\
\text { to withstand particle } \\
\text { impact and differential } \\
\text { pressure without failure }\end{array}$ \\
\hline $\begin{array}{l}\text { KO Pot Lifting } \\
\text { Hook }\end{array}$ & $\begin{array}{l}\text { Limits drop height to } \\
\text { prevent basin pool floor } \\
\text { perforation and prevents } \\
\text { criticality by limiting drop } \\
\text { height of the pots to ensure } \\
\text { that impacted pots will } \\
\text { retain the SNF during and } \\
\text { after a drop. }\end{array}$ & $\begin{array}{l}\text { Heavy load drops } \\
\text { and criticality }\end{array}$ & $\begin{array}{l}\text { Limiting the design } \\
\text { length with a lifting } \\
\text { height restriction }\end{array}$ \\
\hline $\begin{array}{l}\text { Particulate } \\
\text { Settler Tank } \\
\text { Assembly }\end{array}$ & $\begin{array}{l}\text { Prevents criticality by } \\
\text { limiting SNF volume and } \\
\text { controlling the geometry. }\end{array}$ & Criticality & $\begin{array}{l}\text { Physical dimensions to } \\
\text { control geometry }\end{array}$ \\
\hline $\begin{array}{l}\text { Garnet Annular } \\
\text { Filter Vessels }\end{array}$ & $\begin{array}{l}\text { Prevents criticality by } \\
\text { limiting SNF volume and } \\
\text { controlling the geometry. }\end{array}$ & Criticality & $\begin{array}{l}\text { Physical dimensions to } \\
\text { control geometry }\end{array}$ \\
\hline
\end{tabular}




\subsection{SYSTEM OPERATIONAL OVERVIEW}

The IWTS provides water filtering and ion treatment capability to support the basin fuel, debris, and sludge removal activities. The FRS processes involve canister and fuel movement, the removal of the canister caps (decapping), cleaning of the liquor and fuel within the canisters, sorting the contents, and loading fuel and debris for removal from the basin. The FRS fuel processing produces and IWTS accepts the particulate sludge $(<0.25$-in diameter) and dissolved impurities. The IWTS separates the sludge and conditions the dissolved impurities to maintain basin water quality, pool visibility, and radiation dose rates within basin specifications.

The IWTS also provides treated water, suitable for introduction into the basin, to the FRS for SNF cleaning activities. Additional treated water is provided for partially filling the empty MCO before entering the basin pool, South Loadout Pit circulation, debris cleaning and rinsing, sludge removal, and maintaining the basin pool water. The IWTS supplements the existing Basin Water System filtering and ion treatment portion of that system. Another connection to the IWTS allows the water collected from the CVDF processing to be injected into the IWTS for filtering and conditioning.

The system primary components include three (3) submersible pumps, a replaceable KO pot with screen strainers, a set of ten (10) particulate settler tanks, a booster pump and piping skid, three (3) deep bed garnet sand filters, three (3) IXMs, water distribution piping, instrumentation, and a computer control system. Refer to Figure 7-1 for a simplified system schematic.

During normal operation the submersible pumps take suction separately from the FRS decapping, cleaning, and processing equipment. The outlets of the submersible pumps are combined so that the total flow (nominally $320 \mathrm{GPM}$ ) enters the KO pot with its associated $500 \mu \mathrm{m}$ screen for the first stage of particulate separation. The downstream settler tanks are manifolded and arranged in parallel. The reduced flow velocity in the tanks allows the larger particles that passed through the KO pot screen to collect in the bottom of the horizontal settlers tanks for the second stage of particulate removal. The pressure of the outlet flow is then increased by the booster pump before entering the garnet filters, which are also arranged in parallel, for the third stage of particulate removal. The manifolded filter outlet is then routed to the IXMs for removal of dissolved ions. Normally, two of the IXMs are on line with the third being serviced or on standby. The IXMs are also arranged in parallel. There is an automatic water sampler on the IXM inlet manifold, and one on each IXM discharge. The samplers collect water samples that are analyzed to monitor each IXM for ${ }^{137} \mathrm{Cs}$ removal efficiency and to record transuranic isotope loading. The IXM discharge water is returned to the basin via a distribution header that supports various basin activities. The bulk of the flow, about $200 \mathrm{GPM}$, is routed to the South Loadout Pit to maintain basin circulation. When the IWTS is not needed to support FRS activities, the IWTS is available to supplement the Basin Water System in maintaining basin water quality. 
The IWTS is operated and controlled from a remotely located computer interface. All remotely actuated AOV positions, alarms, instrumentation readouts, process flow paths, and alarm summary are graphically displayed. The control system has both a manual and an automatic mode. In the manual mode, all remotely actuated valves and pumps can be operated individually from the computer screen. In the automatic mode, the IWTS operates in pre-programmed sequences. In both the automatic and manual mode, all process variables, AOV positions, and pump running status are displayed. 


\subsection{KW BASIN IWTS DESIGN REQUIREMENTS AND BASES}

\subsection{SYSTEM DESIGN REQUIREMENTS AND BASES}

\subsubsection{Safety}

\section{Requirement:}

The following IWTS equipment or portions thereof shall be designed, fabricated, installed, and operated as Safety Class:

- $\quad \mathrm{KO}$ pot screen integrity and size $(500 \mu \mathrm{m}$ nominal $)$

- $\quad \mathrm{KO}$ pots (limited dimensions, no drop spillage, pot spacing)

- $\quad$ KO pot lifting tool (dimensional to limit potential drop height)

- $\quad$ Settler tanks (limited dimensions)

- $\quad$ Garnet filter vessels (limited dimensions).

The remainder of the IWTS shall be designed, fabricated, installed, and operated as General Service.

\section{Basis:}

The KO pot screen is Safety Class because the results of the criticality analyses of the downstream settler tank assembly and garnet filters were predicated on the screen limiting the downstream sludge particle size to $500 \mu \mathrm{m}$. It was concluded in Section 18.0 of the safety report $K$ West Knockout Pot Screen Erosion and Impact Analysis, SNF-4729 (LC Mauws, 1998), that the screen would not experience unacceptable erosion during its operational life from sludge contact. The criticality analyses of the settler tank assembly and the garnet filters are predicated on the maximum size of the sludge particles being limited to $550 \mu \mathrm{m}$ maximum, so there is a limited margin for $\mathrm{KO}$ pot screen erosion.

The Safety Class designation was also applied to the dimensions of the KO pots, settler tanks, and the garnet filters to ensure criticality safety. The design features necessary for safety (in parentheses after components above) meet the criteria as determined by DOE Order 6430.1A, General Design Criteria. Refer to the Evaluation of Integrated Water Treatment System (IWTS) Compliance to DOE Order 6430.1A, SNF-4774 (KH Bergsman, 1999), for documentation of compliance and applicable requirements.

The criticality analyses determine the requirements and conditions for those IWTS components that have a criticality concern. The IWTS components that must be designated Safety Class, the worst case dimensions, and the analysis results are documented in Sections 7.0 and 8.0 of CSER 98-001: Criticality Safety Evaluation Report for the $K$ West Basin Integrated Water Treatment Systems, HNF-SD-SNF-CSER-011 (DG Ericksen, 1999). 
The KO pots have the added safety requirements of preventing spillage of contents during seismic events or load drops (see the seismic requirement) and of preventing the filled pots from being within 1 inch of each other. Spacers are welded to the pot sides to ensure $\geq 1$ inch separation. The lifting tool limits the height of the lifted pot from the storage basin floor to ensure a dropped pot can perform its safety function of providing control of the fuel during and after a drop. The lift limit is 6 feet, but the lifting tool is designed to only lift a pot $4 \mathrm{ft}-10$ inches from the floor. The lifting tool and hook integrity and operational dimensions were confirmed per Section 3.0 of Structural Evaluation of the Integrated Water Treatment System Knockout Pot Lifting Tool Assembly, $105 \mathrm{KW}$ Basin, SNF-5244 (MA Islam, 1999).

The IXM was also evaluated specifically for the planned IWTS use. It was concluded in the IWTS CSER that the IXMs are critically safe since very conservative operating requirements have been imposed on them that would also cover the IWTS.

These conclusions are based on severely limiting the amount of fuel they collect so the IXMs do not become TRU waste. For further information, refer to the Criticality Safety Evaluation of the 100K Area Ion Exchange Modules and Ion Exchange Columns, WHC-SD-NR-CSER-011 (DG Ericksen, 1994).

The filter radiation monitors and alarms were initially rated Safety Significant. Their purpose was to alert Operations to shut down the operation of any garnet filter vessel and to backwash that vessel before the radioactive inventory became an accident release concern. New calculations in $K$ West Integrated Water Treatment System Annular Filter Vessel Accident Calculations, HNF-1777 (PD Rittmann, 2000), show that this inventory value will never be reached. Subsequently, the monitors were downgraded to General Service.

\subsubsection{Seismic}

\section{Requirement:}

The anchorage of IWTS systems, structures, and components (SSCs) shall be according to the applicable requirements of the Design Loads for Facilities, GC-LOAD-01 (McGinley et al, 1998), and the Guidelines for Assessing the Seismic Adequacy of Existing Performance Category Equipment at the Hanford Site, HNF-SD-GN-DGS-30006 (TJ Conrads, 1997). Piping and hose assemblies shall meet the seismic requirements of the Uniform Building Code, UBC-94 (or later), International Conference of Building Officials. 
Basis:

The basis for the seismic requirements for equipment is found in Section 5.4 of the Functional Design Criteria for the K West Basin Integrated Water Treatment System, HNF-SD-SNF-FDC-003 (KH Bergsman, 1998), and relates to the general requirements of Spent Nuclear Fuel Project Standards/Requirements Identification Document, HNF-SD-SNF-RD-001 (SJ Dechter, 1999). GC-LOAD-01 has since been superseded by Engineering Design and Evaluation, HNF-PRO-097 (TJ Conrads, 1997). Piping and hoses are covered under Section 4.2(b) of the Specification for Design, Fabrication, Testing, and Technical Assistance for the K West Basin Water Treatment System, HNF-S-0564 (KH Bergsman, 1998). The Hanford Site qualifies as Zone 2B under UBC-94. In a seismic event, the hose connectors must sustain the forces imposed by the postulated movement of the hose. The KO pots were seismically qualified per the Integrated Water Treatment System - K West Knockout Pot Drop and Seismic Analysis, SNF-4670 (LC Mauws, 1999). The settler tank assembly was qualified per the Integrated Water Treatment System - K West Settler and Weasel Pit Seismic and Drop Analysis, SNF-4592 (LC Mauws, 1999).

\subsubsection{Criticality Control}

\section{Requirement:}

The design of the IWTS, specifically tanks and vessels, shall include provisions to prevent criticality, and the most preferred method shall be to maintain a safe geometry under all expected operating and accident conditions. Double contingency design shall be required.

Basis:

The basis is found in Sections 3.2.3 and 5.1.1 of HNF-SD-SNF-FDC-003, and briefly in Section 4.3 of HNF-S-0564. The bases also allowed the less desirable provisions of limiting mass accumulation, administrative controls, and fixed neutron poisons.

However, the IWTS has chosen to preclude criticality by maintaining a safe dimensional geometry in the KO pots, settler tanks, and garnet filters that limits the amount of sludge that can be retained. The IWTS also controls the structural integrity under accident conditions, assures the distance between $\mathrm{KO}$ pots, and limits the particle size to support the component geometry. The IWTS tanks and vessels were analyzed and accepted based on the allowable particle size and final dimensions. They were subcritical during all phases of operation. The criticality safety evaluation was performed for IWTS and documented in HNF-SD-SNF-CSER-011. A separate evaluation was conducted specifically for the IXMs by WHC-SD-NR-CSER-011 that shows that the existing IXMs are not a criticality hazard. 


\subsubsection{Piping and Vessel Design Codes}

\section{Requirement:}

IWTS piping and hose assemblies shall be designed, fabricated, installed, and inspected to the applicable requirements of the American Society of Mechanical Engineers (ASME), ASME B31.1, Power Piping Code. Pressure vessels shall be designed and installed to the applicable requirements of the ASME Boiler and Pressure Vessel Code (B\&PVC), Section VIII, Division 1, Unfired Pressure Vessels, and Washington Aministrative Code, WAC 296-104, Board of Boiler Rules, Substantive. The pressure vessel Code requirements shall apply to the following system components:

$\begin{array}{ll}-\quad \text { KO pots } \\ \text { - } & \text { Settler tanks } \\ \text { - } & \text { Annular filter vessels } \\ & \text { IXMs. }\end{array}$

Basis:

These requirements are stated in Sections 3.2.2 and 3.2.3 of HNF-SD-SNF-FDC-003, Sections 4.2.a and 4.3 of HNF-S-0564, and Section 4.3 of the fabrication and procurement General Specification for US Government Water Treatment System for Hanford K West Basin, ES-E-152 (WS Edwards, 1997), found in CVI 50082.

These overall requirements are then allocated to the applicable components. The Section VIII requirement for the underwater KO pot and settler tanks is subsequently stated in Sections 4.3.8 of the specification data sheet for the Hanford WTS Knock Out Pot, ES-E-152-02, and the Hanford WTS Settler Tank System, ES-E-152-03.

The Section VIII and WAC requirement is stated in Section 4.3.8 of the specification data sheet for the Hanford WTS Filter Vessel Assemblies, ES-E-152-01. The ASME B\&PVC Section VIII basis for the IXMs is found in Section 2.2.2 of the Procurement Specification for Ion Exchange Modules (IXM), HNF-4198 (JR Cassidy, 1999). The KO pot, settler tanks, and IXM specification data sheets do not specifically state WAC 296-104 is required.

The IWTS pump nozzles comply with the ASME B31.1 requirement for pipe fittings, but no equivalent or alternate code requirements were found for the pump assemblies in the pump specification data sheets for the Hanford WTS Booster Pump (\&) Skid, ES-E-152-04; Hanford WTS Decapper Pump, ES-E-152-05; Hanford WTS Primary Cleaning Pump, ES-E-152-06; and Hanford WTS Process Pump, ES-E-152-07. It was determined that pumps built to a manufacturer standard were acceptable for this service. 


\subsubsection{Water Clarity (Filtration)}

Requirement:

A level of water clarity shall be maintained so that personnel can perform their daily routine tasks of fuel retrieval and fuel accounting. Filter components shall allow the use of filter media with equivalent nominal filter ratings at least as low as $5 \mu \mathrm{m}$.

Basis:

Visual contact with the fuel from the operating floor of the basin must be maintained to permit the necessary fuel retrieval and transfer, stage work required in the basins, and provide SNF assurance of security. The intent is to provide good visibility through $\geq 15 \mathrm{ft}$ of basin water for objects illuminated from the side. This overall basin requirement is stated in Section IV.C.8 of the Functional Design Criteria, Supplemental N Reactor Irradiated Fuel Storage, $105 \mathrm{KW}$, UNI-410. The specific IWTS requirements are found in Section 4.1 of HNF-S-0564 and Section 3.1.2.1 of HNF-SD-SNF-FDC-003.

\subsubsection{Characterization Inventory}

Requirement:

The following characterization inventory of substances to be treated by the IWTS shall be used in the design of the system:

\begin{tabular}{||l|c|c||}
\hline \multicolumn{1}{||}{ ITEM } & $\begin{array}{c}\text { WORKING VALUE } \\
\text { (NOMINAL) }\end{array}$ & $\begin{array}{c}\text { MAXIMUM VALUE } \\
\text { (ESTIMATED) }\end{array}$ \\
\hline \hline${ }^{137} \mathrm{Cs}$ in Canister Liquids & \multicolumn{2}{|c||}{$\sim 10,000 \mathrm{Ci}$ Total } \\
\hline${ }^{137} \mathrm{Cs}$ per Canister & $\sim 2.1 \mathrm{Ci}$ & $\sim 25 \mathrm{Ci}$ \\
\hline${ }^{137} \mathrm{Cs}$ in Sludge (Total) & $\sim 50,000 \mathrm{Ci}$ & $120,000 \mathrm{Ci}$ \\
\hline Sludge Activity (All Nuclides) & $\sim 150,000 \mathrm{Ci}$ & $400,000 \mathrm{Ci}$ \\
\hline Plutonium Activity in Sludge & $\sim 15,000 \mathrm{Ci}$ & $40,000 \mathrm{Ci}$ \\
\hline Uranium Activity in Sludge & $\sim 7$ Metric Tonnes & 16.2 Metric Tonnes \\
\hline Particulate TRU (Total) & $\sim 2700 \mathrm{Ci}$ & $6700 \mathrm{Ci}$ \\
\hline Soluble TRU (Total) & \multicolumn{2}{|c||}{$\sim 2 \mathrm{Ci}$} \\
\hline Radioactive Decay of Sludge & $\sim 600 \mathrm{Watts}$ & $1400 \mathrm{Watts}$ \\
\hline Sludge per Canister & $0.8 \mathrm{~L}$ & - \\
\hline Sludge (Total) & $\sim 3 \mathrm{~m}^{3}$ & $6.2 \mathrm{~m}^{3}$ \\
\hline $\begin{array}{l}\text { Sludge Contents in Equivalent Fuel } \\
\text { Assemblies }\end{array}$ & $\sim 400$ & 1000 \\
\hline Sludge Particle Density & \multicolumn{2}{|c||}{$1 \mathrm{to} 19 \mathrm{~g} / \mathrm{cc}$} \\
\hline Sludge Particle Size & \multicolumn{2}{|c|}{$\leq 0.25$-in to Submicron } \\
\hline
\end{tabular}


Basis:

The basis for the requirement is Section 4.1 and Attachment B of HNF-S-0564 and Appendix A of HNF-SD-SNF-FDC-003. The source of each quantity listed above is referenced with the table in these appendices.

\subsubsection{Conditioned Water}

\section{Requirement:}

Water treated by the IWTS and released to the basin shall be conditioned to have concentrations of $\leq 0.05 \mu \mathrm{Ci} / \mathrm{L}$ of ${ }^{137} \mathrm{Cs}, \leq 0.05 \mu \mathrm{Ci} / \mathrm{L}$ of ${ }^{90} \mathrm{Sr}$, and $\leq 0.005 \mu \mathrm{Ci} / \mathrm{L}$ of total alpha contamination. The IWTS shall be designed to maintain the basin monthly average concentrations of $\leq 0.5 \mu \mathrm{Ci} / \mathrm{L}$ of ${ }^{137} \mathrm{Cs}, \leq 0.5 \mu \mathrm{Ci} / \mathrm{L}$ of ${ }^{90} \mathrm{Sr}$, and $\leq 0.04 \mu \mathrm{Ci} / \mathrm{L}$ of total alpha contamination. The IWTS shall have the capacity to remove $1 \mathrm{Ci} /$ day of ${ }^{137} \mathrm{Cs}$ from basin pool water having a ${ }^{137} \mathrm{Cs}$ concentration of $0.5 \mu \mathrm{Ci} / \mathrm{L}$ and to remove the ${ }^{137} \mathrm{Cs}$ from the FRS fuel processing operations. The IWTS design shall have the capability to maintain a conductance of $\leq 1 \mu \mathrm{Mho} / \mathrm{cm}$ in the basin pool water. Excess water removed from the basin shall first be treated by the IWTS.

During fuel retrieval, debris removal, or sludge disturbing activities, the IWTS IXMs shall be operational if the center of basin ${ }^{137} \mathrm{Cs}$ sample taken each shift exceeds $10 \mu \mathrm{Ci} / \mathrm{L}$. If the center of basin sample exceeds $12 \mu \mathrm{Ci} / \mathrm{L}$ of ${ }^{137} \mathrm{Cs}$, these activities shall not proceed without permission of Environmental Safety and Permitting. If this level exceeds $15 \mu \mathrm{Ci} / \mathrm{L}$, all operations shall cease until a satisfactory sample result is obtained.

Basis:

These requirements are stated in Section 4.1 of HNF-S-0564 and Sections 3.1.2 and 3.1.2.1 of HNF-SD-SNF-FDC-003. They are considered necessary to maintain basin radiation dose limits at acceptable levels for continued operations. The capacities are basic design parameters used for selecting the initial number of IXMs necessary for IWTS operation. Selection and sizing are based on the predominant isotope of ${ }^{137} \mathrm{Cs}$. The amount of ${ }^{137} \mathrm{Cs}$ received from the FRS varies significantly based on the number of canisters decapped and the type of fuel, but averages $15 \mathrm{Ci} /$ day based on opening seven (7) fuel canisters. The inventory can be $>40 \mathrm{Ci}$ based on opening 12 canisters (about $14 \%$ of the time). Even the individual canister ${ }^{137} \mathrm{Cs}$ inventory varies significantly from 2.1 to $>40 \mathrm{Ci} /$ canister. The pool conductance of $\leq 1 \mu \mathrm{Mho} / \mathrm{cm}$ is dependent on many non-IWTS variables and is a design goal, not a functional requirement.

Section A.4.e of the SNF Project Process Standard 408, Environmental Safety Requirements, requires treatment of the water removed from the basin. Section A.4.d of Process Standard 408 also limits and dictates operations in the basin if the operation shift center of basin sample exceeds $10 \mu \mathrm{Ci} / \mathrm{L}$. This could affect the IWTS if it is needed to 
back up the Basin Water System or support any of these operations because the $10 \mu \mathrm{Ci} / \mathrm{L}$ value requires that two (2) IXMs be in service. The Basin Water System can supply only one (1) IXM. The IWTS is designed to operate with two (2) IXMs, so this is how the requirement is defined for the IWTS, with or without the Basin Water IXM.

\subsubsection{Basin Water Recirculation Capability}

\section{Requirement:}

The IWTS shall have the capability to treat 320 GPM of flow of recirculation water from the Basin Water System as an alternate supply to the water from the FRS operations.

Basis:

This arrangement provides an operational backup to the Basin Water System to maintain the pool water within purity specifications and to continue supplying user needs.

The IWTS design is capable of using water from the recirculation subsystem at 320 GPM and route this water through the garnet filters and IXMs or just the IXMs. The basis is found in Section 4.1 of HNF-S-0564.

\subsubsection{Radioactivity Control and Shielding (ALARA)}

Requirement:

The radiation contamination from the radioactive particles and ions in the $\mathrm{KW}$ fuel storage basin water, when there are no ongoing operations, shall be limited to $5 \mathrm{mRem} / \mathrm{h}$ dose rate to personnel working in the basin. Shielding shall be provided to reduce worker exposure from above pool IWTS piping and components to ALARA. Dose rates in areas requiring routine personnel access shall be $\leq 0.5 \mathrm{mRem} / \mathrm{h}$.

Basis:

Limiting the dose rate is consistent with ALARA programs. The ALARA review process, evaluations, design improvements, dose assessments, and final design optimizations conducted during the design and construction of the IWTS are documented in the ALARA Report for the Integrated Water Treatment System (IWTS) - Project A.9, SNF-5153 (DR Precechtel, 1999). The report covers occupational doses and doses to the general public from operation of the IWTS and FRS. A dose of 1 Rem was considered equivalent to a cost of $\$ 30,000$. The design objective for the IWTS and other basin systems is to limit a worker's annual exposure to 1 Rem from all sources, based on 1500hr basin occupancy. The ALARA program was consistent with the design and control requirements of Subpart K of the Code of Federal Regulations (CFR), Occupational Radiation Protection, 10CFR835. 
The $5 \mathrm{mRem} / \mathrm{h}$ limit is stated in Section IV.C. 1 of UNI-410. This assumes that the depth of the water reduces the dose rate from the fuel to less than $1 \mathrm{mRem} / \mathrm{h}$, and fuel handling operations raise the background further by causing disturbance of radioactive particles in the water and release of radioactive ions. The dose rate limit, when there are no operations $(0.5 \mathrm{mRem} / \mathrm{hr})$, is consistent with 10CFR835 and was also stated in Section IV.C. 2 of UNI-410. The limit was intended to cover the KW basin when no fuel handling operations were being conducted. The above pool shielding requirement is also found in Section 4.1 of HNF-S-0564.

The IWTS design goal, per Section 3.1.2.1 of HNF-SD-SNF-FDC-003, will be to limit the general basin background contribution from ${ }^{137} \mathrm{Cs}$ in the pool water to $\leq 0.3 \mathrm{mRem} / \mathrm{hr}$, consistent with the previous requirement to maintain a monthly average pool concentration of ${ }^{137} \mathrm{Cs}$ to $\leq 0.5 \mu \mathrm{Ci} / \mathrm{L}$.

\subsubsection{Design Life and Availability Factors}

\section{Requirement:}

The design life shall be for a minimum of three (3) years. The subsystems provided shall reduce the impact on fuel and debris removal operations by minimizing service interruptions. The portion of the IWTS that handles contaminated water received from FRS canister decapping, fuel cleaning, and debris cleaning and rinsing functions, including the IWTS distribution system, shall have a minimum availability factor of $95 \%$ (i.e., $24 \mathrm{hr} / \mathrm{d}, 347 \mathrm{~d} / \mathrm{yr}$ ).

Basis:

The basis is to provide the required support to the serviced systems, e.g., the FRS, Debris Removal System, CVD, etc., to support the SNFP. The fuel removal operations are expected to last two (2) years per SNF-4331, and it is reasonable to assume debris removal operations to last an additional year. Systems similar to the IWTS design normally last 20 to 40 years, far beyond the required lifetime when replacement components are used. The lifetime and availability factors are stated in Sections 2.1 and 2.2 of HNF-SD-SNF-FD-003 and Sections 4.1 and 4.1 a of HNF-S-0564.

\subsubsection{Influent and Discharge Flow}

A. Influent Flow

Requirement:

The IWTS shall design pumping and piping for continuously receiving contaminated water from the FRS decapping station (70 GPM minimum), FRS PCM (80 GPM), and the FRS process table (150 GPM). In addition, the IWTS shall be capable of periodically 
receiving 60 GPM of contaminated water from the CVD Process Water Conditioning System and 50 GPM from sludge loadout transfer line flush operations.

Basis:

These flows are required by Section 4.1 and Table 1 of HNF-S-0564, Sections 3.1.2.2 and 3.1.2.4 of HNF-SD-SNF-FDC-003, and documented by ICs-012, 017, 053, and 198. The total (continuous) flow above is $300 \mathrm{GPM}$ and is considered the minimum input flow from the FRS. Per the specification, it is acceptable to decrease the continuous flow inputs when temporarily adding the intermittent flow.

B. Discharge Flow

\section{Requirement:}

The minimum volume of treated water continuously returned to the main pool, either directly or indirectly, shall be 200 GPM to the South Loadout Pit, 30 GPM to the Discharge Chute, 30 GPM to the Debris Loadout Enclosure, and 60 GPM to the FRS (320 GPM total). The IWTS shall also be able to provide intermittent flows of 15 GPM for MCO cask filling, 15 GPM for debris removal in the Dummy Elevator Pit, 50 GPM for sludge removal in the Transfer Bay Area, and 80 GPM for excess water removal.

Basis:

These flowrates are considered necessary to maintain visibility in the pool, provide adequately low radiation doses for the basin operators, provide water for partially filling the MCO cask before it is lowered into the South Loadout Pit, and support SNF and debris removal activities. The intent of the continuous flow to the Discharge Chute is to ensure this volume is filled and flushed with clean water. The water flows over a barrier and weir to the main pool. The need for continuous flow is an Operator Shift Manager decision as this flow may be better used elsewhere. The specific flow requirements are found in Section 4.1 and Tables 2 and 3 of HNF-S-0564. The specification also allows for decreasing the continuous flow when providing all intermittent flows. The same flows are required in Sections 3.1.2.2 through 3.1.2.6 of HNF-SD-SNF-FDC-003.

\subsubsection{Lubricants}

\section{Requirement:}

IWTS components shall be designed to be permanently lubricated to the maximum extent possible. The leakage of IWTS lubricants into the basin water shall be minimized, and the impact from the leakage of any required lubricant shall be included in the design and performance of the IWTS. Only lubricants approved for basin service shall be used by the IWTS. Larger quantities of lubricants, e.g., those contained in a pump gearbox, shall 
be isolated from loss into basin clean areas by use of catch pans having a volume capacity 1.5 times the volume of lubricant available.

Basis:

Lubricants in the basin must be rigidly controlled to prevent contamination of examination specimens, other basin equipment, and degradation of the IXMs. The IWTS requirements are found in Section 4.7.7 of HNF-SD-SNF-FDC-003 and Section 4.5.7 of HNF-S-0564. The intent of the "included in the design" phrase is that an IXM resin must be available to remove any lubricant selected for the IWTS. The restriction on the type of lubricants and the use and size of the catch pan are found in Section 4.3 of the $K$ Basin Design Guidelines, WHC-SD-SNF-DGS-001 (Roe \& Wills, 1995).

\subsection{COMPONENT DESIGN REQUIREMENTS AND BASIS}

\subsubsection{Piping and Hose Assemblies}

A. General Design Guidelines

\section{Requirement:}

Deposition of radioactive material in the piping system shall be reduced by selecting the appropriate flow velocity, using strainers and filters, and ensuring that all piping low points can be flushed and have drains. Piping systems shall be designed with a minimum of pipe fittings, crevices, low points, dead legs, and connections above the centerline of a pipe. Valve selection shall consider internal material (wetted portions) and shall be valve types that minimize crud and hot spot buildups, upright stems, and cavity avoidance. Butt welds and consumable inserts that produce smoother welds shall be used. Suction hose shall be capable of maintaining fluid flow under full vacuum conditions.

The IWTS flow velocity shall prevent the settling of $\leq 0.25$-in uranium metal pieces in the piping and hose assemblies, shall minimize the number of bends in the piping and hose assemblies, and shall minimize piping and hose impact on other basin activities. Material for piping and hoses shall be selected to not only minimize internal contamination but also minimize later decontamination and disposal issues. As a minimum, all water piping upstream of the IXMs shall be stainless steel. Low points shall be minimized and have drains, and piping and hoses shall be sloped for drainage back to the basin. The IWTS design shall include a means to drain free liquid from each IXM.

Basis:

These are the general basin design guidelines for any piping system that would experience the introduction of radioactive material that could settle or deposit within the system. The intention is to reduce personnel exposure from operating and maintaining 
the system by maximizing operability and minimizing the places where hot spots could occur. This is found in Section 2.6.4.3.A.4 of WHC-SD-SNF-DGS-001. The IWTS complies with these requirements by using 300 Series stainless steel, full flow, ball valves, butt welding, and appropriate pipe configurations for portions of the piping where deposition/settling could occur. The specific IWTS requirements are found in Section 4.1 and Section 4.2, Parts (e), (f), (g), (l), and (m) of HNF-S-0564 and Section 3.2.2 of HNF-SD-SNF-FDC-003. The above hose and connector requirements, including the overall system requirements on design code, pressure, service life, and temperature, are found in Section 3.0 of the engineering specification Guidance for Procurement and Field Use of Process Hoses, ES-E-146 (C Wingard, 1997), found in CVI 50082.

B. Decontamination

\section{Requirement:}

To ease maintenance, decontamination, and decommissioning, the IWTS shall include features to sluice the remaining vessel contents and flush the system piping when the system is removed from operation. The decontamination access ports shall be located in the lowest radiation area possible. Sufficient space shall be provided to accommodate hydrolazing.

\section{Basis:}

The hard piping must be designed to accommodate periodic decontamination during the operating life and at the end of life before disposal. There are sufficient penetrations in fabricated IWTS piping to allow decontamination. The requirements are stated in Section 3.2.2 of HNF-SD-SNF-FDC-003 and Sections 4.1 and 4.2.n of HNF-S-0564.

\section{Vents and Pressure Relief}

\section{Requirement:}

High points in the piping shall have vents. Contaminated or potentially contaminated vented material shall either be routed to a discharge point located below the basin water surface or include filtration. Pressure vessel relief valve outlet piping shall extend to the basin (pool).

Basis:

The vent requirement is found in Section 4.2, Part (h), of HNF-S-0564. The intent of the vent requirement is to ensure that gas is not entrapped in the piping, not that all high points have vents. Certain high point sections of pipe do not have vents since the normal operating water velocity will carry gases to a vent point. The pressure relief routing requirement is stated in Section 3.2.3 of HNF-SD-SNF-FDC-003. The purpose is to 
return any released radioactive water back to the pool. This is a general requirement that applied to all pressure vessels (KO pot, settler tanks, garnet filters, and IXMs) at the time it was written. The IXMs do not require pressure relief as they are constantly vented to the pool. Although they are constructed under ASME B\&PVC Section VIII rules, they are not operated as pressure vessels. Filtration in this requirement refers to air and other gases released to the atmosphere. This requirement was met by the HEPA filtration subsystem on the garnet filter vent.

D. Spare Tie-Ins

Requirement:

Pre-engineered connections (spare tie-ins) shall be provided to allow sampling of the IXM inlet and outlets and to allow the future installation of additional water filtration and conditioning capacity.

Basis:

There is significant uncertainty in the quantity and particle size of the sludge and quantity of ${ }^{137} \mathrm{Cs}$ that will be released to the IWTS by the FRS fuel processing operations. Additional water filtration and conditioning may be required. This requirement is found in Section 4.1, Part (g), and Section 4.2, Part (k), of HNF-S-0564 and Section 3.2.2 of HNF-SD-SNF-FDC-003. Tie-ins have been provided for the possible future installation of a minimum of two (2) filter and IXM units (see H-1-80550, Sheet 10).

\section{E. Condensation and Shielding}

\section{Requirement:}

Condensation shall be prevented on piping and hose assemblies located outside the pool. Piping and hoses shall be routed in a manner that allows for the installation of supplemental shielding.

Basis:

These requirements are from Section 4.2, Parts $\mathbb{C}$ and (j), of HNF-S-0564 and Section 3.2.2 of HNF-SD-SNF-FDC-003. Condensation could cause problems with electrical equipment and be mistaken for radioactive water leakage from the system. The IWTS meets the intent of this requirement by providing insulation on overhead piping. The IWTS does provide shielding on the piping from the settler assembly to the filter shield enclosure penetration, starting $4 \mathrm{ft}$ below the pool water surface.

The backwash line is also shielded from the enclosure penetration to $4 \mathrm{ft}$ below the pool water surface. During operation additional shielding may be necessary to meet the ALARA requirements. 
F. Hoses Pressure Rating and Tests

\section{Requirement:}

Unless otherwise specified, all hose components, including hose, fittings, and connections, shall be rated for a working pressure of 150 PSIG. New hose assemblies shall be hydrostatically tested to 1.5 times the design pressure, but shall not exceed the maximum allowable test pressure of any component in the IWTS that cannot be isolated. The test pressure shall never be less than 75 PSIG.

Basis:

The requirement is stated in Sections 3.3.2 and 3.4 of the hose procurement specification ES-E-146. Hose assemblies do not require hydrostatic pressure testing if the pressure and temperature ratings are within the manufacturer's recommendations per the applicable ASME Code. The test requirement would apply to hoses assembled on site or one that would exceed the manufacturer's recommendations. The larger 3-in and 4-in hose

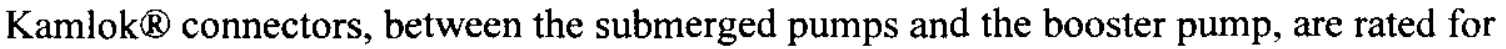
125 PSIG. This means the hose assemblies, which include the connectors, and the settler tank assembly are also rated for 125 PSIG.

G. Pipe Pressure and Temperature Rating

\section{Requirement:}

All interconnecting and distribution header piping shall have a design pressure of 150 PSIG and a design temperature of $100^{\circ} \mathrm{F}$.

Basis:

This requirement is stated in Section 4.3 .9 of the general specification ES-E-152, and the design values encompass the IWTS operating pressures and temperatures.

\subsubsection{Pumps}

A. Arrangement and Type

\section{Requirement:}

The IWTS shall include three (3) stainless steel, submersible pumps. Two (2) of the pumps shall each have a flowrate of 80 GPM, and the other shall have a flowrate of 160 GPM. The pump outlets shall be directed to the IWTS filtration components. A booster pump shall be provided to support operation of IWTS components and treated water distribution. 


\section{Basis:}

These general pump requirements are found in Section 4.1 of HNF-S-0564, and the initial FRS requirements were covered by Section 3.1.2.2 of HNF-SD-SNF-FDC-003.

The submersible pump flowrates provide the required support of the FRS, and the booster pump is necessary for proper operation of the IWTS filters, IXMs, and treated water distribution.

B. Booster Pump (FRW-P-4) and Skid

\section{Requirement:}

The booster pump skid shall provide a centralized location for the system booster pump and associated piping, valves, and instrumentation needed to operate the system in its various modes. The skid shall not exceed the envelope dimensions shown on H-1-83340, shall not exceed the maximum floor loading of $2000 \mathrm{lb} / \mathrm{ft}^{2}$.

The booster pump shall provide the motive force to feed the filter vessels, IXMs, and distribution piping. The self priming booster pump shall be rated for $320 \mathrm{GPM}$ at 100 PSIG total discharge head (TDH). The pump shall be driven by a motor with a variable speed drive and shall be able to operate at temperatures of $32^{\circ}$ to $120^{\circ} \mathrm{F}$.

Basis:

The basis for specific skid and booster pump requirements are found in Sections 1.0 and 4.0 of ES-E-152-04 (CVI 50082). The skid assembly Drawing H-1-83340 was made part of the specification data sheets. The other requirements in the data sheet are covered by the overall general system requirements. The data sheet does not state the pump fabrication code, the required net positive suction head (NPSH), or describe the chemical addition metering pump FRW-P-5 assembly. The chemical addition pump will be used only if basin water clarity cannot be maintained by normal system operation. The basin floor loading requirement is consistent with the source document $K$ Basins Floor Loads and Calculations, WHC-SD-GN-ER-10006 (RM McCoy, 1996).

\section{FRS Decapper and PCM Pumps}

\section{Requirement:}

The IWTS shall provide a pump to be used to draw water and sludge from the FRS decapping station and another pump to draw water and sludge from the PCM. Both pumps shall be submersible and self priming. Each pump shall be rated for $80 \mathrm{GPM}$ at 70 PSIG TDH. The pumps shall be able to operate at temperatures of $32^{\circ}$ to $120^{\circ} \mathrm{F}$. The pumps shall not exceed a maximum weight of $800 \mathrm{lb}$, shall not exceed envelope dimensions of a 4-ft x 20 -in diameter, and shall have lifting lugs for material handling. 
Basis:

The requirements are stated in Sections 1.0 and 4.0 of ES-E-152-05 and ES-E-152-06 (CVI 50082). The original pump weight was $530 \mathrm{lb}$, but this was increased to $800 \mathrm{lb}$ (see $\mathrm{H}-1-83326$ ) which is within the capability of the FRS support table design. The data sheet does not state the pump fabrication code as manufacturer standards were acceptable.

D. FRS Process Table Pump

\section{Requirement:}

The IWTS shall provide a submersible, self priming pump to be used for cleaning the surface of the process table. The pump shall be rated for 160 GPM at 70 PSIG TDH. The pump shall be able to operate at temperatures of $32^{\circ}$ to $120^{\circ} \mathrm{F}$. The pump shall not exceed a maximum weight of $800 \mathrm{lb}$, shall not exceed envelope dimensions of a 4-ft x 20-in diameter, and shall have lift lugs for material handling.

Basis:

The requirements are stated in Sections 1.0 and 4.0 of ES-E-152-07 (CVI 50082). The original pump weight was $530 \mathrm{lb}$, but this was increased to $800 \mathrm{lb}$ (see H-1-83326) which is within the capability of the FRS support table design. The data sheet does not state the pump fabrication code as manufacturer standards were acceptable.

\subsubsection{Knockout (KO) Pot and Lifting Tool Assembly}

\section{Requirement:}

The first stage of particle removal shall be provided by the submerged, cylindrical, screened KO pot. The KO pot shall receive the combined flow from the submersible pumps (320 GPM) and shall be capable of operating at 150 PSIG. Each KO pot shall not exceed the envelope dimensions shown on the assembly drawing. The KO pot discharge screen shall be sized at $500 \mu \mathrm{m}$ (nominal) with a collapse design pressure of 150 PSID. The KO pot shall have a series of internal baffle plates to enhance particle settling. The maximum weight of the empty $\mathrm{KO}$ pot shall be $600 \mathrm{lb}$ and be structurally adequate to hold $3500 \mathrm{lb}$ when lifted. The KO pot shall be able to operate at temperatures of $32^{\circ}$ to $120^{\circ} \mathrm{F}$.

A "below the hook" lifting tool assembly shall be designed for moving the pots. The rated load capacity shall be $4000 \mathrm{lb}$, and the length of the mechanism shall prevent lifting a KO pot (bottom) $>6 \mathrm{ft}$ above the pool floor. The load test shall be $125 \%+0 /-5 \%$ of the rated load capacity. 
Basis:

The KO pot requirements are stated in Sections 1.0, 3.0, and 4.0 of ES-E-152-02 (CVI 50082). The other requirements in the data sheets are covered by the overall general system requirements. Drawing H-1-83320 (pot assembly) and the associated hose and piping isometrics were made part of this specification data sheet. The basis for the initial $500 \mu \mathrm{m}$ (nominal) screen size is to limit the particle size, even with screen erosion, to $550 \mu \mathrm{m}$ that is used in the downstream criticality analyses. The lifting mechanism consists of the lifting bar, shown on the assembly drawing, and the $\mathrm{KO}$ pot lifting tool, shown on H-1-84014. The loaded weight of $3500 \mathrm{lb}$ is a structural requirement only. Operationally, the total pot and tool assembly load is limited by the 2400 -lb monorail above the pots. The "below the hook" design uses the existing hoist and monorail, and the length requirement is with the hoist in the full up position. The lifting tool has been validated per the structural analysis SNF-5244 for $4000 \mathrm{lb}$ to assure an adequate margin. The tool assembly and requirements are listed on Drawing H-1-84014. The testing conforms to Section 11.9.1 of the Hanford Site Hoisting and Rigging Manual, DOE-RL-92-36.

\subsubsection{Settler Tank Assembly}

\section{Requirement:}

The second stage of particle removal shall be provided by the underwater settler tanks in the basin Weasel Pit. The settler tanks shall be normally fed from the KO pot at a flow of 320 GPM. The settler assembly inlet header shall divide the 320 GPM flow into ten (10) individual 20-in diameter, Type 304 Series stainless steel, settling tanks. The settler tank assembly shall not exceed the envelope dimensions shown on the drawings.

The assembly shall not exceed a maximum floor loading of $2000 \mathrm{lb} / \mathrm{ft}^{2}$. The assembly shall be able to operate at 150 PSIG and temperatures from $32^{\circ}$ to $120^{\circ} \mathrm{F}$.

\section{Basis:}

The Drawings H-1-83330 (settler tank assembly) and H-1-83332 (frame) and the associated piping and hose isometrics were made part of the specification data sheets. The size was constrained by the Weasel Pit size and the amount of basin water depth required to provide sufficient shielding. The settler tank assembly design incorporates Stokes Law to assess particle size and density to determine the critical settling velocity. The reduced flow of approximately 32 GPM per settler tank provides retention time for the larger particles in the water to settle in the bottom of the tanks. The requirements are stated in Sections 1.0, 3.0, and 4.0 of ES-E-152-03 (CVI 50082). The other requirements in the data sheets are covered by the overall general system requirements. The basin floor loading requirement is based on fully loaded settler tanks and is consistent with the source document WHC-SD-GN-ER-10006. The assembly was designed and fabricated for 150 PSIG, but it was hydro tested at 188 PSIG that only qualifies the assembly for a 
Code stamp rating of 125 PSIG. The 3 -in and 4 -in hose assemblies that connect the

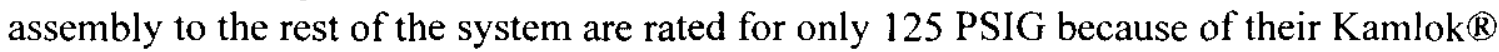
connectors. A decision was made to qualify the settler assembly to this lower value. An upstream rupture disc protects the hose connectors and the settler tank assembly from over pressure events.

\subsubsection{Garnet Filter Vessels and HEPA Subsystem}

A. Dimensions and Flow Distribution

\section{Requirement:}

The third stage of particulate removal shall be provided by three parallel flow, deep bed filters loaded with garnet and sand media. During normal operation, the full system flow from the settler assembly (320 GPM) shall be split among the three (3) vessels giving a flow of 107 GPM (nominal). The backwash flow shall be 150 GPM (nominal), and the backwash operation shall be performed on one vessel at a time. The equipment shall be able to operate at 150 PSIG and temperatures from $32^{\circ}$ to $120^{\circ} \mathrm{F}$. Each filter shall be an annular vessel. The filter shall be a $40^{\prime \prime}$ outside diameter vessel fully contained within a 72 " outside diameter vessel. Vessel piping and valves shall be provided for each filter to allow for filter operation, backwash, top sparge, media air agitation, pressure relief, media sluice in, and media sluice out operations. Each vessel shall not exceed the dimensions shown on the drawings and shall not exceed a maximum floor loading of $2000 \mathrm{lb} / \mathrm{ft}^{2}$.

Basis:

Drawings H-1-83341 (assembly), H-1-83342 (frame and shielding), H-1-83343 (inlet baffle), H-1-83344 (effluent screen), H-1-83345 (vent screen), and H-1-83346 (sparger screen), and the associated piping and hose isometric drawings, were made part of the component specification data sheets ES-E-152-01(CVI 50082). The requirements are found in Sections 1.0,3.0, and 4.0 of the data sheets and the drawings. The required operations are necessary to maintain filter vessel performance. The basin floor loading requirement considers the filter vessels fully loaded and is consistent with the source document WHC-SD-GN-ER-10006. Refer to Figure 7-7.

\section{B. Water Filtration}

\section{Requirement:}

The garnet filter shall be designed to variable sludge loadings from FRS fuel processing (decapping, cleaning, and table operations). The garnet filter and associated piping shall be designed to allow for changes in filter media (sand) to adapt to changes in desired particle capture. The filters shall allow the use of filter media with nominal filter ratings from $20 \mu \mathrm{m}$ to $\leq 5 \mu \mathrm{m}$. 
Basis:

The filters and associated piping have been designed to allow media sluicing to a spent media container. The $5-\mu \mathrm{m}$ level provides adequate clarity in the basin pool. The basis for the requirements is found in Section 4.1 of HNF-S-0564 and Section 3.1.2.1 of HNF-SD-SNF-FDC-003.

C. Hydrogen Flammability and HEPA Venting

Requirement:

Filter vessel design shall preclude the possibility of accumulating either more than one volume percent ( $25 \%$ of the lower flammability limit) or a problematic quantity of hydrogen as determined by a hydrogen fire hazard analysis. All contaminated or potentially contaminated process vents shall be routed to a discharge point consistent with ALARA and air emission considerations.

Basis:

The radiation from accumulated basin sludge is known to decompose water and release free hydrogen and oxygen molecules that can accumulate to flammable concentrations. The lower flammability limit that is commonly used (4 volume percent) and the standard design point (1 volume percent or 25\%) is found in NFPA 69, Explosion Prevention Systems, National Fire Protection Association. To meet this requirement and preclude a buildup, each filter is fitted with a high point float valve that continually releases any accumulated gas when the filter is not in service. The associated filter vent and air sparge lines from the filters are manifolded and routed through a HEPA filtration subsystem to vent gases to the atmosphere outside the building. The design flammability, reference to NFPA 69, discharge requirement, and the discharge option chosen is found in Section 4.3 of HNF-S-0564 and Section 3.2.3 of HNF-SD-SNF-FDC-003.

D. Garnet Filter Temperature

\section{Requirement:}

Filter design shall provide for the removal of heat generated by radioactive decay of the sludge and chemical reactions to prevent bulk sludge temperatures from exceeding $140^{\circ} \mathrm{F}$.

Basis:

To assure stability during sludge accumulation and storage, the preferred sludge temperature is $<68^{\circ} \mathrm{F}$. The surface area of the annular shaped filter provides enough outer surface area to be deemed sufficient to dissipate the estimated heat. To assure 
compliance with the requirement, the surface (skin) temperature of the filter vessel is monitored. The basis is found in Section 4.3 of HNF-S-0564 and Section 3.2.3 of HNF-SD-SNF-FDC-003.

E Backwashing and Water Sparging

Requirement:

A backwashing operation shall be used to remove filtered sludge from the garnet filter media. The backwash design shall be capable of sluicing $\geq 99 \%$ of the sludge from the filter vessel to another vessel that maintains water cover over the sluiced solids. The backwashing operation shall retain $\geq 95 \%$ of the filter media in the filter vessel. The operation shall recapture $\geq 99 \%$ of the sluiced sludge and media.

Basis:

The backwashing operation pumps the backwash solution to the water-covered settler tanks and then to the other two (2) garnet filters. The reduced backwash flow (150 GPM instead of the normal 320 GPM) ensures additional particles will settle in the tanks, and the downstream filters should remove the particles that pass the settler tanks. These percentage values can't be accurately measured, and they are considered design goals. This requirement is stated in Section 4.1 of HNF-S-0564 and Section 3.1.2.1 of HNF-SD-SNF-FDC-003.

F. Air Sparging Vent (HEPA Filter Subsystem)

\section{Requirement:}

Air sparging, consisting of the injection of compressed air into the filter media, shall be used to agitate the filter media to restore filter efficiency. The vent arrangement and filtering design requirements shall include the following:

- Design flowrate of 150 SCFM

- $\quad$ Stainless steel materials

- $\quad$ Agitating one (1) garnet filter vessel at a time

- Moisture separator ( $99 \%$ water removal)

- $\quad$ Preheater to ensure proper HEPA filter performance

- $\quad$ Prefilter (glass microfiber, 60 to $65 \%$ efficiency)

- $\quad$ Nuclear grade HEPA filter (99.95\% efficiency for $0.03 \mu \mathrm{m}$ particles)

- $\quad$ Second nuclear grade HEPA filter (same type to serve as sample collector)

- Differential pressure gauges for each filter (3)

- Bag-in/bag-out HEPA filter housing design

- Exhaust termination outside the building. 
The HEPA filtering subsystem shall be designed according to the applicable requirements of ASME N-509, Nuclear Power Plant Air-Cleaning Units and Components, and shall be designed to test to ASME N-510, Testing of Nuclear Air Treatment Systems.

Basis:

The design of the vent arrangement and the HEPA filtering subsystem is dictated by the design proposed and approved by Sections 6.2, 7.0, 8.0, and 9.0 of the Radioactive Air Emissions, Notice of Construction for the 105-KW Filter Vessel Sparging Vent, DOE/RL-98-02. The operational and filtering capabilities are based on the subsystem considered necessary to provide an acceptable level for the emissions from a garnet filter media air sparge. Refer to the reference document for a full definition of the subsystem, testing requirements, national standards, source assumptions, and alternative design requirements. No measurable concentrations of gaseous radionuclides are expected to be released from the building by the air sparging operation.

\subsubsection{Ion Exchange Modules (IXMs)}

A. Type of Module

\section{Requirement:}

The ion exchange method used for the IWTS shall be based on the same government furnished IXMs being used at the basins by the Basin Water System. These IXMs shall be integrated into the IWTS design.

Basis:

This component has provided proven service, has been code qualified, has undergone extensive analyses, and has an established radioactive waste disposal path for those IXMs prevented from becoming TRU waste. Key reference documents are the IXM specification, HNF-4198, and the IXM CSER, WHC-SD-NR-CSER-011. The basis for disposal of spent IXMs is covered under the Safety Analysis Report for Packaging (Onsite) Ion Exchange Modules, HNF-2760 (JH O'Brien, 1999). The number of IXMs used by the IWTS is consistent with the overall system flow (320 GPM) and the required availability. Each IXM is capable of $160 \mathrm{GPM}$ flow. The availability requirement requires a third IXM be provided for shut down, change out, and standby so the IWTS can always have two (2) available for operation. The use of three (3) IXMs in the IWTS is discussed under sampling piping in Section 4.2(I) of HNF-S-0564. 
B. Radioactive Waste

Requirement:

The IWTS shall operate in a way that maintains the IXMs as non-TRU and low level radioactive waste.

Basis:

The requirement is stated in Section 4.1 of HNF-S-0564. TRU waste is unacceptable and causes excessive (economic) disposal problems. IWTS low level waste must comply with the Hanford Site Solid Waste Acceptance Criteria, WHC-EP-0063-4

(NP Willis, 1996).

C. Design and Operating Parameters

Requirement:

The IXMs shall be designed to the following parameters:

- Design Pressure

150 PSIG

- Design Flow

160 GPM

- $\quad$ Allowable Working Temperature

$200^{\circ} \mathrm{F}$ (maximum)

- Ambient Temperature Range

$30^{\circ}$ to $95^{\circ} \mathrm{F}$

- Process Media/Fluid

- Media Temperature Range

Demineralized Water

- Media Conductivity

- Media pH Range $40^{\circ}$ to $100^{\circ} \mathrm{F}$ (inlet)

$2 \mu$ Siemens $/ \mathrm{cm}$ (inlet)

5.0 to 9.5

Basis:

The design and operating values are found Section 3.2 of the IXM specification HNF-4198. The typical service life will vary, depending on the amount of material received from the FRS. The service life listed in the specification varies from several weeks to several months, but this life would be shortened by the higher ${ }^{137} \mathrm{Cs}$ input expected from the decapping operation and the need to remove a higher percentage $(\sim 99.9 \%)$ of the ${ }^{137} \mathrm{Cs}$ over the IXM's operating life for ALARA considerations.

D. Fabrication

Requirement:

The IXMs shall be fabricated per the dimensions of the assembly and details drawings. The IXM tanks shall be shielded with low alkali concrete with a minimum compressive 
strength of 4000 PSIG (after 28 days). There shall be no voids between the six (6) individual tanks of the IXM and their interconnected piping. All spaces within the module shall be completely filled with concrete as specified in the specification.

There shall be $3.5 \mathrm{ft}^{3}$ of ion exchange media per tank ( $21 \mathrm{ft}^{3}$ total/IXM), and only new ion exchange resins shall be loaded into the tanks.

Basis:

Drawing H-1-46279 (assembly and details) was made a part of the specification per Section 2.2.1 of HNF-4198. Sections 3.3.3 and 3.3.4 of HNF-4198 also provide further details on the concrete to be used and the concrete codes that are applicable. The exact type of resin specified in HNF-4198 will be modified for the IWTS to be more conducive to removing the ${ }^{137} \mathrm{Cs}$ ions.

\subsubsection{Sampling}

\section{Requirement:}

Samplers shall be provided to obtain representative composite and grab samples from the inlet and outlets of the IXMs, considering the intermittent contaminant level that results from the fuel canister decapping and fuel cleaning operations. One (1) autosampler shall be provided upstream of the three (3) IXMs and one individual autosampler shall be provided on the outlet of each IXM to sample periodically. The samplers shall be located near the associated components and have closed loop drains that return excess water to the basin pool. Shielding and liquid containment shall be provided to maintain ALARA conditions during sampling and sample removal.

Basis:

Sampling and subsequent analysis is required to monitor the IXM loadings for ${ }^{137} \mathrm{Cs}$ and TRU isotopes. Excess water is radioactive and either must be contained within the sampler or must be returned to the basin pool by closed loop to prevent contaminating the operating area. The sampler collection bottles were modified to preclude leakage during collection, and any small spills during bottle replacements will be cleaned up using absorbent material. The requirements are stated in Section 4.2, Part (I), of HNF-S-0564 and Section 3.2.2 of HNF-SD-SNF-FDC-003. 


\subsection{INSTRUMENTATION AND CONTROL REQUIREMENTS AND BASIS}

\subsubsection{General Requirements}

\section{Requirement:}

The IWTS instrumentation and control subsystem shall comply with the following requirements:

- Interface and communicate with the Alarm Monitoring System

- Be designed to be "fail-safe" for both personnel safety and environmental protection

- Accommodate calibration and testing, if required

- Collect data for storage and analysis

- Incorporate human factors engineering and color coding

- Self drain to the basin, if applicable

- Use ALARA principles to the use and calibration and testing of instruments

- Employ engineered confinement methods to prevent uncontrolled release of radioactive contamination, whenever possible.

Basis:

These requirements are prudent for integrating the system with the other basin systems and meeting the obligations of the IWTS. The requirements are found in Section 4.4 of HNF-S-0564 and Section 3.3.1 of HNF-SD-SNF-FDC-003. The IWTS report Human Factors Engineering (HFE) Report for the Safety Analysis Report (SAR), SNF-4297 (LC Mauws, 1999), concluded that IWTS process and equipment designers have considered HFE issues as very important to their design. This is especially evident on the component identifiers and on the Control Panel CP-A visual aids.

\subsubsection{Collection and Display}

Requirement:

Instrumentation and controls shall be provided to support the system and mechanical equipment requirements for monitoring and control. Local and remote instrumentation shall be able to collect and display, as a minimum, the following parameters:

- $\quad$ Principal component flows

- $\quad$ Running status of submerged pumps

- Booster pump developed head pressure and running status

- IXM inlet and outlet conductivity.

Local instruments shall be provided for components and operations requiring manual 
control to ensure normal operations, ease of trouble shooting and maintenance, and personnel safety. Instrumentation field contacts shall be powered by 24 VDC unless otherwise authorized (requires specific SNFP approval).

Basis:

These parameters are required for proper control of the IWTS and FRS coordination. The requirements are found in Section 4.4 of HNF-S-0564 and Section 3.3 of HNF-SD-SNF-FDC-003.

\subsubsection{Computer Control and Data Acquisition}

A. Type of System

\section{Requirement:}

The IWTS shall use a Siemens $®$ based supervisory control and data acquisition (SCADA) system consisting of "off-the-shelf" equipment that is custom packaged for the IWTS application. The SCADA shall be designed to be operated in an unmanned mode with periodic attention. The following shall be provided:

- $\quad$ Either a stand alone computer or remote based controller

- Provisions for remote monitoring and control

- Terminal blocks to ease field wiring

- WONDERWARE® run-time software operating on Windows ${ }^{\circledR} \mathrm{NT} \circledast$ platforms

- Tiway system for communicating with the Siemens ${ }^{\circledR}$ programmable logic controller (PLC)

- Specific screens and programs for downloading.

Basis:

The basis for the selection of the computer system is found in Section 4.4 of HNF-S-0564 and Section 3.3.1 of HNF-SD-SNF-FDC-003. The selection was specific to manufacturer and type so that the selected system would interface with the control and monitoring of other basin systems and parameters.

B. Software

Requirement:

Software shall be commercially available with no programming required other than configuring for the IWTS. Software used in the development and running on the computer shall be part of the turnover package along with any applicable license agreements. The software shall be verified to ensure valid results in monitoring and 
controlling all IWTS water treatment equipment. Displays shall be intuitive and shall require a minimum of operator training. The software shall have a $15 \%$ excess capacity to provide for the possible addition of future equipment.

Basis:

The software basis is stated in Section 4.4, Parts (a), (f), and (g), of HNF-S-0564 and Sections 3.3.1 and 3.3.2 of HNF-SD-SNF-FDC-003. The intent is to procure a system proven for IWTS service and independent of outside control of any kind once turnover has been achieved.

\subsection{TESTING AND MAINTENANCE}

\subsubsection{Testing Requirements}

This SDD does not cover required factory acceptance tests (FAT) of the system, of individual components, or of instrumentation. The FAT was documented by the Integrated Water Treatment System Factory Acceptance Test - Acceptance Report, SNF-4913 (LC Mauws, 1999). This section also does not cover the installation acceptance testing. This SDD assumes all requirements for installation acceptance have been satisfied, the contract completion verified and validated, and the system qualified for basin operation.

\subsubsection{Maintenance Requirements}

A. General

\section{Requirement:}

The design and material selection shall include features that simplify maintenance of the IWTS equipment and the parts of the facility affected by IWTS operations. Particular attention shall be paid to pumps, valves, and any equipment in high or very high radiation areas. The IWTS shall be designed to facilitate safe cleanup (decontamination).

Basis:

Items requiring the most maintenance time are active components like pumps and valves while the most difficult are normally items within radiation areas because these areas are usually space restricted and require radiation exposure. Therefore, it is prudent to try to restrict expected maintenance by design of better equipment and/or by better access to maintenance items. Any maintenance that requires access to the garnet filter enclosure should have filter backwash done before entry. The basis for the requirement is found in Section 4.7 of HNF-SD-SNF-FDC-003 and Section 4.5.1 of HNF-S-0564. 
B. Replacement Parts and Common Components

\section{Requirement:}

The equipment shall be designed to use standard replacement parts to the extent possible. Any parts, materials, or assemblies expected to degrade or wear during normal use or exposure to radiation shall be easily replaceable. The IWTS design shall consider interchangeable equipment for these components. The failure of any system component shall not reduce the design life, diminish the maintainability, or reduce the capabilities of the IWTS or any associated interface. Components that may fail or wear out before the end of their projected life shall be identified on a spare parts list. To the maximum extent practical, common components, including instruments, shall be used to reduce spare parts, tools needed, and maintenance procedures.

Basis:

The purpose of these requirements is to maintain the capability of the IWTS to meet its design and operational goals. There has been a concerted effort to standardize the type of components and the vendors of those components in the IWTS design.

These requirements are found in Sections 4.1, 4.5.2, 4.5.4, and 4.5.5 of HNF-S-0564 and Sections 3.3.1, 4.7.2, and 4.7.4 of HNF-SD-SNF-FDC-003.

\section{Working Space}

\section{Requirement:}

Sufficient piping corridor working space shall be provided to facilitate inspection, maintenance, and emergency repair.

Basis:

This requirement is found in Section 4.2, Part (o), of HNF-S-0564 and is necessary for proper maintenance access. This requirement reduces maintenance required, IWTS downtime, and personnel radiation exposure.

\section{Special Tools}

\section{Requirement:}

The design shall minimize the need for special tools required to perform routine maintenance. If required, the component vendor shall design and provide any special tool needed. 
Basis:

These requirements are found in Sections 4.7.3 and 4.7.5 of HNF-SD-SNF-FDC-003 and Section 4.5.3 of HNF-S-0564. The use of standard tools simplifies maintenance and reduces the chance that the tool will not be available when needed.

E. Periodic Maintenance

\section{Requirement:}

Periodic maintenance capabilities shall be included in the design to prolong the effective lifetime at a minimum cost and downtime. Components shall be designed to be permanently lubricated to the maximum extent possible. If lubrication is required, the equipment shall be designed to allow lubrication by using fittings and without requiring the disassembly of any parts other than the simple removal of protective caps or booting. The leakage of any lubricants into the basin water shall be minimized.

Basis:

Components, such as the submersible pumps, are not easily accessible for routine maintenance and would require excessive system downtime for an item like lubrication. Also, any lubricant leakage would be direct into the basin pool. Therefore, permanent lubrication is necessary. These requirements are found in Sections 4.7.6 and 4.7.7 of HNF-SD-SNF-FDC-003 and Sections 4.5.6 and 4.5.7 of HNF-S-0564. 
This page is intentionally left blank. 


\subsection{KW BASIN IWTS DESIGN DESCRIPTION}

\subsection{SUMMARY}

The IWTS is a service system that supports the removal of SNF, debris, and sludge from the basin. The IWTS supports FRS activities that involve canister and fuel movement, the removal of the canister caps (decapping), cleaning of the fuel within the canisters, sorting the contents, and loading fuel and debris for removal from the basin. The primary purpose of the IWTS is to capture and treat the soluble and insoluble products released during fuel retrieval, processing, and removal activities to minimize the radiation dose from the water in the basin and to maintain water clarity for continued operations. The IWTS treats and returns this water to the basin. When not needed for fuel removal operations, the IWTS is available to be used with the Basin Water System for bulk treatment of basin water. The IWTS is shown as a simplified schematic in Figure 7-1.

Particles received from the FRS and basin pool are removed by a three-stage filtration process and important dissolved radionuclides are removed by an ion exchange process. The system primary components include three (3) submerged pumps, a submerged KO pot and strainer, an assembly of ten (10) submerged particulate settler tanks, a booster pump, three (3) deep bed garnet filters, three (3) IXMs, water distribution piping, and a programmable computer control system.

During normal operation the submerged pumps take suction separately from the FRS decapping, cleaning, and processing equipment. The pumps discharge the introduced water, sludge, and dissolved impurities into the $\mathrm{KO}$ pot for the first stage of particulate removal. The water flows from the KO pot to the settler tanks for the second stage of particulate removal. After exiting the settler tanks, the water and smaller particulate are routed to the suction side of the booster pump. The booster pump discharges the water and particulate into the garnet filters for the third and final stage of particulate removal. The combined garnet filter outlet is then routed to the IXMs for removal of most of the dissolved ions. The water that comes from the IXMs is then discharged via a distribution header to support various basin activities.

The impurities introduced into the IWTS include dissolved radioactive ions, canister and fuel particulate $(<0.25$-in sludge), and the corrosion inhibitor in the capped fuel canisters. The KO pot (first stage) uses a $500 \mu \mathrm{m}$ screen to remove and retain the larger particles of sludge. The settler tanks (second stage) are in parallel and connected by common inlet and outlet manifolds. The flow velocity is reduced from a 3 -in pipe to the ten 20 -in pipes that comprise the settler tanks. The effective settling range is expected to be 15 to $50 \mu \mathrm{m}$. The garnet sand filters (third stage) are expected to remove the particulate that passes the settler tanks down to about $5 \mu \mathrm{m}$. Estimates were made of the expected nominal and bounding quantities of sludge that would be introduced into the IWTS to provide meaningful data for the filtering component design. These estimates are in $K$ West Basin Sludge Volume Estimates for Integrated Water Treatment System, HNF-3165 (KL Pearce et al, 1998). 
When the IWTS is not needed to support FRS activities, the IWTS is available to supplement the Basin Water System in maintaining overall basin water quality. The usual arrangement is to route the discharge of the Basin Water System recirculation pumps through the IWTS IXMs and distribution header. If the garnet filters are needed, the discharge must be routed through the IWTS booster pump to increase the water pressure. The skimmer pump is rarely used for this purpose because of the lower flow capacity.

The IWTS system is operated and controlled from a remotely located computer interface in Room 20A of the $105 \mathrm{KW}$ Reactor Building. All AOVs, their positions, alarms, instrumentation readouts, process flow mimic, and the alarm summary are graphically displayed. The control system has both a manual and automatic mode. In the automatic mode, any of the eleven (11) preprogrammed sequences can be selected and started. Nine (9) of these sequences are related to the filter media backwashing, sparging, and air agitation (sparge) for the three (3) garnet filters. In the manual mode, all AOVs and pumps can be operated individually from the computer screen.

\subsection{INTERFACES AND BOUNDARIES}

The main systems that the IWTS provides services to are the FRS and the existing Basin Water System. The IWTS also provides treated water for other basin users, including MCO cask loading, debris cleaning and rinsing, and sludge removal. Another connection to the IWTS allows for treating the contaminated water returned to the basin from the CVDF operations. All interfaces and boundaries are discussed in detail in Section 2.0 of this SDD, including those that the IWTS services and those that supply services that allow the IWTS to function.

\subsection{PHYSICAL LOCATION AND LAYOUT}

All IWTS mechanical equipment is located in the basin, either submerged in the basin pool or in the Transfer Bay Area. The control and monitoring instrumentation is located in Rooms 4 and $20 \mathrm{~A}$ of the $105 \mathrm{KW}$ Reactor Building. The piping for the Basin Water System and the IWTS are shown on P\&ID H-1-80550. Sheet 8 (in-pool and booster pump skid), Sheet 9 (garnet filters), Sheet 10 (IXMs), and Sheet 11 (HEPA subsystem and treated water distribution header). The following discussion refers to piping and valves shown on the drawings. Refer also to the General Arrangement Drawings H-1-83310 and H-1-83311.

The submersible pumps, the associated magnetic flowmeters, and the KO pots that are used to service the FRS processing operation are located in the West Bay of the basin. The canister decapping and process table pumps are retained within pump stands that include particulate strainers. These stands are near the bottom of the pool and shown on Drawings DW-213 (for FRW-P-1) and DAG-356 (for FRW-P-3). The decapping pump (FRW-P-1), flowmeter, pump stand, and strainer are found at approximately Column Line $12.3 / \mathrm{C} .8$. The process table pump (FRW-P-3), pump stand, and strainer are found at approximately Column Line 12.3/D.2. The PCM pump (FRW-P-2) and its flowmeter are mounted on the top of the PCM as noted on Drawing DAG-330. They are found at approximately Column Lines 12.0/C.9. 
The KO pots are stored within the fuel racks along Column Lines 12.3/A.4 to B.8. The KO pot (FRW-KOP-100) being used is in the Column Lines 12.3/B.8 position. Flexible hoses are used to combine the flow from the pump outlets and to connect the pump flow to the KO pot.

Another hose is used within the pool to connect the KO pot to the settler assembly inlet piping. The settler assembly (FRW-STLR-100) is also submerged and is located across the basin in the Weasel Pit. The Weasel Pit is connected to the main basin pool east of the East Bay. The settler tanks are centered at about Column Lines 5.0/D.3. The arrangement plan for the pumps and KO pots is shown in Figure 7-2.

Most of the major components and associated piping are in the northwest corner of the Transfer Bay Area within the area bounded by Column Lines 13 to 16/A to Ba. The major equipment includes the three (3) garnet filters, the three (3) IXMs, and the booster pump skid. The skid not only includes valving and piping associated with the booster pump (FRW-P-4) but also includes the metering pump assembly, CVD water inlet, the inlet connections for the Basin Water System skimmer (SKW-P-6) and recirculation (RBW-P-1A/B) pumps, and the flow control components for their use when backwashing and sparging the garnet filters.

The local readout instruments for the garnet filter radiation monitors, conductivity monitors, HEPA filter subsystem, automatic samplers, and existing Basin Water sand filter are also in this northwest corner. The radiation detectors are installed within the garnet filter shield enclosure. The plan view of this area is shown on Figure 7-3, and an isometric of the main equipment in this area is shown on Figure 7-4.

\subsection{PRINCIPLES OF OPERATION}

\subsubsection{Main Flow Path Operation}

The discharge hoses of the canister decapping pump (nominally at $80 \mathrm{GPM}$ ), primary cleaning pump (nominally at $80 \mathrm{GPM}$ ), and the process table pump (nominally at $160 \mathrm{GPM}$ ) are combined through two (2) stainless steel "Y" connections into a 2-in hose that feeds the KO pot. The hoses are connected to the components and " $Y$ " fittings with Kamlok $®$ connectors. The combined flow of $320 \mathrm{GPM}$ exits the KO pot via a 3 -in hose routed along the pool north wall across the fuel canisters, then south along the east wall, and up to connect to the settler assembly in the Weasel Pit. The settler assembly has a 10-in diameter inlet distribution header with 1.5 -in connected hoses that feed the ten 16 -ft long by 20 -in diameter settler tanks. Refer to H-1-80550, Sheet 8 .

The approximate flow to each settler tank is 32 GPM. The reduced flow velocity increases the particulate retention time in each settler tank. The effect is that the larger particles settle. The effluent from the settler tanks is recombined in an outlet header and exits the header via a 4-in hose. The hose drops down to the level of the fuel canisters and runs parallel to the settler assembly inlet hose along the pool north wall. Near the west wall, the 4-in hose turns south approximately $20 \mathrm{ft}$ and then is connected to the 4 -in booster pump inlet pipe by a Kamlok $\otimes$ connector. When the pipe exits the pool, it is shielded and extends west to the booster pump 
where it connects to AOV FRW-V-001. Water flowing through the valve then enters the suction side of the booster pump, and it is discharged to a 4 -in pipe that serves as the header feeding three (3) garnet filter vessels through 2 -in takeoff pipes. The flow is balanced to about $107 \mathrm{GPM}$ /filter. The sand within the filters separates and retains the finer particulate. The filter isolation valves are inside the filters' shielded enclosure and are remotely actuated AOVs. The valves are FRW-V-100, 200, and 300 (inlets) and FRW-V-101, 201, and 301 (outlets), respectively. Refer to $\mathrm{H}-1-80550$, Sheet 9.

The flow is recombined by a shielded 4-in header, and the 320 GPM is directed to the three (3) IXMs to remove radioactive ions from the process water. Normally, only two (2) IXMs are online at a time; so the flow to each IXM is balanced to about $160 \mathrm{GPM}$. This flow is fed to an IXM through a shielded 3-in line and manual isolation valve IXS-V-100, 200, or 300. Effluent from the IXM flows through an unshielded 2-in line and manual isolation valve IXR-V-010, 020, or 030 , respectively. The recombined flow of $320 \mathrm{GPM}$ flows through a 4 -in pipe to the treated water distribution header. Refer to H-1-80550, Sheet 10.

The distribution header runs along floor level to the west edge of the basin and is routed to various basin users. The primary service is a flow of 200 to $320 \mathrm{GPM}$ to the South Loadout Pit. This service is supplied through automatic control valve IXR-FCV-001 (all other header valves are manual). This control valve repositions, as necessary, to maintain header pressure by varying flow to the pit. The flow available varies, depending on the other intermittent basin uses.

Since the total user need exceeds the available water, priority use and coordination between users is necessary. Other basin uses are the Discharge Chute flush water (30 GPM, 2-in line, IXR-V-011), the MCO filling (15 GPM, 1-in line, and IXR-V-008), the sludge removal operations (50 GPM, 2-in line, IXR-V-007), the FRS (80 GPM, 2-in line, and IXR-V-009), debris rinsing (15 GPM, 1.5-in line, and IXR-V-006), and the debris high pressure pump (30 GPM, 2-in line, and IXR-V-005). Refer to H-1-80550, Sheet 11.

\subsubsection{Auxiliary Operations}

Periodically, particulate must be sparged or backwashed from the garnet filters by using water supplied by the Basin Water System. The skimmer pump (SKW-P-6) is preferred over the recirculation pumps (RBW-P-1A/B) for these operations. The connections to the skimmer pump (2-in line and FRW-V-010) and the recirculation pump (4-in line and FRW-V-004), the intertie valving (FRW-V-005 and AOV FRW-V-006), the sparging control manifold (AOV FRW-V-008, FIT-206-04, and FRW-V-012), and the backwash flow control manifold (AOV FRW-V-007, FIT-206-02, and FRW-V-011) are all located on the booster pump skid. The sparge and backwash lines combine and extend to the filters shielding enclosure where AOVs remotely control the selected flow path.

The sand in the garnet filter is also agitated with air (sparging) when backwashing does not adequately clean the filter. Air from a portable compressor is used to supply the 1-in piping control manifold (FRW-V-014 and 015, FIT-206-03, and AOV FRW-V-016). The manifold is just outside the filter enclosure with the piping extending into the enclosure and connecting to the 
water sparge and backwash header. The air enters the same top sparge connection used for water, but exits the selected filter through 1-in vent lines and AOV FRW-V-104, 204, or 304. The vent lines are combined, valved, and the air flows through a 3-in line to the HEPA filter subsystem before being released outside the building. The HEPA filter train consists of a moisture separator, an air heater, a roughing filter, and two (2) HEPA filters in series. The garnet filters also have a pressure relief manifold that vents and drains to the basin pool.

Media sluicing is used if the sand in a filter needs replacing (garnet being one of the three types of sand used). The used media is sluiced out of the filter by introducing water or air into the tank. The water or air forces the sands into the sluice line that penetrates the vessel's false bottom to the sand region of the vessel. The used sand passes through FRW-V-105, 205, or 305 and enters the backwash line to BBW-V-002 where it is loaded into a disposable container. The new media is hydraulically pumped into the top of the filter through a 2 -in line and FRW-V-102, 202, or 302, respectively. The sluice pump (FRW-P-6) is connected to the selected filter valve by a hose assembly.

The IXMs do not require a pressure relief subsystem since they are continually vented during operation and are empty of water when on standby. Each IXM has a top vent manifold consisting of mainly 0.5 -in lines, a float valve (IXV-FCV-3, 4, or 5), a float isolation valve (IXV-V-100, 200, or 300), and a float bypass valve (IXV-V-101, 201, or 301, respectively). The vent lines are combined and vent and/or drain to the pool. The four (4) IXM autosamplers are on the inlet header and on the outlet piping of each IXM. They are provided to monitor each IXM for TRU isotopes and radionuclide loading.

The connection for receipt of the CVD water (FRW-V-003) allows this water to enter the suction side of the booster pump. The chemical addition subsystem (FRW-P-5, isolation valves FRW-V-017 and 018) is used to add coagulation chemicals to the suction side of the booster pump when needed.

\subsection{COMPONENT DESIGN DESCRIPTION}

\subsubsection{Pumps}

\subsubsection{Submersible Pumps (FRW-P-1, 2 \& 3) and Lifting Tool}

The canister decapping pump (FRW-P-1), the PCM pump (FRW-P-2), and the process table pump (FRW-P-3) provide suction flow to remove contaminants released from fuel processing activities. The pumps are all self priming, submersible, and operate at 3450 RPM. The pumps are manufactured by the R.S. Corcoran Corporation and are Models A50 US-RX and A60 US-RX. The pump casings and impellers are fabricated from Type SAF-2507 high carbon duplex stainless steel to reduce erosion. The pump inlets and outlets are flanged. The pumps are powered by tandem seal $25 \mathrm{HP}$ Reliance Electric motors that require $480 \mathrm{VAC}$, three phase power supplies. Tandem seals allow the pumps motors to be operated underwater. The pump motors are equipped with circuitry that monitor winding moisture and temperature. An adaptor, 
shown on Drawing H-1-83326, was used to mate all submersible pump inlets to the FRS piping and various stands.

The decapping pump (FRW-P-1) and PCM pump (FRW-P-2) are identical. The pumps normally provide $80 \mathrm{GPM}$ at $273 \mathrm{ft}-\mathrm{H}_{2} \mathrm{O}$ TDH at the maximum pump speed of $3600 \mathrm{RPM}$ (nominal).

Both pumps have a 3-in suction inlet and a 1-1/2-in discharge. The Serial Numbers are 3397 and 3398. The decapping pump sets in a pump stand within the basin pool (see Drawing DW-213) with legs that extend through the fuel rack to the basin floor. The stand is provided by the FRS and is equipped with a strainer that removes particles $>0.25$-in so that only sludge is allowed to enter the pump and the IWTS piping. The PCM pump uses the PCM top surface as its pump stand. The PCM also has an integral, similar sized strainer to restrict particles entering the pump to sludge size (see Drawing DAG-330).

The process table pump (FRW-P-3) normally provides $160 \mathrm{GPM}$ at $263 \mathrm{ft}-\mathrm{H}_{2} \mathrm{O}$ TDH at the maximum pump speed of 3450 RPM (nominal). The Serial Number is 3396 . This pump has a 3 -in suction inlet and a 2-in discharge. It also sets in a similar pump stand with a similar sized strainer that is also provided by the FRS. The stand was fabricated separately from the decapper pump stand by Westinghouse Corporation. The stand was equipped with a seismic restraint that was later considered unnecessary (see Drawing DAG-356) because the effect of tipping was found insignificant.

Placement and removal of a submerged pump assembly require the use of a "below the hook" support assembly shown on Drawing H-1-83991. This type of assembly uses the existing basin monorail and hoist. The hoist hook fits into a top bolt shackle on the assembly. The assembly has fixed, dual hooks that fit and engage on both sides of a pump. The assembly is rated for $1000 \mathrm{lb}$ and weighs about $28 \mathrm{lb}$. The requirements for load testing, tagging, and rating qualifications are noted on the drawing. The tool structural adequacy was summarized in Section 4.0 of the Integrated Water Treatment System Pump Lifter Strength Evaluation, SNF-5163 (JS Huisingh, 1999). Standard load tests are conducted according to Section 11.9 .1 of DOE-RL-92-36.

\subsubsection{Booster Pump (FRW-P-4)}

The booster pump provides the motive force to feed the garnet filters, the IXMs, and the distribution piping. The pump is a self priming, centrifugal pump, and manufactured by the R.S. Corcoran Corporation as Model A70-2 with a 4-in suction inlet and a 3-in bottom discharge, both flanged. The casing and flanges are constructed of Type 316 Series stainless steel.

The pump normally operates at 320 GPM with the speed controlled by a Siemens $\otimes$ micro master variable speed drive. The reference speed is determined by the pressure and flow control loop. The pump provides 320 GPM at 281.4-ft TDH at the maximum speed of 3450 RPM (nominal). The required NPSH is $3.5 \mathrm{ft}$. The $50 \mathrm{HP}$ motor is manufactured by Reliance $B$ Electric and uses a $480 \mathrm{VAC}$, three phase power supply. 


\subsubsection{Metering Pump (FRW-P-5) and Assembly}

The Vario metering pump is manufactured by the ProMinent ${ }^{\circledR}$ Company, and it is used for injecting water treatment (coagulant) chemicals into the IWTS piping. The pump motor uses a $220 \mathrm{VAC}$, single phase power supply. The $0.24 \mathrm{HP}$ positive displacement pump is rated at $0.1 \mathrm{GPM}$ and can develop $>50$ PSIG for injection purposes. The pump discharges to a 0.5 -in line that connects to the main 4-in IWTS piping near the suction inlet of the booster pump (nominally at 8 PSIG at this location per $\mathrm{H}-1-83301$ ).

This small metering pump and assembly are on the booster pump skid. The metering assembly consists of the valve FRW-V-018 that isolates the metering pump inlet from the chemical addition reservoir, the metering pump itself, the pump outlet isolation valve FRW-P-017, piping, and the injection check valve FRW-CV-003. The check valve prevents backflow during the pump shutdown.

\subsubsection{Fílter Media Sluice Pump (FRW-P-6)}

This pump is an air powered, double diaphragm pump used to add all three grades of sand from drums to either of the three (3) garnet filters. Therefore, it pumps a slurry of sand and water. The type used is a SandPIPER $B$ Model SB2-A, Type TN-3-C1, Type 316 stainless steel, top porting pump manufactured by the Warren Rupp Company. The pump is rated at a maximum flow of 135 GPM and head of 125 PSIG (not concurrently). Actual head and flow are based on supplied air pressure and air consumption. The average water displacement per pump stroke is 0.48 gallons. The pump has 2 -in inlet and outlet ports (fitted with Kamlok $®$ connectors).

\subsubsection{Knockout Pot (FRW-KOP-100) and Lifting Tool (KW-KOPH-1)}

The submerged KO pots (refer to Figure 7-5) are Type 304 Series stainless steel. Each pot was fabricated and inspected to ASME B\&PVC, Section VIII, Division 1 requirements. The KO pot design pressure is $150 \mathrm{PSIG}$ and rated for operation at $320 \mathrm{GPM}$. Only one pot is used at a time, and normally operates at an internal pressure of about 50 PSIG. The pressure vessel in protected by and cannot be isolated from a downstream rupture disk rated for 125 PSIG. Each pot is fabricated from a 16-in diameter Schedule 20 pipe. The internal dimensions of the KO pot are within the dimensions allowed by the criticality analysis as the analysis allows 18-1/4 inches maximum diameter. Approximate pot weights are $600 \mathrm{lb}$ empty and $\sim 2100 \mathrm{lb}$ when half full of sludge. All submerged pots are located in storage rack positions.

The bottom is a welded standard pipe cap, and the top is a blind flange. The pot stands as a right circular cylinder. The overall length of the pot, bottom to flange, is 30 inches. The 2 -in inlet pipe enters the KO pot slightly above mid height. The inlet pipe is equipped with a 2 -in male Kamlok $B$ connector that is $28-1 / 2$ inches from the bottom of the pot. Refer to $\mathrm{H}-1-83320$ for details on the KO pot fabrication. The top flange is a standard 16-in flange using a 1/16-in compressed carbon fiber sealing gasket. The top flange has double 3 -in penetrations for the flow discharge, a 2 -in backflush penetration, a vent for hydrogen release, and a lifting bar. The two 
3 -in outlet pipes are teed together and end with a single 3-in male Kamlok ${ }^{\circledR}$ connector 49.5 inches from the bottom of the pot. The flush pipe penetration ends with a 2-in male Kamlok $\circledast$. The vent is equipped with a valve for periodic venting of the gas that collects in a vent assembly (tube-in-tube). This tube is oriented vertically within the pot. The lifting bar is constructed of 1 -in round stock, is welded to the top flange, and extends to 20.75 inches above the flange. All pipes, including the inlet, are oriented vertically for ease of access from the basin grating for connecting and disconnecting the female Kamlok@ connectors of the interfacing piping.

The internal pot volume is filled with a series of perforated baffle plates, oriented at $30^{\circ}$ to the horizontal, that reduce turbulence and aid in particle settling. The inlet pipe extends into the pot above the baffle plates and has fourteen 5/16-in holes, oriented horizontally, on each side of the pipe. The pipe is closed at the end except for a 1/2-in bottom slot. Most of the flow exits through the holes with the remainder exiting through the slot. The upper portion of the pot contains two $500 \mu \mathrm{m}$ (nominal) screens, one on each 3-in outlet. Refer to H-1-83320 for details on the KO pot screen. An insignificant amount of screen erosion is expected during the limited operational life of the KO pot. Particles removed by the screens drop down onto and through the baffle plates into the bottom of the pot. The vent tube assembly extends down through 2 -in holes in the baffle plates to near the bottom of the pot. During later sludge removal, this vent assembly is removed; and the backflush nozzle is opened. The suction hose of the Sludge Removal System is inserted through the vent penetration and holes in the baffle plates to near the bottom of the pot. Pool water and sludge are then sucked out the hose. The backflush nozzle is just at the top flange and does not extend into the pot.

The differential pressure across an operating pot is measured by DPIT-206-01 on the inlet and outlet hoses. When particle loading causes the differential pressure to rise to about 12 PSID, the IWTS is shut down, inlet and outlet hoses are disconnected, the spent pot is removed and replaced with a fresh pot. The hoses are then reconnected, and the IWTS is returned to service. Acceptance tests have shown that the differential pressure rises exponentially near the end-of-life of the screens. The KO pot is taken out of service at 12 PSID based on the analysis of the safety class screen performed in SNF-4729. The total weight of pot and sludge at that time is estimated to be about $2100 \mathrm{lb}$.

Moving a $\mathrm{KO}$ pot requires the use of the lifting tool assembly (KW-KOPH-1). The lifting tool assembly weighs about $80 \mathrm{lb}$. The assembly is shown on fabrication Drawing H-1-84014, is rated for $4000 \mathrm{lb}$, consists of a top handle with an eye bolt for attaching the hoist hook, an extension ( $16 \mathrm{ft}$ long) which includes a 4000-lb load cell, and ends in a hook designed to fit the $\mathrm{KO}$ pot lifting bar. The length of the assembly prevents lifting the KO pot higher than $6 \mathrm{ft}$ above the pool floor when the hoist is in the full up position. The monorail used with the tool is only rated for $2400 \mathrm{lb}$, so lifted loads must be less than the monorail rating. If later it is decided to exceed this load restriction, the monorail will have to be upgraded accordingly. The requirements for load testing, tagging, type of load cell, and rating qualifications are noted on the drawing. The tool's structural adequacy was summarized in Section 3.0 of SNF-5244. 
The passive vent valve is closed during normal operation; but when the used pot is moved into storage, the vent valve is opened so that gas generated by the collected sludge is allowed to escape. The tool used to open the valve is the same tool used by the Fuel Handling System (FHS) and the FRS to open and close fuel canister vent valves. See Drawing H-1-81198.

During operation there is the possibility that lighter (non-SNF) material could cover the surface of the filters, severely restrict flow, and indicate a high differential pressure. This would cause the KO pot to be taken out of service before collecting a significant inventory of filtered sludge. The filters can be backflushed to clear them by reversing the flow in the filters. In this off-normal situation, the submerged pumps are stopped; and the backflush outlet nozzle is opened. The inlet hose is disconnected, fitted with a $2 \times 3$-in adaptor, and fastened to the main outlet nozzle. The pumps are started and the lighter particles are flushed off the filters and out the backflush nozzle to the basin. The KO pot can then be returned to service.

\subsubsection{Settler Tank Assembly (FRW-STLR-100)}

The settler tanks and assembly are designed and fabricated to the requirements of ASME B\&PVC, Section VIII, Division 1. The settler tank assembly was designed for 150 PSIG and 320 GPM combined flow. The rated pressure is only 125 PSIG based on a reduced assembly hydrostatic pressure test at the factory. The pressure was reduced to comply with the 125 PSIG rating on the 3-in and 4-in Kamlok $\otimes$ connectors on the inlet and outlet headers. A rupture disc is located just upstream of the inlet header to provide Section VIII Code compliance. Refer to the assembly and frame details shown on $\mathrm{H}-1-83330$ and $\mathrm{H}-1-83332$, respectively, and the schematic representation shown on Figure 7-6. The settler tanks are fabricated from ten 20 -in diameter by 16-ft long, Type 304 Series stainless steel closed pipes (tanks). The tanks are arranged side by side, horizontally, five levels high, and piped in parallel (approximately 32 GPM per tube). The inlet header is 10 inches in diameter, receives water through a 3 -in hose connection, and distributes flow to the ten (10) settler tanks through 1.5 -in hoses. The settler tank outlets are 2 -in pipes feeding into a 4-in outlet header that ends with a 4-in hose connector. The design was verified by vendor calculation PF-001, "Hanford Pool Filtering System - Settler Size."

Each closed settler tank also has four 2-in inlet and outlet pipes for eventual removal of the accumulated sludge. The pipes come out the bottom of the horizontal tanks, bend upward for above-pool access, and terminate in 1.5-in hose connectors. They are designated for the inlet and outlet sluice, an inlet for possible "lancing" flow to dislodge the sludge, and an inspection access to determine the removal effectiveness. These operations will be performed by the Sludge Removal System when necessary. The top of each tank is vented for removing gases released from the settled sludge and entrained in the process flow. The 0.75 -in vent pipes are all combined and lead to a float valve (FRW-FCV-1) that provides continual venting of the gases through a 0.5 -in outlet pipe. The gases are released to the pool in the Weasel Pit where the tank assembly is located. The overall assembly dimensions vary from top to bottom to fit inside the Weasel Pit and allow sufficient clearance. Approximate overall dimensions (frame and assembly) are $5 \times 24 \times 13 \mathrm{ft}$ high. There is at least $3.5 \mathrm{ft}$ of water over the 10 -in inlet header for shielding personnel from the assembly. 


\subsubsection{Garnet (Sand) Filter Vessels (FRW-F-1, 2 \& 3)}

The garnet filter vessels are 150 PSIG ASME B\&PVC, Section VIII, Division 1, pressure vessels constructed of Type 304 Series stainless steel. The filters are called garnet filters to differentiate them from the existing sand filter that is in the Basin Water System. The vessels are annular in design to resolve criticality concerns. A 40-in diameter inner vessel is housed within the 72 -in diameter outer vessel shell. Therefore, the filtering space is an annular ring between the inner and outer vessels. The empty inner vessel acts as a space for neutrons to escape the filter and preclude nuclear criticality. Refer to filter assembly and detail Drawings H-1-83341 and H-1-83343 for fabrication details and Figure 7-7 for a schematic representation.

The filter normally operates with an approximately $5.8 \mathrm{GPM} / \mathrm{sq}$.ft. cross sectional flowrate during normal three (3) filter operation (107 GPM/filter). Each vessel is constructed with a false bottom, a series of sixteen (16) flow screens to retain filter material above the false bottom, an inlet distribution header, a top sparge header, a vent screen, and associated nozzles for the water and vent piping. The bottom sluicing penetration extends through the false bottom into the media. The inner vessel is equipped with a passive drain to remove any unexpected water leakage into the inner vessel. The operating differential pressure of a clean, unused filter is approximately 10 to 12 PSID. When a filter being used reaches about 25 PSID, it is normally backwashed or top sparged to decrease the pressure drop, but it can be operated to about 40 PSID.

The deep bed filter vessels are filled with three (3) layers of different grades of sand, called filter media. The bottom layer, which covers the filter outlet screen (H-1-83344), uses approximately 25 cu.ft. of very coarse sand. The coarse sand contains sand particles predominately in the 6 to 10 mesh range. This layer protects the outlet screen and provides a foundation bed for good water distribution during normal and backwash operations. The second layer of sand is approximately $30 \mathrm{cu}$.ft. of a very fine, almandite garnet $\left[\mathrm{Fe}_{3} \mathrm{Al}_{2}\left(\mathrm{SiO}_{2}\right)_{3}\right]$ with a nominal size of 80 mesh. This garnet media is specially procured from the Emerald Creek Garnet Company of Coeur d'Alene, ID. The top layer of media is $25 \mathrm{cu} . \mathrm{ft}$. of fine sand with a size of about 60 mesh. This segregation of filtering media allows a longer filter run time. These three layers provide the "depth" filtration process where the larger particles are trapped above or in this upper layer with subsequently smaller particles trapped deeper in the bed. The garnet layer is where the smallest particles are captured. A filter of this design has a nominal $5-\mu \mathrm{m}$ filtration capability, and the media occupies about $70 \%$ of the annulus.

The vessels are equipped with two vent paths. One path is for pressure relief in accordance with ASME Code compliance. Each line is equipped with a pressure relief valve (FRW-PRV-111, 211 , or 311 ). The lines combine and vent to the basin pool below the water surface. The second path is related to the air agitation (sparging) of the filter media. Each line is equipped with a fail-open isolation valve (FRW-V-104, 204, or 304). These lines also combine to a line that can be either routed through a float valve (to prevent water release) or routed direct to the HEPA filter venting subsystem (discussed separately). Each vent path is equipped with a screen so that sand is retained in the vessel (see Drawings H-1-83345 and H-1-83346). 
The operating area is shielded from the garnet filter vessels by a combination of ASTM A36 carbon steel, lead, and concrete enclosure (see Drawing H-1-83342). The east and west side walls have 2.25-in (minimum) thickness of lead sheets in a 3-in space between 1-in steel plate on the exterior and interior surfaces. The sides have 8 -in of commercial concrete $(\sim 150 \mathrm{lb} / \mathrm{cu}$.ft. density) between 2-in steel plate on the exterior and interior surfaces. Steel stiffener plates on the exterior and interior surfaces add to the shield effectiveness and partially offset penetrations. Shield enclosure penetrations are filled with lead wool or other acceptable shielding material. The top is fabricated from 1-in steel plate with equivalent plate thickness on the opening covers. The overall shield dimensions are $10 \mathrm{ft}-2$ in by $20 \mathrm{ft}-2$ in by $13 \mathrm{ft}$ high.

The filters are not shielded from each other, and Basin Maintenance personnel will normally need to have the filters backwashed before entering the enclosure. There are 8 -in and 10-in access ports above the process radiation monitors that can be opened to allow radiation surveys to determine the enclosure dose rate and need for flushing before opening the larger 28-in access port above each filter. There is also a floor drain within the enclosure that collects water from inadvertent vessel and piping water leaks. The drain connects to a sump for eventual return to the basin pool (see interface with the Radioactive Drain System in SDD Section 2.0).

\subsubsection{Ion Exchange Modules (IXM-1, 2 \& 3)}

The IWTS has three (3) installed, single use, disposable IXMs for removing soluble radionuclides from the basin water. Each module consists of six (6) stamped ASME B\&PVC, Section VIII, Division 1, pressure vessels that are 42 inches high with a volume of $4.1 \mathrm{cu}$.ft. The vessels are fabricated from 16-in Schedule 30 (0.375-inch thick wall), ASTM A106 carbon steel pipe, with equivalent pipe caps on the ends. The maximum allowable working pressure (MAWP) is $150 \mathrm{PSIG}$ at $200^{\circ} \mathrm{F}$.

Each IXM has four (4) lifting lugs for transferring it into and out of the Transfer Bay Area. The total weight of each IXM is 44,000 pounds wet and 42,000 pounds dry. The IXM lifter is shown on H-1-46311, and the IXM assembly is shown on H-1-46279. See also Figure 7-8. The IWTS IXM design is almost the same as that used for the Basin Water System IXM-4 that has a different top manifold arrangement.

The vessel inlet and outlet pipes are 1.5-in ASTM A106, carbon steel pipe. The vessel vent pipe is 0.5 -in ASTM A312, Type 304 stainless steel pipe. Each vessel has an outlet screen to contain the resin. The outlet screens are 100 mesh stainless steel wire with $140 \mu \mathrm{m}$ openings. A flow control valve at the outlet of each vessel maintains the flow through that vessel at 26.6 GPM over a loading pressure range of 4 to 57 PSID. This equates to the nominal total flow of $160 \mathrm{GPM}$ for each of the two operating IXMs (the third on standby or being changed). The top inlet and bottom outlet pipes combine into common 3-in pipe IXM headers that are ASTM A312, Type 304 stainless steel. The IWTS outlet is fitted with a $3 \times 2$-in reducer to match the hose connector. The IXMs are connected to the plant piping and the vent header with hoses and quick disconnects. The area where the IXMs are located has a floor drain to conduct water inadvertently released from the piping to a sump and back to the basin pool. 
The six (6) vessels of each module are encased in a concrete structure $(86 \times 70 \times 79.5$ inches high) placed around the vessels to provide radiation shielding from the internal radioactive inventory. The vessel code stamp and other essential information are attached to a top lifting bracket so it will be visible after the concrete pour.

Each of the IXM vessels has a vent. These vent pipes are offset within the concrete to eliminate radiation streaming and extend above the concrete where they are fitted with hose connectors. A removable manifold is attached to these hose connectors. The fixed part of the manifold includes a strainer (IXV-ST-100, 200, or 300) to block any resin transfer, a float valve (IXV-FCV-3, 4, or 5) to block water flow, a float valve bypass, and corresponding float/bypass isolation valves. The manifold lines for all IXMs combine and vent and/or drain to the basin pool. Placing the resin screens in the vent header rather than with the module allows changes in the resin type and sampling of the resin. The automatic vent (float) valve continually releases gases trapped in the vessels and prevents over pressure. No pressure relief protection is provided or necessary as the design pressure is well above the maximum operating pressure and the IXM is vented during use and storage.

Each of the six (6) vessels of an IXM contains 3.5 cu.ft. of Purolite ${ }^{\circledR}$ NRW ${ }^{\text {TM }}-35$ mixed resins principally for removal of ${ }^{137} \mathrm{Cs}$ and ${ }^{90} \mathrm{Sr}$ from the process stream. Other radioactive ions are present in the basin water and add to the overall dose; however, ${ }^{137} \mathrm{Cs}$ and ${ }^{90} \mathrm{Sr}$ are orders of magnitude greater than these others and dominate. An IXM typically remains in service until it no longer is effective (or soon will not be effective) in removing radionuclides from the process stream or is nearing the radionuclide limits. The IXM can remain in service as long as the ${ }^{137} \mathrm{Cs}$ removal efficiency remains $>99 \%$ (a preliminary estimate), the amount of ${ }^{137} \mathrm{Cs}$ retained by the beds is $<300 \mathrm{Ci}$, and the retained transuranic inventory is $<80$ nanoCi/gram (administrative limits). An administrative limit has not yet been set for the IWTS IXMs. The Basin Water System's IXM-4 has a ${ }^{137} \mathrm{Cs}$ administrative limit $>70 \%$, but the process water is pool water with a relatively low ${ }^{137} \mathrm{Cs}$ concentration. The IWTS IXMs will treat the much higher concentrations found in the canister liquor from the decapping operations, and it is expected that the required removal efficiency will need to be much higher to prevent as much ${ }^{137} \mathrm{Cs}$ as possible from passing through the IXMs and entering the pool. The typical IXM service life is based on these limits may vary from several weeks to several months based on the actual throughput.

Purolite ${ }^{\circledR}$ NRWTM-35 is a mixed bed resin and consists of 1.7 parts NRW'M-600 (strong anion) combined with 1.0 part NRWTM-160 (strong cation). The mixture is formulated for the demineralization and decontamination of radioactive IWTS water and has a high selectivity for cesium.

\subsubsection{Automatic Samplers (AS-420-1, 2, 3 \& 4)}

The IWTS has four (4) identical automatic water samplers with component numbers AS-420-1, 2,3 , and 4. One sampler (AS-420-4) collects water samples over time to be used to characterize the combined water flow to the IXM inlet header. The others are used at the outlets of each 
IXM, numbered respectively, to characterize the water and determine the quantity of contaminants removed from the water.

The samplers are Isolok $\circledast$ samplers, Model SAB-11-04-12, and are manufactured by the Bristol Equipment Company. The wetted portions of the samplers are stainless steel. The samplers take a $10 \mathrm{ml}$ water sample from the main pipe periodically. The samplers can be operated in either the manual or automatic mode. In the manual mode, a sample is taken by placing the control switch in the HAND position. In the AUTOMATIC mode, a sample is taken at a preset interval as set by the timer in the sampler control box. The interval can vary from 14 seconds up to 3 hours. Refer to the 105 KW SNF Basin Water Sample Analysis Plan, SNF-5906 (PE Stanley, 2000 ) for sampling details. In the automatic mode, a proximity switch attached to each sample plunger actuates an alarm if the plunger fails to stroke when the start signal is energized. A 2-liter polyethylene bottle is connected to each sampler to collect the samples. The air vent in this bottle has been plugged so that the bottle cannot overflow with sampled water. The plug prevents significant water release requiring drainage. Drains are present from each sample location to the IXM pad and floor drain, but any water leakage during bottle change out will be retained by absorbent material.

The sampler is attached to and penetrates the process line. When sampling, the probe is inserted into the line, withdraws $10 \mathrm{ml}$ of the water, and then releases it into the attached bottle. A sample from the bottle of collected samples is later analyzed for average conductivity and concentration of ${ }^{137} \mathrm{Cs}$ and alpha emitting radionuclides in that sample set. The IXM inlet concentrations of ${ }^{137} \mathrm{Cs},{ }^{90} \mathrm{Sr}$, and alpha contaminants can be compared with the outlet concentrations to determine the near term cesium removal efficiency of an IXM and the amounts of these constituents being retained in the resin over that sample period. The total periodic sample data and flow history is used to estimate the amount of ${ }^{137} \mathrm{Cs}$, ${ }^{90} \mathrm{Sr}$, and alpha waste (TRU) retained in the resin and is used to decide the end of life of the IXM.

\subsubsection{HEPA Subsystem}

The HEPA subsystem was fabricated by Waterlink $®$, Barneby, and Sutcliffe for filtering of air released from the garnet filters during normal venting and media air agitation (sparging). Their Model NMC System/42279 was installed which is rated for 150 SCFM, constructed of Type 304 stainless steel, and allows bag in/bag out contamination control of the filters used in the filtering process. The air flow first enters a moisture separator (FRW-MS-1) that drains to the basin. This air then flows through a heater chamber (FRW-H-1) and three (3) filters in series. The first filter is a $12 \times 12 \times 6$-in roughing filter with 60 to $65 \%$ particle removal efficiency (Flanders@ Econocell or equivalent). This prefilter is followed by two (2) $12 \times 12 \times 5-7 / 8$-in HEPA filters with $99.97 \%$ particle removal efficiency for $0.3 \mu \mathrm{m}$ median diameter particles (Flanders $®$ Nuclear Grade HEPA Filter or equivalent). The prefilter extends the operational life of the downstream HEPA filter and provides a measure of protection against damage. The HEPA filters, when installed new, have a pressure drop of 1.0 in-w.g. and experience no loss of removal efficiency up to a pressure drop of 10 in-w.g. Normal change out usually occurs at 4 to 5 in-w.g. in most nuclear applications. However, the IWTS has chosen to be conservative and 
change the filters when the pressure drop reaches 2 in-w.g. The filtered air is exhausted through a 3 -in pipe that penetrates the north wall of the basin and ends $12 \mathrm{ft}$ above the basin roof.

Notice of Construction DO/RL-98-02 justified the use of this method to control and monitor air emissions from garnet filter air sparging. The filter subsystem was designed in compliance with ASME N-509-1989 and ASME N-510-1989 standards. The first HEPA filter provides the required particle filtering capability. The second filter is the "sampler" for the entire air stream. The sampler filter capture efficiency is $\geq 99.95 \%$ for $0.3 \mu \mathrm{m}$ median diameter particles and undergoes a periodic non-destructive assay with a gamma spectrometer to detect ${ }^{137} \mathrm{Cs}$ trapped by this second filter. The detection limits are 100 nanoCi or less. This provides a conservative measurement of what is released to the atmosphere. Tests are conducted annually, if air sparging has not occurred during this period (passive venting only), and quarterly if air sparging has occurred. The difference in activity readings is the recordable emissions measurement during that period. Aerosol penetrant testing is also performed annually to assure the filters maintain a $299.95 \%$ removal efficiency of the test aerosol. The HEPA subsystem is isolated with the garnet filter vent valves when conducting the test.

The filter housings were isolated with butterfly valves (FRW-V-022, 023, 024, and 025) for the initial pressure test of the system since the housings are qualified for only 5 PSIG. The valves do not have any other isolation requirement, so the valves have been secured in the open position. Blocking the valves open prevents an inadvertent over pressure condition at a housing. The filters are instrumented to measure the pressure drop across each filter (DPI-206-40, 50, and 60 ). The housings allow bag in/bag out radiation control when changing the filters.

The moisture separator is periodically drained through ball valve FRW-V-050 to the basin pool. The separator tank has a level detector LE-206-40 with a remote alarm to alert Basin Operations that it is time to drain the tank. The level should be checked and/or the tank drained before each filter air injection to preclude moisture carryover to the heater and filters. The heater chamber includes a 750 Watt, 120 VAC Chromalox immersion heater with shutoff thermocouple switch for protection from an over temperature condition. The downstream thermocouple (TE-206-40) measures the temperature of the air exiting the heater.

\subsubsection{Piping and Valves}

\subsubsection{Piping and Hoses}

IWTS process piping is normally Type 304 stainless steel and is butt welded. Material exceptions are limited, and they can be found in either temporary or limited use components or parts that are not significantly wetted by process water. A component exception is the IXM distribution piping and tanks that are high grade carbon steel. This steel does not degrade in the low conductivity basin water, and the IXM has a limited use lifetime. Flange connections throughout the IWTS are also limited and can be found where there are replaceable components, e.g., pumps, inline flowmeters, garnet filters, certain hose manifolds, future or temporary connections, and air vents. 
The types of hoses to be used for suction and pressure applications are given ES-E-146 (CVI 50082). This engineering specification also covers connectors, hoses not to be used, materials, and criteria for replacement. The specific hose used must be acceptable for basin service. The hose sizes from the pumps to the settler assembly have been optimized for maintaining sufficient velocity to prevent particle accumulation and still provide acceptable frictional head losses.

\subsubsection{Valves}

The valves are normally ball type to provide a full flow through capability required for radioactively contaminated systems and particulate. This type of valve does not have the constricted throat design which can trap significant contamination or plug. The valves are installed with butt welds to eliminate contamination traps. Special purpose valves are used where the water or air is relatively clean or the use demands it.

The full port ball valves are supplied by Flow-Tek. The main process valves, both air and water, are Type 316 stainless steel, Flow-Tek Series 7000, and have ends. They are rated for a $1000 \mathrm{lb}$ working pressure. A few, installed at junctures reserved for possible future additions of garnet filters or IXMs, have flanges on the blank ends. Flow-Tek also supplies some small ball valves ( 0.5 -in), primarily for pressure indicator root valves. These are Model S-40, stainless steel, and have NPT ends. These valves have an $800-1 \mathrm{~b}$ working pressure. The Flow-Tek air operators for the Series 7000 AOVs are TRIAC® Models TR500SR (4-in), TR200SR (2-in), and TR80SR (1-in). The air operators are rated for 150 PSIG and $175^{\circ} \mathrm{F}$, operate in the range from 40 to 150 PSIG, and include position limit switches.

The flow control valve on the IWTS distribution header is a 2-in AOV V-shaped ball valve manufactured by Fisher $B$ Controls. The valve is Fisher $\circledast$ Type V-150 stainless steel, and it has butt weld ends. The valve casing is rated for 150 PSIG and $180^{\circ} \mathrm{F}$. It is an automatic valve with a Model 1052, Size 20, diaphragm rotary actuator that regulates the header pressure by controlling the flow in the main header line. The valve has a Fisherß Type 4210 position transmitter and a Series $3620-\mathrm{J}$ electro pneumatic positioner. The positioner is mounted on the valve. As the loading pressure increases, the positioner opens the valve further to allow more flow, and subsequently to begin lowering the pressure. As the pressure decreases, the flow allowed decreases.

The globe flowrate control valves are manufactured by WE Williams and are used to control and set the flowrate for garnet filter media air agitation, water sparge, and backwash. The valve for air is 1-in Model S202, rated for $200 \mathrm{lb}$ working pressure, and has threaded ends. The valves for water are 2-in Model S152, rated for $150 \mathrm{lb}$ working pressure, and have flanged ends. All are Type 316 stainless steel.

The float valves used on the IXM, the settler assembly, and the common garnet filter vent lines are manufactured by Val-Matic $($ and are Model 25 with a working pressure of 150 PSIG. The size is 1 -in (component water side) x 0.5 -in (vent) with threaded ends. 
The ASME B\&PVC, Section VIII, Division 1, rated pressure relief valves for the garnet filter

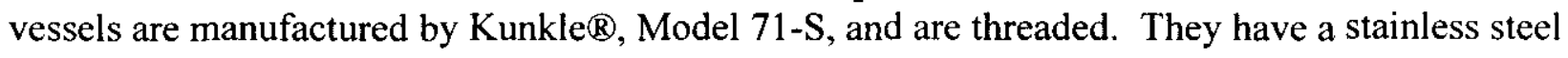
seat/disk and a cast iron body. The size is $1 \times 1.5$-in (outlet) with a 150-lb rating (set).

The larger (4-in, 3-in, and 2-in) check valves are manufactured by Techno Corporation and are, Series 5000, stainless steel, and with flanged ends. The smaller (2-in, 1 -in, and 0.5 -in) check valves are used for low pressure water or air applications and are manufactured by Check-All Valve ${ }^{\circledR}$. The Models are UN-3-200, 100, and 050, respectively. These latter valves are stainless steel, have threaded ends, and are rated for $700^{\circ} \mathrm{F}$ and a working pressure of 3000 PSIG.

\subsubsection{Instrumentation and Control}

\subsubsection{Process Computer (CP-A)}

The IWTS is controlled from Panel CP-A in Room 20A of the $105 \mathrm{KW}$ Reactor Building. The panel is used with either a touch screen or computer mouse to control IWTS operations or call up both IWTS and basin pool parameters. The man/machine interface of Panel CP-A communicates with PLCs located in the basin (IWTS PLC-2) and Room 4 (pool parameters PLC-1). Eleven (11) programmed computer IWTS operating modes can be selected from the main menu of Panel CP-A by the operator. They are the following:

$$
\begin{aligned}
& \text { Mode } 1 \text { - FRS Shutdown } \\
& \text { Mode } 2 \text { - Normal Operation } \\
& \text { Mode } 3 \text { - Top Sparge Vessel } 1 \\
& \text { Mode } 4 \text { - Top Sparge Vessel } 2 \\
& \text { Mode } 5 \text { - Top Sparge Vessel } 3 \\
& \text { Mode } 6 \text { - Backwash Vessel } 1 \\
& \text { Mode } 7 \text { - Backwash Vessel } 2 \\
& \text { Mode } 8 \text { - Backwash Vessel } 3 \\
& \text { Mode } 9 \text { - Air Sparge Vessel } 1 \\
& \text { Mode } 10 \text { - Air Sparge Vessel } 2 \\
& \text { Mode } 11 \text { - Air Sparge Vessel } 3
\end{aligned}
$$

When any mode is selected, all automatic valves, pumps, alarms, and instruments associated with that particular mode are activated and the process proceeds. If any shutdown alarm set point is exceeded or any automatic valve is not positioned properly, the system will automatically shut down and return to Mode 1 "FRS Shutdown." Mode 1 causes all IWTS pumps to be turned off and for all AOVs to close except the vent valve on each garnet filter which fails in the open position. Operator action is required to change modes, usually returning to Mode 1 to assure proper standby valve alignment before proceeding with any other operating mode.

Under Mode 2 "Normal Operation" the IWTS control loop maintains a total system flow of $320 \mathrm{GPM}$ and a discharge header pressure of 25 to 35 PSIG (preset). The two (2) parameters are maintained by the booster pump variable speed drive and the flow control valve (IXR-FCV-001) 
on the distribution header discharge to the South Loadout Pit. The control valve positions to maintain system pressure, and the booster pump variable speed drive regulates pump speed to maintain system flow.

The nine (9) remaining modes are related to the required remote filter operations. Most of the valves for the media water top sparge, backwash, and air sparge operations are within the shield enclosure and require remote operation. Also, the preprogrammed modes assure proper AOV alignment for the selected operation. These operations also require at least one operator and heath physics technician in the Transfer Bay Area to do manual valve alignments and monitor operations. The condition of the sparge and backwash water is viewed through a common sight glass (FRW-SG-001) that is within the filter shield enclosure. The camera is mounted to the inside shield wall and is the Panasonic $\otimes$ Model WV-CS404, with cam controller Model WV-CU151 and Series CT receiver.

\subsubsection{Control Panels (CP-B \& CP-C)}

Reference is sometimes made to a non-IWTS Panel CP-B containing PLC-1. Panel CP-B collects, controls, and transmits non-IWTS basin parameters, e.g., pool temperature, level, and conductivity signals, to Panel CP-A. Panel CP-B and PLC-1 are in Room 4 of the $105 \mathrm{KW}$ Building. These items are mentioned in some procedures and descriptions that are also used by the IWTS as the IWTS has access to these signals through Panel CP-A. CP-B and PLC-1 are not part of the IWTS and will not be discussed further in this SDD.

The IWTS has a Siemens $\otimes$ Somatic Series 505, designated PLC-2, which collects all IWTS transmitted process data delivered in the signal range of 4 to 20 milliamps. This controller is within the local IWTS Transfer Bay Area Panel CP-C. Panel CP-C contains the local hardwired radiation indicators for the garnet filters and is used to transform and distribute power to the IWTS instrumentation. Panel CP-C is found just south of the garnet filter shield enclosure near Column Lines B4/15.5.

The PLC-2 data acquisition system is linked to the overall basin control computer interface (Panel CP-A) in Room 20A. The transmitted IWTS outputs can be visually displayed to an operator at the CP-A control console. Transmission between the local IWTS PLC (PLC-2) and the overall basin PLC (CP-A) is continuously monitored. If communication is lost between the PLCs, an alarm is actuated; and the IWTS is shut down. The $105 \mathrm{~K}$ West Basin Water Treatment Report - 105 K West PLC 2 Program, SNF-4916 (LC Mauws, 1999) documents the program for developing the PLC. The report Integrated Water Treatment System - K West Basin Ladder Logic, SNF-4671 (SA Najjar, 2000) documents and creates a baseline for the ladder logic and human interface code. This latter report is used to track all modifications and changes to the software.

The power for the PLC-2 and instrumentation is fed from 480 VAC Breaker B3 of MCC 8. The $480 \mathrm{VAC}$ power enters the control Panel CP-C where it is transformed to $120 \mathrm{VAC}$ to power 
PLC-2. The power is further transformed to $24 \mathrm{VDC}$ for various feeds to each instrument. The wiring for PCL-2 is shown on Wiring Diagrams H-1-83403 and H-1-83405.

\subsubsection{Conductivity Monitors (CE/CITs)}

The conductivity monitors are Honeywellß, Inc., Smart Probe, Series 9782, conductivity and resistivity sensors, analyzers, and controllers. The basin $\mathrm{CE}$ instrument designation represents the probe sensing element, and the CIT designation represents the indicator transmitter portion. The conductivity sensor measures the ability of a solution to conduct an electrical current between two electrodes by ion transport. The lower the concentration of ions (conductivity), the more resistive the solution is to the flow of electrical current. The probe measures the current and digitally transmits the signal to an analyzer. The analyzer scales the value and sends the signal to PLC-2, and subsequently to Panel CP-A as a 4 to a 20-milliamp signal that is displayed in $\mu$ Mhos. The designators, uses, and ranges are as follows:

$\begin{array}{lll}\text { DESIGNATOR } & \text { TITLE } & \text { RANGE } \\ \text { CE/CIT-420-01 } & \text { IXM-1 Outlet Conductivity } & 0.1 \text { to } 10 \mu \mathrm{Mhos} \\ \text { CE/CIT-420-02 } & \text { IXM-2 Outlet Conductivity } & 0.1 \text { to } 10 \mu \mathrm{Mhos} \\ \text { CE/CIT-420-03 } & \text { IXM-3 Outlet Conductivity } & 0.1 \text { to } 10 \mu \mathrm{Mhos} \\ \text { CE/CIT-420-04 } & \text { IXM Combined Inlet Conductivity } & 0.1 \text { to } 100 \mu \mathrm{Mhos}\end{array}$

\subsubsection{Pump Current Monitors (CT's)}

Current is measured for the three (3) submerged suction pumps serving the FRS. The current measuring sensors are designated CT-206-1, 2, and 3 for pumps FRW-P-1, 2, and 3, respectively. Each sensor measures 0 to 55 amps (normal operating range is about 20 to $30 \mathrm{amps}$ ), and the signal is read at the IWTS PLC-2 and at Panel CP-A. The monitors are in MCC 8. The devices are loop powered analog current sensors, called the Hawkeye ${ }^{\circledR}$ Type, Model H-721, and manufactured by Veris Industries, Inc.

The winding current is also measured for the small metering pump FRW-P-5, but there is not a specific designator for the device as the pump size does not warrant it. The signal is read at PLC-2 and Panel CP-A.

\subsubsection{Flow Monitors (FE/FITs)}

The flow elements FE-206-01, 02, and 04 are on the booster pump skid. FE-206-03 is at the east end of the garnet filter shield enclosure. FE-206-05 and 06 are submerged and found at the outlets of the pumps. FE-420-01, 02, and 03 are in the outlet piping of each individual IXM.

Two types of flowmeters are used on the IWTS, the normal above pool type and the submerged type. All are inline, i.e., located directly in the flow stream. The above pool flow elements 
(FE-206-1, 2, 3, and 4; FE-420-1, 2, and 3) are used with both water and air. They are vortex

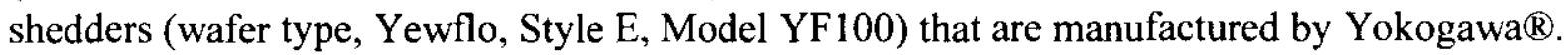
The water flowmeter transmitters are Model YF105-A (2-in meter), and the air flowmeter transmitter is Model YF102-A (1-in meter).

The submerged flow elements (FE-206-5 and 6) are the electromagnetic type. The design is mainly a straight through section of pipe for flow purposes. They measure a combination of turbulence and electrical conductivity in the flow stream. The magnetic flow elements are manufactured by Turbo Instruments and are Messtechnic Type MG, Model 911/e. They are equipped with Type NDF signal preamplifiers. The signal converter is Turbo transmag pulsed AC converter. Model $911 / \mathrm{E}$ is rated for 150 PSIG and 100 GPM and designed for use with low conductivity media such as the basin water. The electrodes are mounted flush with the internal diameter of the flow tube.

All flow elements are directly coupled to locally mounted flow indicator transmitters. The flow transmitters all transmit a 4 to 20 -milliamp signal to PLC-2, which feeds the signal to the main control Panel CP-A, and have high and low flow alarms. The flow indicator transmitters are as follows:

$\begin{array}{lll}\text { DESIGNATOR } & \text { TITLE } & \text { RANGE } \\ \text { FE/FIT-206-01 } & \text { Booster Pump FRW-P-4 Flow } & 0-400 \mathrm{GPM} \\ \text { FE/FIT-206-02 } & \text { Filter Backwash Flow } & 0-250 \mathrm{GPM} \\ \text { FE/FIT-206-03 } & \text { Filter Air Sparge Flow } & 0-150 \mathrm{SCFM} \\ \text { FE/FIT-206-04 } & \text { Filter Water Sparge Flow } & 0-250 \mathrm{GPM} \\ \text { FE/FIT-206-05 } & \text { Decap Pump FRW-P-1 Flow } & 0-100 \mathrm{GPM} \\ \text { FE/FIT-206-06 } & \text { PCM Pump FRW-P-2 Flow } & 0-100 \mathrm{GPM} \\ \text { FE/FIT-420-01 } & \text { IXM-1 Outlet Flow } & 0-300 \mathrm{GPM} \\ \text { FE/FIT-420-02 } & \text { IXM-2 Outlet Flow } & 0-300 \mathrm{GPM} \\ \text { FE/FIT-420-03 } & \text { IXM-3 Outlet Flow } & 0-300 \mathrm{GPM}\end{array}$

\subsubsection{Flow Switch (FS)}

The flow switch is found on the distribution header and detects flow going to the Discharge Chute. It is a paddle type, Model FS-550, Type 316 stainless steel switch manufactured by GEMS Corporation for a 2-in line tee fitting. It is set to activate at 22 GPM (flow) and deactivate when flow drops back to 15 GPM or less (no flow). The discharge line has a nominal flow of 30 GPM. The switch indicates either flow $>22$ GPM (allowing for header fluctuations) or inadequate flow $\leq 15$ GPM that transmits a low flow alarm to the PLC. 


\subsubsection{Liquid Level Detector Switch (LE)}

The detector alerts basin operators when the water level in the garnet filter vent moisture separator has risen to the point where the separator needs draining. The moisture separator precedes the HEPA filter train and is just upstream of the heater and roughing filter.

The detector/switch is a Flotect ${ }^{\text {TM }}$ Model L6-EPB flow switch with a Type 304 stainless steel float manufactured by Dwyer Instruments. It is rated for $220^{\circ} \mathrm{F}$ and 350 PSIG. The electrical assembly can be removed for maintenance without removing the entire assembly.

\subsubsection{Differential Pressure Indicators (DPITs and DPIs)}

Differential pressure is measured across the KO pot, each garnet filter, and each filter in the HEPA filter train. All indicators are assessable for local basin operator viewing and surveillance testing of transmitters. The transmitters provide a 4 to 20 -milliamp signal to PLC-2.

The KO pot and garnet filter pressure sensors and the indicator transmitters are supplied by

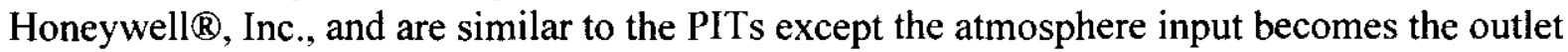
line pressure (see below). The air filter sensors and local indicators (DPIs) are supplied by Dwyer Instruments. The DPIs are the Magnehelic $(B)$ Gauge, Series 2003 . They are the following:

$\begin{array}{lll}\text { DESIGNATOR } & \text { TITLE } & \text { RANGE } \\ \text { DPIT-206-01 } & \text { KO Pot Pressure Drop } & 0 \text { to 75 PSID } \\ \text { DPIT-206-10 } & \text { Garnet Filter 1 Pressure Drop } & 0 \text { to } 50 \text { PSID } \\ \text { DPIT-206-20 } & \text { Garnet Filter 2 Pressure Drop } & 0 \text { to } 50 \text { PSID } \\ \text { DPIT-206-30 } & \text { Garnet Filter 3 Pressure Drop } & 0 \text { to } 50 \text { PSID } \\ \text { DPI-206-40 } & \text { Roughing Filter Pressure Drop } & 0 \text { to } 3 \text { in w.g. } \\ \text { DPI-206-50 } & \text { HEPA 1 Filter Pressure Drop } & 0 \text { to } 3 \text { in w.g. } \\ \text { DPI-206-60 } & \text { HEPA 2 Filter Pressure Drop } & 0 \text { to } 3 \text { in w.g. }\end{array}$

\subsubsection{Pressure Indicators (PIs)}

Local pressure indication is used throughout the IWTS. All local indicators are Ashcroft巴

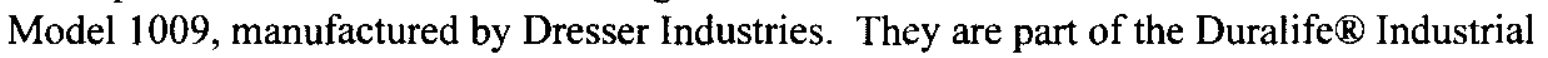
Gauge line and are the standard Bourdon tube/dial pressure measuring instrument. They have stainless steel wetted parts and are bottom stem mounted. The difference is in the pressure range measured. The designators, uses, and ranges are as follows: 


$\begin{array}{lll}\text { DESIGNATOR } & \text { TITLE } & \text { RANGE } \\ \text { PI-420-01 } & \text { IXM-1 Outlet Pressure } & 0-160 \text { PSIG } \\ \text { PI-420-02 } & \text { IXM-2 Outlet Pressure } & 0-160 \text { PSIG } \\ \text { PI-420-03 } & \text { IXM-3 Outlet Pressure } & 0-160 \text { PSIG } \\ \text { PI-420-05 } & \text { Debris HP Pump Line Pressure } & 0-160 \text { PSIG } \\ \text { PI-420-06 } & \text { Debris Rinsing Line Pressure } & 0-160 \text { PSIG } \\ \text { PI-420-07 } & \text { Sludge Removal Line Pressure } & 0-100 \text { PSIG } \\ \text { PI-420-08 } & \text { MCO Cask Filling Pressure } & 0-100 \text { PSIG } \\ \text { PI-420-09 } & \text { FRS Decap \& PCM Line Press } & 0-60 \text { PSIG } \\ \text { PI-420-10 } & \text { Header Distribution Pressure } & 0-100 \text { PSIG } \\ \text { PI-420-11 } & \text { Discharge Chute Line Pressure } & 0-60 \text { PSIG }\end{array}$

PI-420-01, 02, and 03 are on the outlet lines of the IXMs to provide individual outlet pressure indication when the respective IXM is in use and to show the pressure when the IXM is isolated. All other indicators are associated with the IWTS outlet distribution header.

\subsubsection{Pressure Indicator Transmitters (PITs)}

The pressure indicator transmitters monitor key system parameters needed for remote control and operation of the IWTS. All signals feed 4 to 20-milliamp signals into PLC-2 that provides the signals to the CP-A with appropriate alarms necessary for proper operation of the system. The local readout is at the instrument. The indicator transmitters are all manufactured by Honeywell $B$, Inc. They are called Smart Meters (SM), Type F103, Model STG94L-EIG-0000-00, and have the following basin designators, uses, and ranges:

$\begin{array}{lll}\text { DESIGNATOR } & \text { TITLE } & \text { RANGE } \\ \text { PIT-206-01 } & \text { Booster Pump Suction Pressure } & 0-100 \text { PSIG } \\ \text { PIT-206-02 } & \text { Booster Pump Outlet Pressure } & 0-200 \text { PSIG } \\ \text { PIT-206-03 } & \text { Skimmer Pump Skid Pressure } & 0-100 \text { PSIG } \\ \text { PIT-420-01 } & \text { Filter Disch/IXM Inlet Pressure } & 0-150 \text { PSIG } \\ \text { PIT-420-02 } & \text { IXM Discharge Pressure } & 0-100 \text { PSIG }\end{array}$


PIT-206-01, 02, and 03 are on the booster pump skid. PIT-420-01 is mounted on the common 4-in garnet filter outlet header, and PI-420-02 is mounted on the common 4-in IXM outlet header.

\subsubsection{Pump Instrumentation}

The submerged pumps FRW-P-1, 2, and 3 have similar instrumentation. They can be operated locally from hand switches HS-206-01, 02, and 03, respectively, and have ON/OFF indicator lights (see also interlocks). Each is equipped with a winding moisture probe switch and temperature switch for pump protection and a method to monitor winding current (see CT-206-1, 2 , and 3). If moisture or high temperature is detected in the windings, the switch shuts the pump down. The pumps are interlocked so they operate as a unit, i.e., all three (3) pumps must operate simultaneously. If one is shut down, they all are. The pumps can be monitored and controlled from the IWTS PLC-2 in control Panels CP-A and CP-C.

The booster pump FRW-P-4 and the small chemical addition metering pump FRW-P-5 have a similar arrangement, except they are not equipped with moisture probes or temperature switches. The pumps have hand switches HS-206-04 and 05, respectively.

\subsubsection{Temperature Elements (TEs)}

Temperature is not normally a concern of the IWTS piping since it operates using cool basin pool water. However, there are specific instances where temperatures are monitored to protect system equipment. Each garnet filter surface near where solids would be removed and collected within the vessel is monitored. The temperature is used to ensure that decay heat from the solids collected is not allowed to cause the vessel to reach the vessel design temperature.

These platinum resistance temperature detectors (RTDs) are designated TE-206-10, 20, and 30, and are mounted directly to the vessel outer surfaces. The other RTD (TE-206-40) is associated with the air temperature downstream of the HEPA filter train heater. It is used to ensure that the heated air does not exceed the filter temperature ratings. These four (4) RTDs are manufactured by JMS Southeast, Inc. They are Type E, $100 \mathrm{ohm}$, collar type, with 24-in leads. These temperatures can be monitored at Panel CP-A.

$\begin{array}{lll}\text { DESIGNATOR } & \text { TITLE } & \text { RANGE } \\ \text { TE-206-10 } & \text { Filter 1 Surface Temperature } & 50-250^{\circ} \mathrm{F} \\ \text { TE-206-20 } & \text { Filter 2 Surface Temperature } & 50-250^{\circ} \mathrm{F} \\ \text { TE-206-30 } & \text { Filter 3 Surface Temperature } & 50-250^{\circ} \mathrm{F} \\ \text { TE-206-40 } & \text { Vent Heater Outlet Temperature } & 50-250^{\circ} \mathrm{F}\end{array}$

All pump windings have high temperature thermocouples and power cut off switches as part of the normal protection instrumentation. These thermocouples are integral to the components, are not discussed here, and have no specific component instrument numbers. The HEPA filter heater 
was supplied with two (2) internal Chromalox ${ }^{\circledR}$ Type J (iron-constantan) thermocouples for heater protection.

\subsubsection{Radiation Indicators (RE/RITs)}

The radiation monitors are associated only with operation of the garnet filters. The ion chamber detectors (RE-206-01, 02, and 03) are within the filter shield enclosure. The mounting assemblies are attached to the filter sparge inlet piping, adjacent to and about 1 inch from Filters 1,2 , and 3, respectively, in the sludge collection region. The signal is read locally (RIT-206-01, 02, or 03) at the Transfer Bay Area Panel CP-C that is just south of the filter enclosure.

The signals are hard wired from the detectors to the indicators. Each indicator can activate a local audible element failure alarm and a high alarm. There are also high and high-high alarms at Panel CP-A. The monitors have been downgraded from Safety Significant to General Service as the original purpose has become unnecessary. The process monitors and alarms now support operation and maintenance.

$\begin{array}{lll}\text { DESIGNATOR } & \text { TITLE } & \text { RANGE } \\ \text { RE/RIT-206-01 } & \text { Filter 1 Radiation Level } & 10 \mathrm{mR} / \mathrm{H} \text { to } 100 \mathrm{R} / \mathrm{H} \\ \text { RE/RIT-206-02 } & \text { Filter 2 Radiation Level } & 10 \mathrm{mR} / \mathrm{H} \text { to } 100 \mathrm{R} / \mathrm{H} \\ \text { RE/RIT-206-03 } & \text { Filter 3 Radiation Level } & 10 \mathrm{mR} / \mathrm{H} \text { to } 100 \mathrm{R} / \mathrm{H}\end{array}$

The detector is an Eberline ion chamber, Type RMS II, Model DA1-8. The detectors send signals to Model EC1-4 remote indicators that have logarithmic scales over their ranges. The detector assembly comprises the ion chamber, high voltage supply, pulse amplifier, and line drive. The assembly operates in the proportional region with the current output proportional to the radiation field monitored. The output signals are amplified, read, and alarmed locally. The signals are collected by PLC-2 and are transmitted to the basin control Panel CP-A in Room 20A where they can be read remotely. The hard wired alarm is a Model AN-3100C MicroLarm visual annunciator manufactured by RIS $\otimes$ Rochester Scientific Systems.

\subsection{SYSTEM RELIABILITY FEATURES}

System reliability is assured by fabricating the IWTS from piping and components that exceed the temperature, pressure, and lifetime requirements required of the overall system. The IXMs are designed for redundancy in that the normal operation uses two (2) IXMs while the other IXM can always be brought online to replace a spent IXM while the system continues to provide service demands. A certain amount of flexibility is designed into the system by using a variable speed booster pump and a control valve that regulates header pressure and flow. This system and user load following capability adds to the operational reliability of the system. 


\subsection{SYSTEM CONTROL FEATURES}

\subsubsection{Computer Control and Monitoring}

The IWTS is designed so that all major operations are controlled remotely from Room $20 \mathrm{~A}$ of the $105 \mathrm{KW}$ Reactor Building through Panel CP-A. Panel CP-A receives basin signals, e.g., pool $\mathrm{pH}$ and basin area radiation levels, from Panel CP-B located in Room 4 and the IWTS signals from Panel CP-C located just south of the filter enclosure in the Transfer Bay Area. Panel CP-C also contains PLC-2 and the local filter enclosure radiation indicators that communicate with Panel CP-A. The computer software, the hardware, the control settings, the logic, control interfaces, ladder logic, and alarm function are described in a separate document. This document is now in the initial review stage and not able to be referenced at this time as the tentative document number and title may change before release.

All AOV valve positions, alarms, transmitted instrumentation readouts, process flow mimic, and alarm summaries are graphically displayed on Panel CP-A. The control uses a touch screen (mouse optional) and has a manual and automatic mode. In manual mode all AOVs and pumps can be operated individually from the computer screen. The normal system operation is in an automatic mode as the proper valve positions have been preprogrammed for each mode. The readouts for variables, AOV positions, and pump status are displayed. The CP-A computer also has the capability to trend system parameters, both real time and historical, log alarm status, and permit alarm and set point changes using appropriate administrative controls.

There are eleven (11) different automatic modes that can be selected from the CP-A screen. The modes cover FRS shutdown (IWTS standby), normal operation, and the garnet filter media top water sparge, water backwash, and air sparge operations. There are separate modes for each of the three (3) filters. When any mode is selected, all valves, pumps, alarms, and instruments associated with that particular mode are displayed on the screen; and the selected process proceeds. Should any shutdown alarm set point (trip) be exceeded, any pump fail to operate, or any AOV not position properly, the system will automatically shut down and return to the standby mode. Modes are discussed separately in this SDD under components, see Process Computer (CP-A).

\subsubsection{Interlocks and Trips}

The set points listed below are approximate for information only. Refer to the procedures for the current values as they can be changed by conditions and operational experience during the life of the IWTS. Certain interlocks may be added or deleted later if operating conditions warrant the change. The IWTS will initially undergo an automatic shut down when the following conditions occur: 
Booster pump low suction pressure (PIT-206-01) drops below 5 PSIG (prevents pump damaging cavitation)

Booster pump low-low flow (FIT-206-01) for pump protection

Garnet filter vessel high-high differential pressure (DPIT-206-10, 20, or 30) exceeds about 40 PSID

A common IXM high-high outlet pressure (PIT-420-02) exceeds about 70 PSIG

- Air filter high-high inlet temperature (TE-206-40) to protect the HEPA filters

- Garnet filter high-high radiation (RIT-206-01,02, and 03). This alarm may be deleted as it serves no useful purpose now and may inadvertently impede operations.

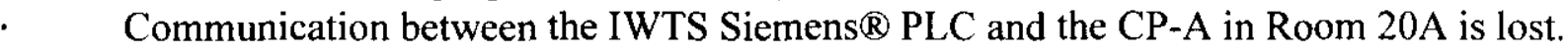

- Any remotely actuated valve does not assume the proper position (valve misalignment) for the automatic mode selected.

The submerged pumps (FRW-P-1, 2, and 3) are interlocked so that in the event that one pump trips, the others will trip to prevent backflow through the initially tripped pump. The pump outlets are not equipped with backflow prevention valves.

The skimmer pump or backup recirculation pump must provide at least 10 PSIG, as indicated on PIT-206-03, before a filter backwash or water sparge automatic mode can be initiated.

The instrument provides a "permissive" signal. 
This page is intentionally left blank. 


\subsection{KW BASIN IWTS OPERATIONS}

\subsection{OPERATIONAL SUMMARY}

The primary objective of the IWTS is to support the retrieval, decapping, cleaning, sorting, and removal of spent nuclear fuel from the $105 \mathrm{KW}$ Basin. The IWTS also supports debris and sludge removal operations. The IWTS provides the suction pumps used by the FRS to remove and strain the canister liquor and remove sludge released when processing fuel. The IWTS filters the sludge particles introduced into the system by a series of particulate separation components, i.e., the KO pot screen to remove the larger particles, settling tanks to remove medium sized particles, and deep bed garnet filters to remove finer sized particles and to maintain water clarity. The filtered water must also be conditioned for radioactive dose minimization. The treated (filtered and conditioned) water must then be distributed to the pool and users to support basin spent fuel, debris, and sludge removal operations. When the system is not needed for its primary mission, it must be available to support the pool water cleanup normally performed by the Basin Water System. Although automatic operation is preferred, the system must also be manually operable for increased availability.

Most of the operational modes support continued operation of the system. Spent IXMs or filled KO pots need to be replaced. The pressure drops across the garnet filters need to be reduced by media backwashing, water sparging, and air sparging. When a KO pot is nearing the end-of -life, the IWTS must be shut down while the pot is replaced. The IWTS can continue to operate when replacing an IXM. Normally, the IWTS operates with one (1) of the three (3) IXMs in standby. When an IXM nears end-of-life, the standby IXM is brought on line. The spent IXM is then removed from service, isolated, drained, physically removed, and replaced with a new IXM. The actual replacement of an IXM is considered part of maintenance, but there are certain operational requirements for tracking the condition of the IXMs and taking them out of service.

The following discussion of various filter operating modes use the Basin Water System skimmer pump (SKW-P-6). These operations can also use the Basin Water System recirculation pumps (RBW-P-1A and 1B) as backup by changing the position of a few manual valves. This will be understood in the following applicable discussions and will not be further discussed as the use of the recirculation pumps would be a rare occurrence. The IWTS operations can be planned and scheduled so that the preferred skimmer pump is usually available.

The IWTS can operate as a backup for the Basin Water System pool water treatment. During this operation water from the recirculation pumps is preferred as the pumps can provide a flowrate equivalent to the normal IWTS flow. 


\subsection{SYSTEM STARTUP}

Certain startup operations are required during the initial startup of the IWTS and after lengthy shutdowns. All are related to filling the system, or portions of the system, with water and venting the trapped air. The major components are equipped with float valves to allow continual venting. A float valve is at the air outlet of each IXM and on the common air vent lines from the settler tanks and from the garnet filters. A float valve allows air to pass the float, but the rising float seals and prevents passage of water.

The IWTS piping is arranged so that the motive force for garnet filter, IXM, and distribution header fill and vent operations can be provided by the Basin Water skimmer pump (SKW-P-6), the Basin Water recirculation pumps (RBW-P-1A/B), or the IWTS pumps. All three IWTS submerged pumps (FRW-P-1, 2, and 3) are interlocked and must operate together, with or without the booster pump. Certain pumping arrangements are preferred under different situations, but knowing that the system has these capabilities is important. The distribution header can only be filled from the IXMs.

Many system startup operations use the skimmer pump. When using the skimmer pump, the head pressure at the pump should be maintained at 40 PSIG as read on downstream gauge PI-204-1. The pump will be shut down if the pressure drops below 26 PSIG. The head pressure is also measured at the IWTS booster pump skid by PIT-206-03. The pressure at this transmitter must be at least 10 PSIG for the operation to proceed. Normally, this will also be understood in the following discussions and not repeated further except in the reference operating procedures.

Once the system is operational, the preferred method to fill and vent partially empty components, a standby IXM, and/or the header is with the IWTS pumps as the system is brought on line. Any trapped air will be carried to a point in the system where is can be vented through the float valves or header siphon break lines.

\subsubsection{KO Pot and Settler Tank Assembly Fill and Vent}

The settler tanks are all vented through a common float valve that cannot be isolated from the tanks. The float valve vents gases directly to the basin, so the settler tanks remain full of water. The submerged KO pot may contain some air, but it will be carried over to the settler tanks and vented there when the flow from the submerged pumps begin. No special operations are necessary.

\subsubsection{Booster Pump and Garnet Filter Fill and Vent}

Normally, the booster pump and the garnet filters only need to be filled and vented during the initial startup of the IWTS, after the filters have been drained for maintenance, after an air sparge (lowered water level), or after a long shutdown period. Each filter is filled separately.

The procedure uses an operator at the CP-A computer in Room 20A and at least one operator in the Transfer Bay Area to position the manual valves, operate the selected pump, and verify 
readings. The preferred computer control is in the Manual Mode. This allows operation of all AOVs from the computer screen and remote readout of instruments.

The skimmer pump outlet is arranged so that the pump flow enters the booster pump skid (through FRW-V-010, 005, and 006), goes past the isolated settler tanks (FRW-V-001 closed), through the deactivated booster pump, and into the selected filter (through FRW-V-100, 200, or 300). Air exits the filter (through FRW-V-104, 204, or 304, respectively) to the HEPA filter subsystem. Therefore, as prerequisites for this operation, the CP-A and operators must be available, the skimmer pump must be operating and available, the filter outlet valves are closed (other that the inlet and vent), and the HEPA subsystem must be online. Since water carryover through the vent is a distinct possibility, the subsystem moisture separator drain (FRW-V-50) should be open or the separator drained before the operation.

The last valve to be opened is manual valve FRW-V-005 that controls the flowrate for this operation. This valve is slowly opened to provide an initial flowrate of 50 GPM (FIT-206-01), and left at this valve position. The flow will decrease almost to zero as the filter is filled with water. When the flow nears zero, the valve is closed, and the filter is isolated. If another filter is to be filled, the next filter valves are positioned accordingly. The step with FRW-V-005 and the initial flow is repeated. At the end of this operation, all valves are returned to the original position.

\subsubsection{IXM Fill and Vent}

The IXMs can be filled directly by the skimmer pump or indirectly through one or more garnet filters. During the initial system fill it is assumed that the garnet filters have just been filled, and the filter fill prerequisites are still viable. A flow path must be available through at least one filter to the IXM inlet header. The manual valve that controls the skimmer pump flow is closed, and the filter vent valves are closed (see garnet filter fill and vent). The vent path through the float valve (IXV-FCV-3, 4, or 5) is first established for the selected IXM by ensuring the FCV isolation valve (IXV-V-100, 200, or 300) is open and the respective FCV bypass valves (IXV-V-101/102, 201/202, or 301/302, respectively) are closed. All manual IXM inlet, outlet, and drain valves should be closed.

A flow path is then established from the skimmer pump by opening the skid inlet valve used for the garnet filter fill, opening the garnet filter(s) inlet and outlet valves, and ensuring the IXM header inlet valve (IXS-V-002) is open. The IXM inlet valve (IXS-V-100, 200, or 300) is slowly opened until a flow of about 20 GPM is shown on FIT-206-01. This will allow the inlet water pressure to maintain the resin and allow the air to be vented. The flow will be automatically stopped by the float valve. If a vent path exists through the distribution header, it can be used at this time to vent the IXM outlet piping by opening IXR-V-010, 020 , or 030 , respectively. It is recommended that the IXMs be filled and isolated individually during the initial fill. If the distribution header is not to be filled and vented at this time, the skimmer pump is isolated from the IWTS; and the IWTS put on standby. 
During normal operation of the system when it is time to bring the standby IXM online, the vent path through the FCV is first established, and all drain valves are ensured closed. With the other IXMs still operating, the inlet valve of the standby IXM is slowly opened. When filled, as evidenced by the closure of the FCV valve, the IXM outlet valve can be opened slowly. This maintains pressure on the resin bed to hold it in place. Opening the outlet valve too soon or before the inlet valve could cause a reverse flow from the pressurized header (about 30 PSIG) and disturb the resin bed.

\subsubsection{Distribution Header Fill and Vent}

The only flow path to the distribution header is through the IXM(s) so at least one IXM must be operational. The flow path is from the skimmer pump through the bypass line valve FRW-V-009 and the inlet and outlet valves of the IXM(s) to be used in this operation. The header high point vent valves (IXR-V-012 and 023), the discharge chute valve (IXR-V-011), and IXR-FCV-001 are opened. The flow control valve is opened about $25 \%$ from Panel CP-A. The skimmer pump is then brought online until water flow is seen through the opened header valves. The IWTS valve position and the skimmer pump are then returned to their normal condition.

\subsection{OPERATIONAL MODES}

\subsubsection{Computer Control of Operations}

Normally, the IWTS is operated and controlled from a central basin computer interface (Panel CP-A) that allows access to all basin parameters. The IWTS is controlled through a PLC (PLC-2) that allows graphical display monitoring of all remotely actuated valve positions, operating status of pumps, instrumentation readouts, alarm conditions and summaries, process flow paths, and historical trends. This arrangement allows both automatic and remote manual control of operations and remote monitoring of parameters. Even when controlling manually, all remotely actuated valves and components (pumps) can be operated individually from the CP-A computer screen. The operator can select any of eleven (11) pre-programmed sequences by use of the computer touch screen and a standard computer mouse. The modes are:

$$
\begin{aligned}
& \text { Mode } 1 \text { - FRS Shutdown } \\
& \text { Mode } 2 \text { - Normal Operation } \\
& \text { Mode } 3 \text { - Top Sparge Vessel } 1 \\
& \text { Mode } 4 \text { - Top Sparge Vessel } 2 \\
& \text { Mode } 5 \text { - Top Sparge Vessel } 3 \\
& \text { Mode } 6 \text { - Backwash Vessel } 1 \\
& \text { Mode } 7 \text { - Backwash Vessel } 2 \\
& \text { Mode } 8 \text { - Backwash Vessel } 3 \\
& \text { Mode } 9 \text { - Air Sparge Vessel } 1 \\
& \text { Mode } 10 \text { - Air Sparge Vessel } 2 \\
& \text { Mode } 11 \text { - Air Sparge Vessel } 3
\end{aligned}
$$


When any mode is selected, all pumps, valves, alarms, and instruments associated with that particular mode are started, aligned, displayed on the computer screen, and the process proceeds. If any shutdown alarm set point is exceeded or any remotely actuated valve is not positioned properly, the selected mode will automatically shut down and return to Mode 1 - FRS Shutdown. A new operator action is then required to change or restart a mode after automatic shut down. The air sparge modes refer to the media air agitation to loosen particulate before backwash.

\subsubsection{FRS Shutdown (Mode 1)}

This mode shuts off IWTS pumps and closes all AOVs except the air vent valves on the garnet filters (FRW-V-104, 204, and 304). This mode is not only used for system shutdown and standby but also is used as a starting point for many of the following operations since it assures the initial position of the valves. Subsequently, putting the Panel CP-A selector in "Manual" allows the selective positioning of all AOVs. For instance, the garnet filter vent valves could be closed or any closed valve opened.

\subsubsection{Normal Operations (Mode 2)}

Mode 1 is first used to position the valves in the safe shutdown position. Mode 2 will later position the AOVs so that a flow path exists through the submerged pumps (FRW-P-1, 2, and 3), through the KO pot (FRW-KOP-100) and settler tank assembly (FRW-STLR-100), through the booster pump (FRW-P-4), through the garnet filters, through at least one IXM (manual inlet and outlet valves), and finally through the distribution header flow control valve (IXR-FCV-001).

The manual valves are not positioned by the mode selection. Assuming these valves are closed initially, the following IXM manual valves must be opened before starting Mode 2 and pump activation:

- The common IXM inlet header valve (IXS-V-002)

- The inlet and outlet valves of the IXMs that will be used

- The pressure gauge root valves on the IXM outlet lines that will be used.

The required IXM autosamplers are started and placed in service for automatic operation. The control is then put into Mode 2 which correctly aligns the flow path, starts the pumps in timed sequence (in numerical order), and controls flow at $320 \mathrm{GPM}$ and at the preselected header pressure.

Operation can also be established manually. Mode 1 first establishes the AOV valve positions, and the CP-A mode selector is put in manual to position the selected AOVs. The garnet filter vent valves (FRW-V-104, 204, and 304) are closed, FRW-V-001 opened, the filter inlet and outlet valves opened, and IXS-FCV-001 opened. This duplicates the Mode 2 flow path. 
The manual valves are positioned as above. The pump's HAND/OFF/AUTO control switches are placed in the HAND position, and the pumps brought online in the same sequence. The flow is balanced manually by adjusting the pump speeds and the header flow control valve position.

\subsubsection{Garnet Filter Bed Top Sparge (Modes 3, 4 \& 5)}

Filter top water sparge can be initiated by high differential pressure or technical request. This sparge is accomplished by admitting water flow near the top of the filter media and removing the water from the top of the filter bed using the normal backwash outlet piping. Top sparge reduces bed differential pressure by removing the upper layer of larger contaminates from the bed, thus restoring filter differential pressure without disturbing the bulk of the filter media. This action allows the bed to operate more efficiently for small particle removal for longer periods.

The IWTS is not in service during a top sparge, and the preferred source of sparge water is from the skimmer pump. When using the skimmer pump, the head pressure at the pump should be maintained at 40 PSIG as read on downstream PI-204-1. The pump will be shut down if the pressure drops below 26 PSIG. The head pressure is also measured at the IWTS booster pump skid by PIT-206-03. The pressure at the transmitter must be at least 10 PSIG for the operation to proceed.

The manual valves used are on the booster pump skid, and the operation requires at least one operator at the skid and one at Panel CP-A. Filters are top sparged one at a time while the other two filters remain in service to filter the sparge water. Top sparge water from the skimmer pump will flow through the skid inlet (FRW-V-010), through the common sparge headers valves (FRW-V-008 and 012, FRW-CV-005), and through the selected filter sparge lines. Assuming Filter-1 is the selected filter, the water will flow through FRW-V-103, through the filter, through the backwash valves (BBW-V-100 and 005, BBW-CV-001), through the settler tanks, through the two (2) filters in service, through the IXMs, and out the distribution header. The flow will be established at about $150 \mathrm{GPM}$ by FRW-V-012. This counter flowrate is higher than the normal flowrate in the filter (107 GPM) and lower than normal in the settler (320 GPM), allowing adequate sparging and increased settling.

Top sparge flow is monitored by remotely viewing the sight glass (FRW-SG-001) that is within the filter shield enclosure. The top sparge water will start clear, become discolored as the suspended solids are discharged from the filter, and return to a near clear state at the end of the sparge period. Top sparge time is dependent upon filter loading but a general time for top sparge is estimated between 20 and 30 minutes per filter.

The Panel CP-A is first set to Mode 1 to put the AOVs in the initial position. Assuming the skimmer pump is available, FRW-V-010 is open, IXMs are online, Mode 3, 4, or 5 is selected according to the filter to be sparged. The control system will automatically align the rest of the AOVs and pump to sparge at the preset rate. The sparge rate (FIT-206-04) and condition of the water should be checked. After the sparge is complete, the system is returned to Mode 1. 
A manual sparge is usually only conducted when the initial sparge flowrate is established.

Panel CP-A is used to put the system in Mode 1 and then in the Manual condition. Assuming this is the first sparge, the flow control valve (FRW-V-012) is closed. The valve will later be opened to set the rate at 150 GPM nominally. The flow path is then established by positioning the associated AOVs remote manually; then the skimmer pump brought online. The sparge rate is established. When finished with the sparge, the pump is valved off; and the valves are put in the Mode 1 position.

\subsubsection{Garnet Filter Bed Backwash (Modes 6, 7 \& 8)}

The backwashing operation is performed to clear sediment particles from a filter when the filter is experiencing a high differential pressure across the bed or the operations supervisor determines backwash is appropriate to support required future operations. The backwash operation reverses flow in the filter (bottom to top). The backwash solution goes to the settler tanks, through the inoperative booster pump to the two (2) filters not being backwashed. The filtered water then is conditioned by the online IXMs before returning to the pool through the distribution header. In other words, the backwash water is treated like the sparge water once it passes through the site glass (FRW-SG-001) and common outlet BBW-V-005. The backwash rate is also a nominal $150 \pm 5$ GPM, and the setting of the flow control valve (FRW-V-011) is determined during the initial manual backwash. The backwash header is on the booster pump skid.

The IWTS is first placed in Mode 1 for initial valve positioning and pump shutdown. The skimmer pump is made available, and manual valve FRW-V-010 is assured open. Mode 6, 7 , or 8 is then selected which automatically aligns the AOVs and skimmer pump to backwash the selected filter at the preset flowrate. The backwash flowrate is verified on FIT-206-02, and the water condition is monitored remotely through the sight glass. The backwash water will start clear, become discolored as the suspended solids are discharged from the filter, and return to a near clear state at the end of the backwash. Backwash time is dependent upon filter loading, but a general time is between 20 and 30 minutes per filter.

A manual backwash is usually only conducted when the initial backwash flowrate is established. Panel CP-A is used to put the system in Mode 1 and then Manual condition. Assuming this is the first backwash, the control valve (FRW-V-011) is closed. The valve will later be opened to set the flowrate at 150 GPM nominally. The flow path is then established remote manually with the associated AOVs, and the skimmer pump brought online. The backwash rate is then established. When finished with the backwash, the pump is valved off and the valves put in the Mode 1 position.

\subsubsection{Garnet Filter Air Sparge (Modes 9, 10 \& 11)}

Periodically, it may be necessary to sparge the filter media with air injection to loosen particulate for maintaining operating performance. Only one filter is sparged at a time. The air flow direction is similar to the backwash flow path (bottom to top direction), but with more media

agitation. The air agitation/sparge is always followed with a normal backwash cycle to clean the 
filter media thoroughly. Before initiating a sparge, the selected filter is isolated and partially drained. The free space in the vessel allows for more vigorous media agitation than can be obtained with a full vessel, and it also helps prevent water carryover.

During the media air agitation, a portable air compressor is connected to the IWTS upstream of normally closed manual valve FRW-V-014. The air line also includes the flowrate control valve FRW-V-015, the flowmeter FIT-206-03, the check valve FRW-CV-004, and the remote AOV valve FRW-V-016. The position of FRW-V-015 has been preset at a nominal rate of 100 SCFM, but the rate can vary between 80 and 125 SCFM. After the flow path is assured and the air injection begins, the flow can be checked and adjusted to 100 SCFM if necessary. The air is injected into the same line used for backwash. The air flows through the media, exits the filter through the vent line, and is filtered by the HEPA filter subsystem before release to the atmosphere. Therefore, the compressor needs to be connected; and the HEPA subsystem needs to be in operation before the media is agitated.

Mode 1 is initially selected to align the valves and shut down the pumps. The filter is then partially drained by injecting air into the vessel through the top sparge line (FRW-V-015, 016, 103). The filter is pressurized and forces water out the opened valve FRW-V-101 to the IXMs. This will require first placing the $\mathrm{CP}-\mathrm{A}$ selector in Manual condition to position the AOVs. The draining should take about 10 minutes. The valves are then closed. Mode 9,10 , or 11 is then selected to align the valves automatically for the filter to be sparged. The air flowrate is verified as or adjusted to 100 SCFM as monitored on FIT-206-03. The sparge operation will continue as long as determined by the Shift Manager before the control is returned to Mode 1 . The compressor is then taken off line, and the filter is refilled and backwashed.

The manual sequence is similar for draining and isolating the selected filter. The difference from automatic operation is that the system is left in Mode 1/Manual and the air sparge valves are first aligned, then closed individually.

\subsubsection{IXM Replacement (Manual)}

This operation involves bringing the standby IXM online while the system is operating, isolating the spent IXM, preparing the spent IXM for removal, and putting the new IXM in a standby condition. Determining when an IXM is ready to be taken out of service is dependent on the desired percentage of ${ }^{137} \mathrm{Cs}$ removal and the estimated TRU content. Data on times of service and the final removal efficiency must be gathered during the procedure.

The standby IXM is prepared by assuring the outlet line drain valve is closed, and the vent path through the FCV float valve is open (bypass closed). The correct sequence involves first slowly opening the inlet valve (IXS-V-100, 200, or 300) to pressurize the bed and vent the air from the IXM. The outlet valve (IXR-V-010,020, or 030, respectively) is then opened to bring the new IXM online. Caution: Opening the outlet valve first causes reverse flow to occur from the pressurized outlet header and disturbs the resin beds. The respective autosampler is then started and put in the automatic operating mode. 
The spent IXM is then isolated by closing the inlet valve, then the closing the outlet valve, taking the autosampler out of service, and collecting the final water samples for analysis. The isolated IXM is monitored to assure that there are no leaks from the piping and through the closed valves by observing the flowmeter reading. Assuming the IXM isolation is satisfactory, the IXM FCV bypass valve (IXV-V-101, 201, or 301) is opened. The IXM and the IXM outlet line are drained to the basin through IXM-V-013, 023, or 033, respectively. The IXM is allowed to drain for about 24 hours. Afterwards, the remaining water is drained from the local drain (IXM-V-012, 022 , or 032) into a plastic container(s). Further operations involve known radiation hazards to operators, and require full ALARA practices as to water leakage, contamination, ventilation air flow, and HEPA filtering. The operation disconnects the IXM piping, caps the outlet nozzle, and installs nuclear grade filters on the top inlet nozzle and the six (6) vent pipes. The IXM is then prepared for storage or burial. Removal and replacement of an IXM are considered part of normal basin maintenance and are established from previous service.

After a new IXM with disconnects has been positioned, the main concern is possible water leakage from the IXM and system pipe connections. Nearly the same ALARA considerations and preventive measures are taken as for the spent IXM removal. Most operations are conducted by maintenance in connecting the inlet and outlet hoses, putting the vent manifold in place, and connecting the vents. The IXM is left connected with the FCV bypass closed, the FCV vent line open, drain valves closed, and header inlet and outlet valves remaining closed. It is now in standby.

\subsection{OFF-NORMAL OPERATIONS}

\subsubsection{Garnet Filter Media Sluicing}

This is necessary when the garnet filter media (different types of sand) needs to be replaced. The spent media is removed from the filter vessel by adding water to the top of the vessel with either the top sparge line or the normal inlet header. This media/water mixture is removed from the vessel bottoms through a bottom nozzle that extends through the screen holding the media. This nozzle connects to the sparge/backwash line through FRW-V-105, 205, or 305. The media flows through the common backwash line and out BBW-V-002 to a disposal container. The sluice out operation requires the disposal of radioactive material and must be governed by detailed procedures and extensive health physics monitoring. The sluice out valves are then closed, and the new filter media is hydraulically pumped (FRW-P-6) into the vessel top through FRW-V-102, 202, or 302, respectively. The media is normally contained in 50 to $100 \mathrm{lb}$ bags that are added to a 55-gallon drum, mixed with water, and fed to the pump.

\subsubsection{Emergency Garnet Filter Backwash}

If a remotely operated backwash valve (BBW-V-100, 200, or 300) fails to open in the normal backwash mode, a filter can be backwashed by manual operation. This operation reduces the amount of particles contained in the filter media, thereby lowering the radioactive dose rate in the filter enclosure before entering and performing maintenance. 
The emergency backwash is accomplished by attaching a hose between the manual sluice inlet valve (FRW-V-102, 202, or 302) to the filter to be backwashed and the normal common backwash line at the outlet of manual valve BBW-V-004. The hose connection is shown on P\&ID H-1-80550, Sheet 9. The hose must be equipped with Kamlok $B$ connectors that match the pre-installed Kamlok ${ }^{\circledR}$ connectors of the valves. The hose connection allows the failed valve to be bypassed so that backwash flow can be routed to the settler tanks once the respective sluice valve and BBW-V-004 valve are opened. Except for this hose arrangement, the normal backwash mode is followed.

\subsubsection{Filter Sparge or Backwash Using Recirculation Pump}

If the Basin Water skimmer pump is unavailable for a garnet filter backwash or top sparge, the Basin Water recirculation pump can be used. There are existing piping connections that extend from either pump to the IWTS booster pump skid. The normal path using the skimmer pump is through FRW-V-010. This valve and AOV FRW-V-006 are assured closed, and manual valves FRW-V-004 and 005 are opened. This arrangement supplies water to the backwash inlet header, and the normal sparge or backwash procedure is followed. The flowrate may have to be adjusted to accommodate the difference in pump flow and pump head pressure. The booster pump may also need to be started to force flow through the other two filters during this operation to meet their flow and head requirements.

Particulate buildup in a filter is very gradual, and ample time exists to schedule a sparge or backwash when the skimmer pump is available. Therefore, this operation would be necessary only if a skimmer pump breaks down before a scheduled sparge or backwash.

\subsubsection{Backflushing KO Pot Filters}

A situation may occur that would render a KO pot unusable early in its life. This is the introduction of lighter particles that would attach to the surface of the filters (blinding). This would severely restrict the flow through the filter and increase the pot differential pressure. The proposed method to remove these particles from the filter surface involves shutting down the submerged pumps, opening the backflush outlet nozzle, and then attaching the pump outlet hose to the pot nozzle that is normally the outlet. This requires an adaptor to match the 2-in inlet connector on the hose from the pumps to the 3-in outlet nozzle of the pot. When the pumps are restarted, the reverse flow should blow the lighter particles off the filter surface and carry them out the backflush nozzle. The actual procedure has not been finalized and will depend on operational experience.

\subsubsection{CVD Water Return}

Some basin water is retained by the MCO and fuel when it leaves the basin. This water is removed by the draining and drying activities conducted at the CVDF. The water is initially treated at the CVDF to reduce impurities and radioactive contamination and is periodically returned to the IWTS by tanker truck. The truck is brought into the Transfer Bay Area, and the 
tank connected by hose to a IWTS 2 -in male Kamlok $ß$ connector (normally capped) reserved for this purpose. The water is injected into the IWTS through FRW-V-003 and FRW-CV-001 that are located near the west face of the IXC caves. The connection allows this water to bypass the settler tanks and enter the suction side of the booster pump for final filtering and treatment. The IWTS is designed to accept $\leq 60$ GPM. The water is added to the pool inventory. Any leakage from the temporary connections will be cleaned promptly so that the work area is maintained with no radioactive contamination that can be smeared.

\subsubsection{Excess Water Removal}

The ETF in the 200 Area is designated to receive excess water from the basin pool that accumulates from demineralized water washdowns and water returned from the CVDF. Filtered and conditioned water is removed from the IWTS through valves IXR-V-004, IXR-CV-012, and a 2-in male Kamlok $®$ capped loadout connection near the west face of the IXC caves. The present plans are for a tanker truck to be brought into the Transfer Bay Area, a hose connected between the truck and the IWTS loadout connection, and the required portion put into the truck. The IWTS line has sufficient normal pressure so no separate water removal pump is needed. The water will then be transported to the ETF for final treatment and disposal. Truck venting and any leakage will be within the basin, and any leakage will be cleaned promptly so that the work area is maintained with no smearable radioactive contamination. The present water disposal agreements include dedicating a transport truck to the SNFP during operations that is housed and based in the $100 \mathrm{~K}$ Area.

\subsection{SYSTEM SHUTDOWN}

A system shutdown is normally accomplished by placing the system controller in Mode 1 - FRS Shutdown (IWTS fail safe). This trips the pumps and closes all the AOVs except the garnet filter vent valves FRW-V-104, 204, and 304. This is the safe shutdown mode. Any automatic trips will also place the system in Mode 1, including a loss of communication between the PLC and $\mathrm{CP}-\mathrm{A}$. The manual valves can be left in the normal position. Under long term shutdown conditions, basin operations may choose to isolate portions of the system manually.

\subsection{SAFETY MANAGEMENT AND ADMINISTRATIVE CONTROLS}

Special considerations were made during the design and fabrication stages to preclude unsafe operating conditions. Safety management and administrative controls that will be used by the IWTS are those established for the $105 \mathrm{KW}$ Basin. 


\subsection{LIMITATIONS AND PRECAUTIONS}

\subsubsection{IXM Operating Life}

The 105 IXMs are operated within the following parameters:

- $\quad<4 \mu \mathrm{S} / \mathrm{cm}$ outlet conductivity

- $\quad>99 \%$ cesium removal efficiency

- $\quad<100 \mathrm{nanoCi} / \mathrm{g}$ of alpha waste collected.

An IXM outlet conductivity of $<4 \mu \mathrm{S} / \mathrm{cm}$ prevents the water in the basin from exceeding a $\mathrm{pH}$ of 5 on the acid side and a $\mathrm{pH}$ of 9 on the base side. Exceeding these $\mathrm{pH}$ limits accelerates the corrosion rates of the structural elements and fuel. This also limits the TRU burden on an IXM that conditions just pool water; however, the life of the IWTS IXMs will probably depend on the TRU and cesium released by the FRS decapping and cleaning processes. The shielding evaluation in HNF-2760 shows that an IXM with the worst case source term is still within the dose rate limits for transportation.

Alpha concentrations exceeding 100 nanoCi/g of waste make the waste TRU, and this level is an economic limit. The disposal cost of TRU waste is prohibitive, and the disposal path is uncertain. This issue should be strictly avoided whenever possible. A level below 100 nanoCi/g allows disposal of the IXM as low level waste.

\subsubsection{IXM and Garnet Filter Venting}

An isolated or spent and drained IXM should be continually vented to protect against a hydrogen buildup. Hydrogen is generated by the effect of radiation (radiolysis) on the water retained in the IXM and can be a hazard if it is allowed to build up and concentrate.

If a garnet filter is isolated, it should remain filled with water and should be vented to preclude any hydrogen buildup within the vessel. The filters are equipped with pressure relief valves that vent to the basin and protect the vessel from over pressure conditions, but there is a precaution to ensure that the vent valves (FRW-V-104, 204, and 304) and the vent path through the HEPA filters are open during this period.

\subsubsection{Garnet Filter Operation}

The differential pressure across a filter should not be allowed to exceed 45 PSID to preclude internal structural damage to the filter. Normally, a filter is sparged and/or backwashed when the differential pressure reaches 25 to 30 PSID.

A media air agitation (sparge) of a filter releases airborne radiological contamination that must be HEPA filtered before venting into the atmosphere. The precaution and limitation would be to ensure that the HEPA train is operational before conducting a filter air sparge. This includes 
ensuring that the moisture separator is drained or has sufficient capacity, the air heater is operating, the filter pressure drops are satisfactory, the filter housings are sealed, and all HEPA train valves are still blocked open (they have been secured in the open position).

\subsubsection{System and Pump Flow}

The submersible pumps and booster pump must maintain suction flow to the FRS during FRS decapping and fuel processing operations to reduce the amount of canister liquor and corrosion and fuel particles that enter the main basin pool. The FRS design is based on flows of $80 \pm 10$ GPM from the decapping station, $80 \pm 10$ GPM from the PCM, and $160 \pm 10$ GPM from the process table secondary cleaning station. This totals a nominal IWTS system flow of 320 GPM. The precaution is to maintain this flow balance during FRS operations.

A minimum of 70 GPM from the decapping station allows $95 \%$ to $98 \%$ of the canister liquor to be captured and treated by the IWTS. The minimum flows of 70 GPM and 150 GPM to the PCM and process table will capture enough particles to maintain pool visibility and allow processing operations to continue as scheduled.

The booster pump is not submerged and has a minimum suction requirement of 5 PSIG NPSH. This requirement must be met or exceeded to prevent pump cavitation.

\subsubsection{KO Pot Operation}

KO pot operation must allow adequate flow so that FRS minimum flows are maintained and the booster pump suction has adequate suction ( $\geq 5$ PSIG NPSH). The KO pot remains in service until a differential pressure is reached across the $500 \mu \mathrm{m}$ outlet screen that prevents adequate flow through the pot. When the booster pump has inadequate suction, the system is automatically shut down to prevent pump cavitation damage. This could negatively affect FRS processing operations by causing materials to be released into the pool. During KO pot acceptance testing, this differential pressure was determined to be approximately 15 PSID. The current limit on KO pot operation is based on the KO pot screen analysis (SNF-4729) that used 12 PSID. Therefore, the pot must be changed out when it reaches this pressure differential across the screen.

\subsubsection{Basin Water Cleaning}

If the ${ }^{137} \mathrm{Cs}$ activity of the overall pool, as measured by a center of basin sample, exceeds $10 \mu \mathrm{Ci} / \mathrm{L}$, the IWTS IXMs must be operational to lower the pool activities to comply with Process Standard 408. The IWTS equipment may already be operational in support of the FRS fuel processing activities; but the FRS, debris removal, and sludge disturbing activities must cease if this activity level exceeds $12 \mu \mathrm{Ci} / \mathrm{L}$ without permission of Environmental Safety and Permitting. Permission will not be granted if this activity level exceeds $15 \mu \mathrm{Ci} / \mathrm{L}$, and the IWTS IXMs are required to help lower the ${ }^{137} \mathrm{Cs}$ level until satisfactory sample results are obtained. 


\subsection{CASUALTY EVENTS AND RECOVERY PROCEDURES}

A casualty event considered for the present design is failure of any pressurized portion of the system that releases radioactive water and sludge into the Transfer Bay Area. The system would be shut down immediately by placing the computer control in Mode 1 - FRS Shutdown (IWTS fail safe shutdown). This shuts down the pumps and isolates the failure. The water and contamination would then be cleaned up using standard procedures and exposures ALARA. The failed portion of piping would be decontaminated to the extent that repairs could take place and the cause of failure would be determined and evaluated. The worst case conditions during FRS operation and garnet filter backwash were examined in the spray leak accident calculations of HNF-1777. All postulated leaks are within risk evaluation guidelines. The source term of concern is the TRU, potentially associated with the cesium, not the cesium itself.

Types of credible casualty events that could potentially occur in a garnet filter vessel are bound by a hydrogen explosion. This accident combines an isolated filter annulus, a vessel leak which drains the annulus headspace, allowing hydrogen and oxygen, mainly from water radiolysis, to accumulate, and possibly explode. The event was determined "extremely unlikely" by HNF-1777, but the event would result in a damaged filter and a contamination release to the basin and site boundary. As above, decontamination would involve ALARA guidelines, including filter and header replacements; but the event is within risk evaluation guidelines.

Criticality and excessive radiation exposure have been precluded by preventive design measures as documented by the ALARA optimization report SNF-5153.

\subsection{OPERATING PROCEDURES}

A complete listing of the current IWTS operating procedures (OPs) can be obtained online with Acrobat Reader $(B)$ and through computer access to the Tech Pro Main Menu.PDF. Refer to the screen called "SNFP Technical Procedures Online," select "Operating," refer to "OP-70-" procedures and their titles, select the procedure of interest, and print the procedure if it is necessary to obtain a copy. To ensure procedural compliance, always refer to this source to obtain the latest revision of the procedure of interest before planning and performing work. 


\subsection{KW BASIN IWTS TESTING AND MAINTENANCE}

\subsection{TEMPORARY CONFIGURATIONS}

There are no known temporary maintenance configurations. For instance, replacement or temporary maintenance shutdown of an IWTS pump requires shut down of the system; but it does not require a special configuration. Replacement of an IXM requires that the spent IXM be taken out of service, but operating with the other two (2) IXMs is a normal configuration. Water sparging, backwashing, and air sparging garnet filters could be considered temporary configurations. The filters need to be valved to allow Basin Water skimmer pump flow, alternate filters are used for normal filtering operations, and an air compressor connected for air sparging. However, these configurations are a part of periodic planned operations rather than maintenance.

\subsection{TSR-REQUIRED SURVEILLANCE}

There are no Technical Safety Requirements (TSRs) directly relating to the IWTS. There is a TSR in Section 5.9.2, Part 6, of the FDH K Basins Technical Safety Requirements, HNF-SD-SNF-TSR-001, concerning "Unmanned Pumping/Siphoning Controls." The IWTS pumps remove water below the 12.5-ft level in the basin pool and would be limited to 24-hr unmanned operation by this TSR. However, the IWTS plans no significant unmanned operations during the life of the system. The Basin Water skimmer pump can be used with the IWTS water treatment components, but this pump draws water from above this level.

\subsection{NON-TSR SURVEILLANCE}

The type of periodic surveillance to be performed on the IWTS is related to instrument calibration, booster pump inspection, HEPA filter testing and qualification, and pressure vessel Code inspection.

\subsubsection{Instruments}

The flowmeter, pressure indicator, and process radiation signal transmitters are calibrated to assure the remote and local readouts comply with the test signal. It was determined that the flow and pressure sensing instruments would not require testing as these instrument lifetimes far exceed the operating life of the IWTS. The process radiation sensors are associated with the garnet filters and are calibrated every two (2) years.

\subsubsection{Booster Pump}

The only accessible, active component that needs periodic surveillance is the booster pump. These inspections are limited to visual (cracks, leaks, etc.) and bearing vibration measurements. The submerged pumps are not readily accessible for inspection. 


\subsubsection{HEPA Filters}

The two (2) inline HEPA filters must be periodically requalified to meet the required filtration efficiency. The second inline filter is used to provide a conservative estimate of the quantity of emissions released to the atmosphere by the first inline filter. Aerosol penetrant testing is done initially to certify the filters and annually to requalify the filters. The purpose is to ensure that the filters provide $\geq 99.95 \%$ removal efficiency of the representative test aerosol.

The second filter is considered the "sample" filter, and it periodically undergoes a non-destructive assay with a gamma spectrometer in the counting lab to decide the quantity of ${ }^{137} \mathrm{Cs}$ collected since the last assay. The ${ }^{137} \mathrm{Cs}$ value is used to estimate the isotopes of ${ }^{238} \mathrm{Pu}$, ${ }^{239 / 240} \mathrm{Pu},{ }^{241} \mathrm{Pu},{ }^{241} \mathrm{Am}$, and ${ }^{90} \mathrm{Sr}$ if they are not detected by the gamma spectrometer. The detection limit for the gamma spectrometer is $\leq 100$ nanoCi for ${ }^{137} \mathrm{Cs}$. A log is maintained with the dates of filter installation, inspections, and results of assays. The assays are performed quarterly when a garnet filter air sparge has occurred, or the assays are performed annually if the vent has been used for only passive ventilation.

\subsubsection{Code Inspections}

ASME B\&PVC Section VIII, Division 1, examinations are performed by a third party on the settler tank assembly, filter vessels, and their over pressure protection equipment.

\subsection{MAINTENANCE}

\subsubsection{Maintenance Philosophy}

Usually, the maintenance option with the lowest cost is a direct replacement and throw away approach. Though costs are a key factor, other considerations, such as ALARA adherence and total system down time, also contribute to the decision to pursue this approach. These items are identified as all underwater fittings, pumps, flowmeters, and hoses. These components have been designed for remote replacement and/or ease of maintenance access. The components to be remotely replaced have been modularized and fastened with standard captive nuts designed for use with long pole tools.

Equipment above the pool is maintained in place, using planned maintenance, e.g., predictive, periodic, corrective, etc. The IWTS maintenance philosophy complies with the following guidelines: 
- Basing the IWTS maintenance program on the limited design life of the equipment

- $\quad$ Reducing radiation exposure (ALARA) during maintenance operations

- Being able to decontaminate all equipment

- $\quad$ Basing ease of equipment decontamination on the frequency of change out

- Having a minimum of contamination traps on IWTS equipment and piping

- Designing equipment to allow safe handling by maintenance operators wearing protective clothing and gloves by eliminating sharp protrusions that could abrade or cut protective clothing and gloves

- Using common components, wherever possible, to reduce maintenance training and procedures

- Designing equipment to allow bagging or other confinement services for contaminated handling

- Designing equipment with lifting features to aid removal and replacement.

\subsubsection{Special Tooling}

\subsubsection{Long Reach Tools - Existing}

The upper end of all the fuel handling tools is designed to be operated or otherwise manipulated from the working level of the basin. The lower end of the tool is designed to engage the item of interest, e.g., a fuel assembly or element, a fuel canister, a sample container, a miscellaneous item of equipment, a pump, debris, etc. The long reach tools available to the IWTS are described in System Description for the $K$ Basins Fuel Handling System, HNF-SD-SNF-SDD-014 (MJ Langevin, 1997).

One tool routinely used by the FHS and the FRS is the tool used for opening and closing fuel canister vent valves. It is shown on Drawing H-1-81198. This tool is also used by the IWTS to fit over the KO pot vent valve to open and close the valve. During system operation, the valve is closed. Any gas released from the collected sludge is carried out by the normal flow. When the pot is considered full enough, it is removed and put in a temporary storage position. The valve is then opened to allow gas released from the sludge to escape to the pool.

\subsubsection{Special Component Tools}

Special tools for vendor supplied components are to be minimized. If necessary, they will be provided by the component supplier. None have yet to be identified.

\subsubsection{Rigging}

\subsubsection{IWTS In-Pool Equipment Rigging}

Lifting lugs are provided on the submerged pumps and KO pots. The monorails and the associated hoists, as described in the System Description - Cranes and Hoists Systems, HNF-1914 (WA Frier, 1998), are used to reach and position these components. Monorail 30 is 
in line with the decapper and process table pump stands and the $\mathrm{KO}$ pots. Monorail 28 is in line with the PCM pump. The submerged pumps are not expected to fail during the life of the IWTS, and removal during this period is not expected. However, all equipment in the basin pool can always need replacement and, as a minimum, will be removed at the end of use.

Placement and removal of any submerged pump require the use of the pump lifting assembly as shown on H-1-83991. The assembly is a "below the hook" lifting device that uses the existing monorail and hoist above the pumps. The hoist hook fits in the assembly top shackle. The lower assembly has fixed dual hooks that engage on both sides of the pump. The assembly is rated for $1000 \mathrm{lb}$ and weighs about $28 \mathrm{lb}$.

Moving the KO pots require the use of the lifting tool assembly (KW-KOPH-1). This assembly is rated for $4000 \mathrm{lb}$ and consists of a top handle with an eye bolt for attaching the monorail hoist hook, an extension ( $\sim 16 \mathrm{ft}$ long) that includes a 4000 -lb load cell, and the $\mathrm{KO}$ pot lifting bar hook (see H-1-84014). The approximate weight of the lifting assembly is $80 \mathrm{lb}$. Although the tool is qualified for $4000 \mathrm{lb}$, it normally operates on Monorail 30 that is currently rated for only $2400 \mathrm{lb}$. A pot is estimated to weigh $\sim 2100 \mathrm{lb}$ when it is half full at change out time.

\subsubsection{Transfer Bay Area Rigging}

The 22-ton (maximum) lifts of the IXM during planned periodic removal and replacement activities are conducted with the 32-ton Transfer Bay Area crane. The rigging and precautions are described in the existing critical lift procedure that covers lifts between the staging area and the Transfer Bay Area. The minimum non-IWTS equipment necessary for IXM movement is two (2) certified slings (21,000 lb capacity, each leg), and four (4) certified shackles $(22,000 \mathrm{lb}$ minimum). Other rigging equipment is provided, as required, consisting of spreaders, shackles, choker bars, tag lines, etc. Smaller cranes and rigging are used to remove and replace shield enclosure covers, move a sluice pump, and maintain major components.

HNF-1914 describes the cranes and hoists available in the Transfer Bay Area. The type of lift equipment and use of rigging for possible maintenance of the heavier IWTS components will be decided based on the type of maintenance to be done.

\subsection{SURVEILLANCE AND MAINTENANCE PROCEDURES}

A complete listing of the current IWTS surveillance and maintenance procedures (SPs and MPs) can be obtained online with Acrobat Reader $B$ and through computer access to the Tech Pro Main Menu.PDF. Refer to the screen called "SNFP Technical Procedures Online," select "Surveillance" or "Maintenance," refer to "-70-" procedures and their titles, select the procedure of interest, and print the procedure if it is necessary to obtain a copy. To ensure procedural compliance, always refer to this source to obtain the latest revision of the procedure of interest before planning and performing work. 


\subsection{FIGURES}

These figures are found in order on the following pages:

Figure 7-1 KW Basin IWTS Flow Schematic

Figure 7-2 KW Basin IWTS Equipment in the Fuel Pool

Figure 7-3 KW Basin IWTS Equipment in the Transfer Bay Area

Figure 7-4 Transfer Bay Area Equipment Isometric

Figure 7-5 Knockout Pot

Figure 7-6 Settler Tank Assembly

Figure 7-7 Garnet Filter Vessel Schematic

Figure 7-8 Ion Exchange Module 


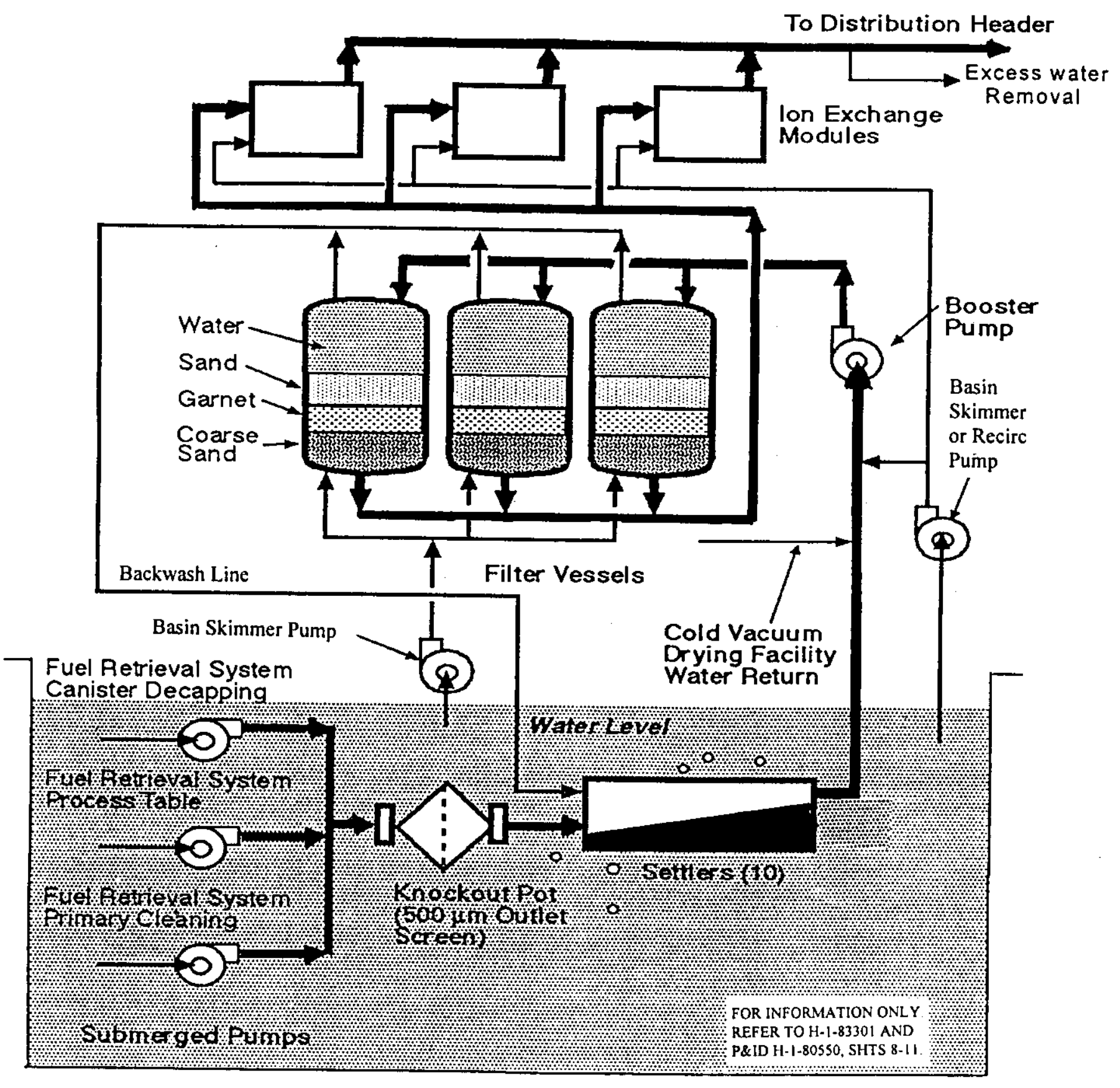

Figure 7-1 KW Basin IWTS Flow Schematic 


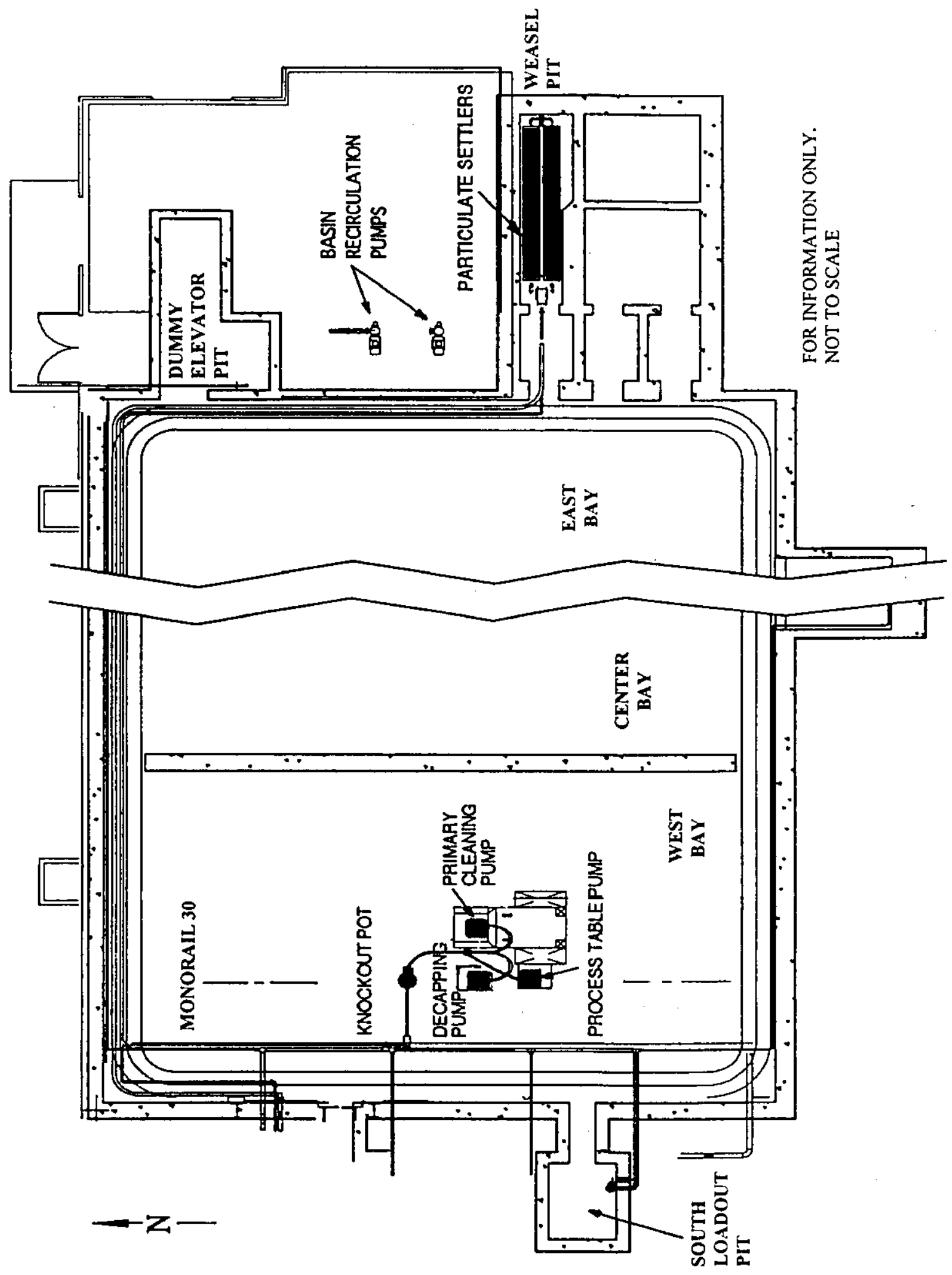

Figure 7-2 KW Basin IWTS Equipment in the Fuel Pool 


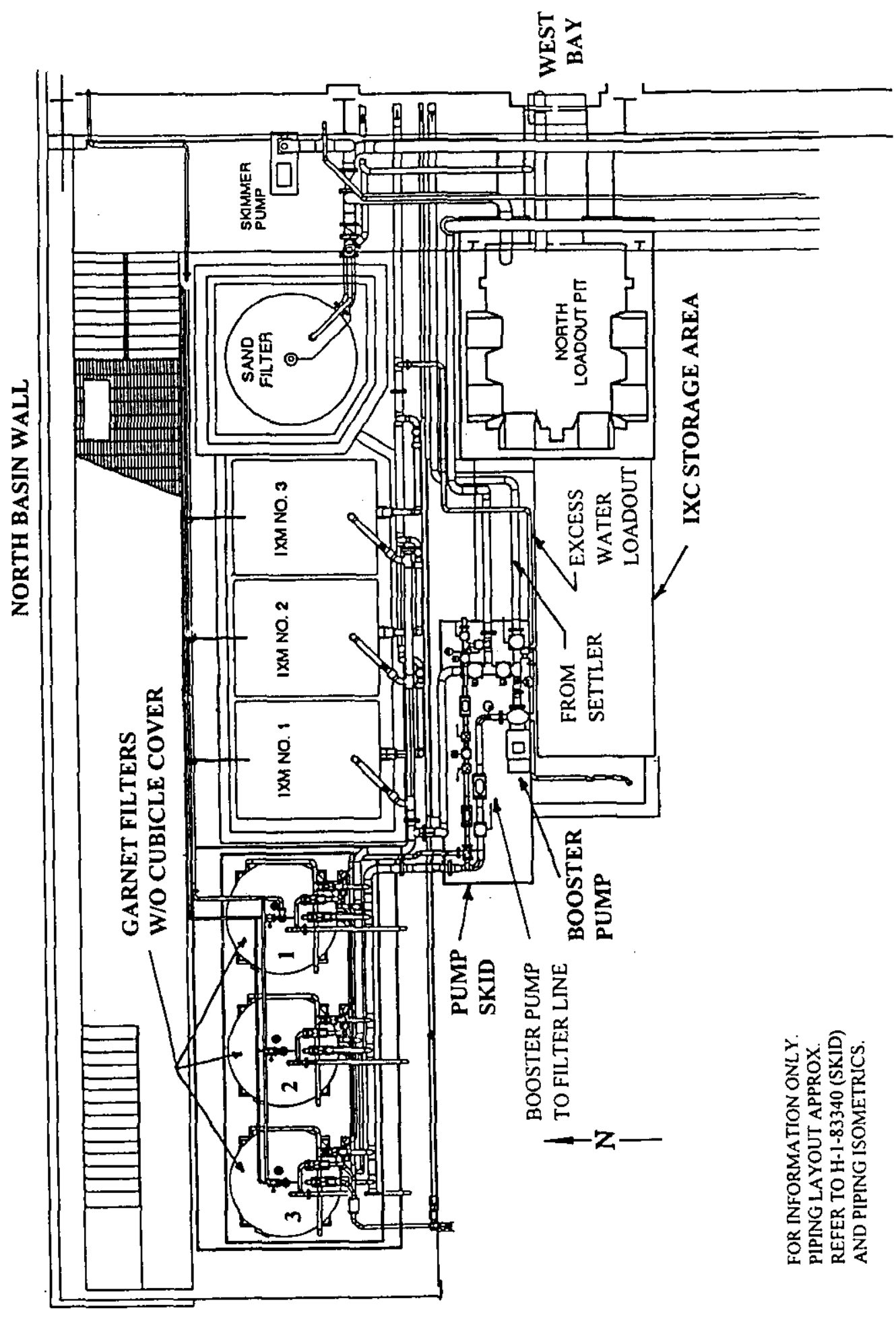

Figure 7-3 KW Basin IWTS Equipment in the Transfer Bay Area 


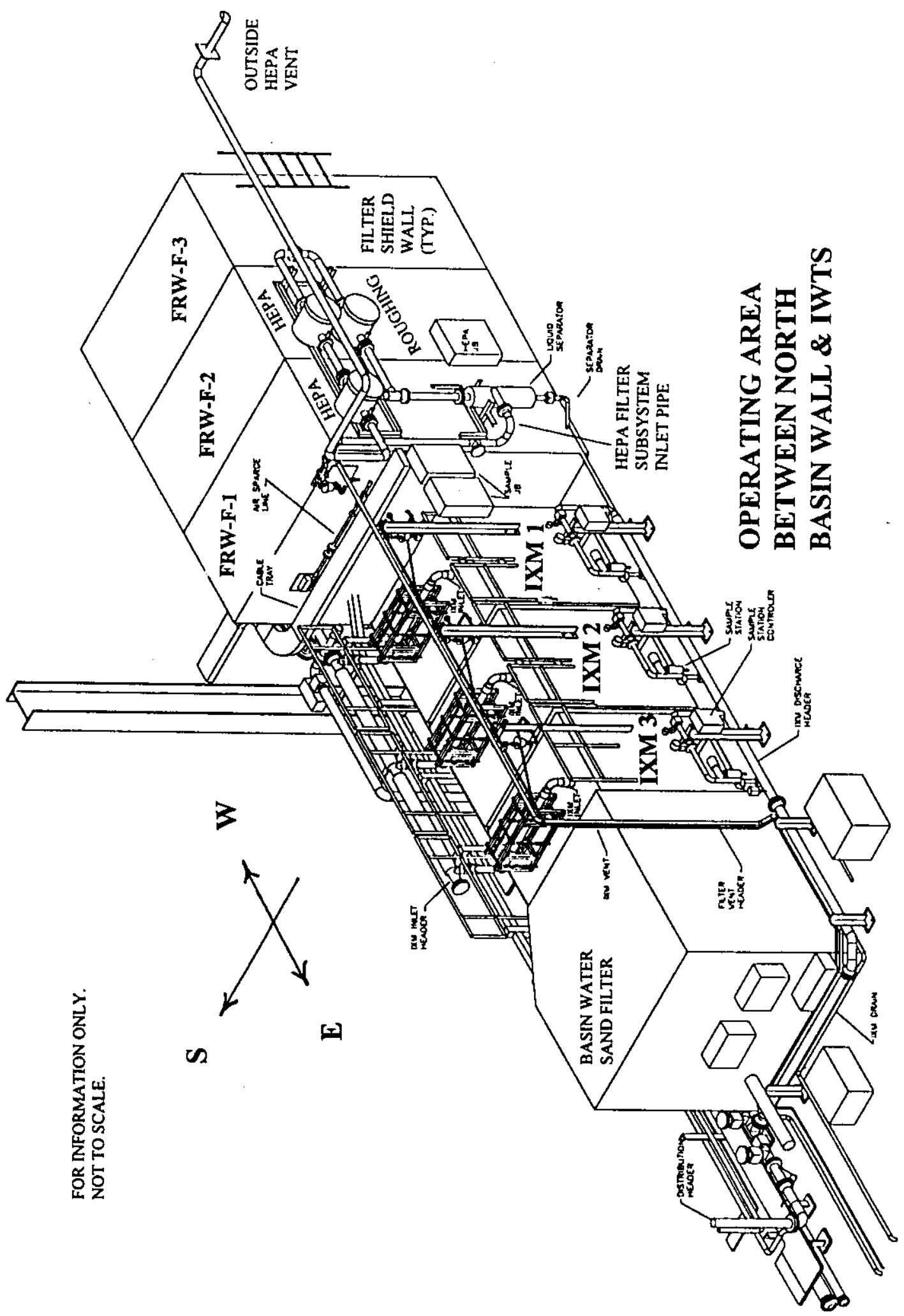

Figure 7-4 Transfer Bay Area Equipment Isometric 

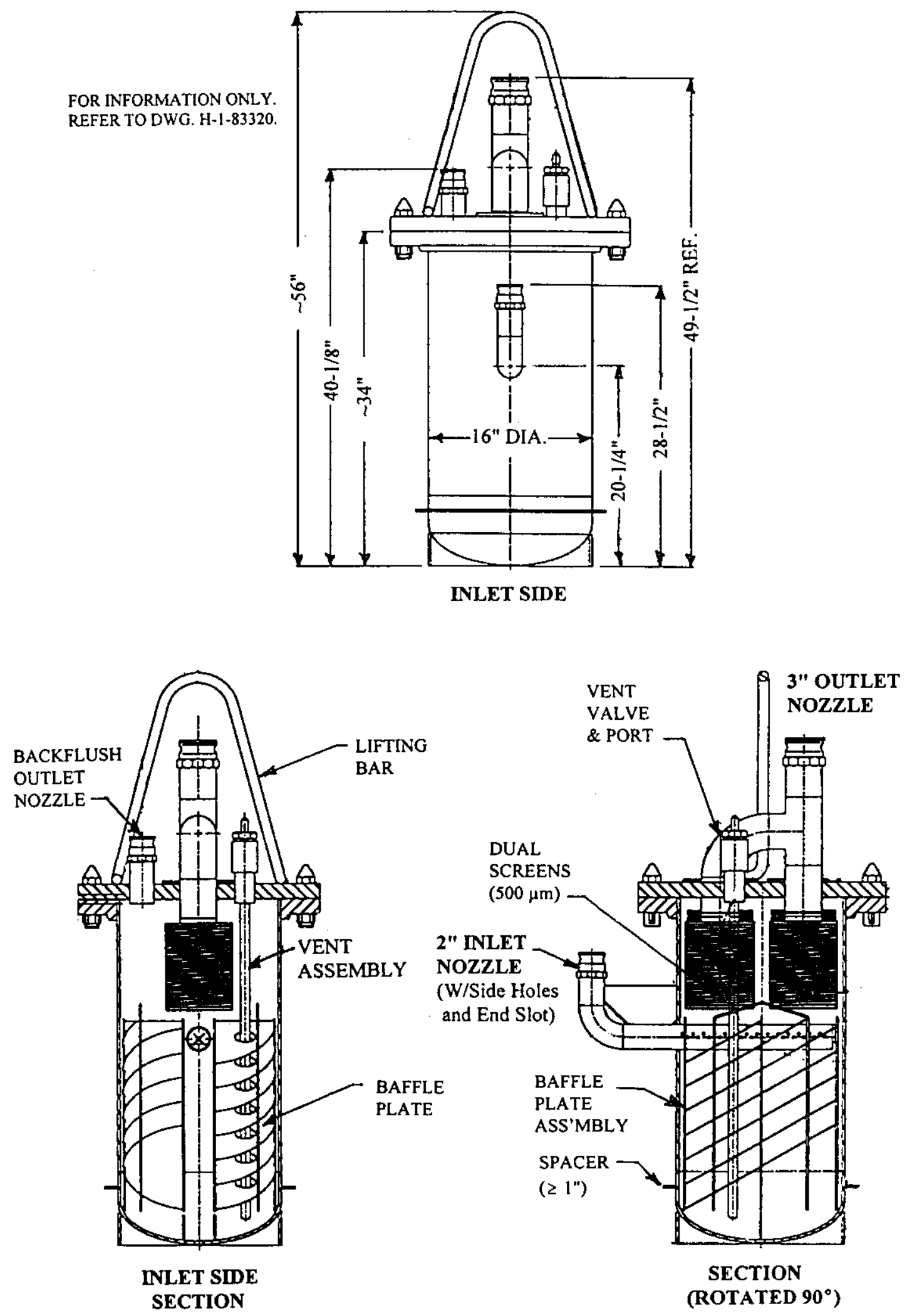

Figure 7-5 Knockout Pot 


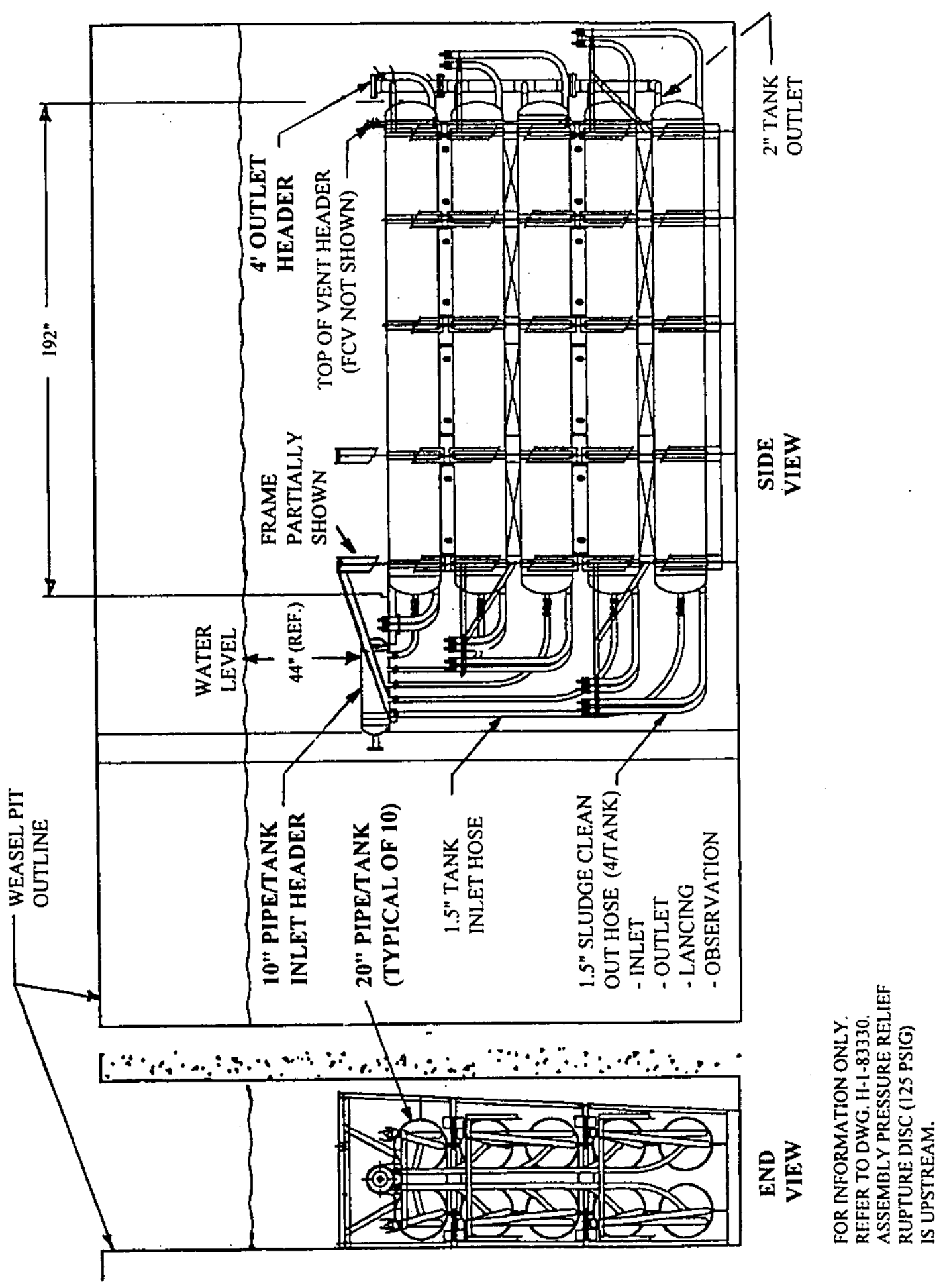

Figure 7-6 Settler Tank Assembly 


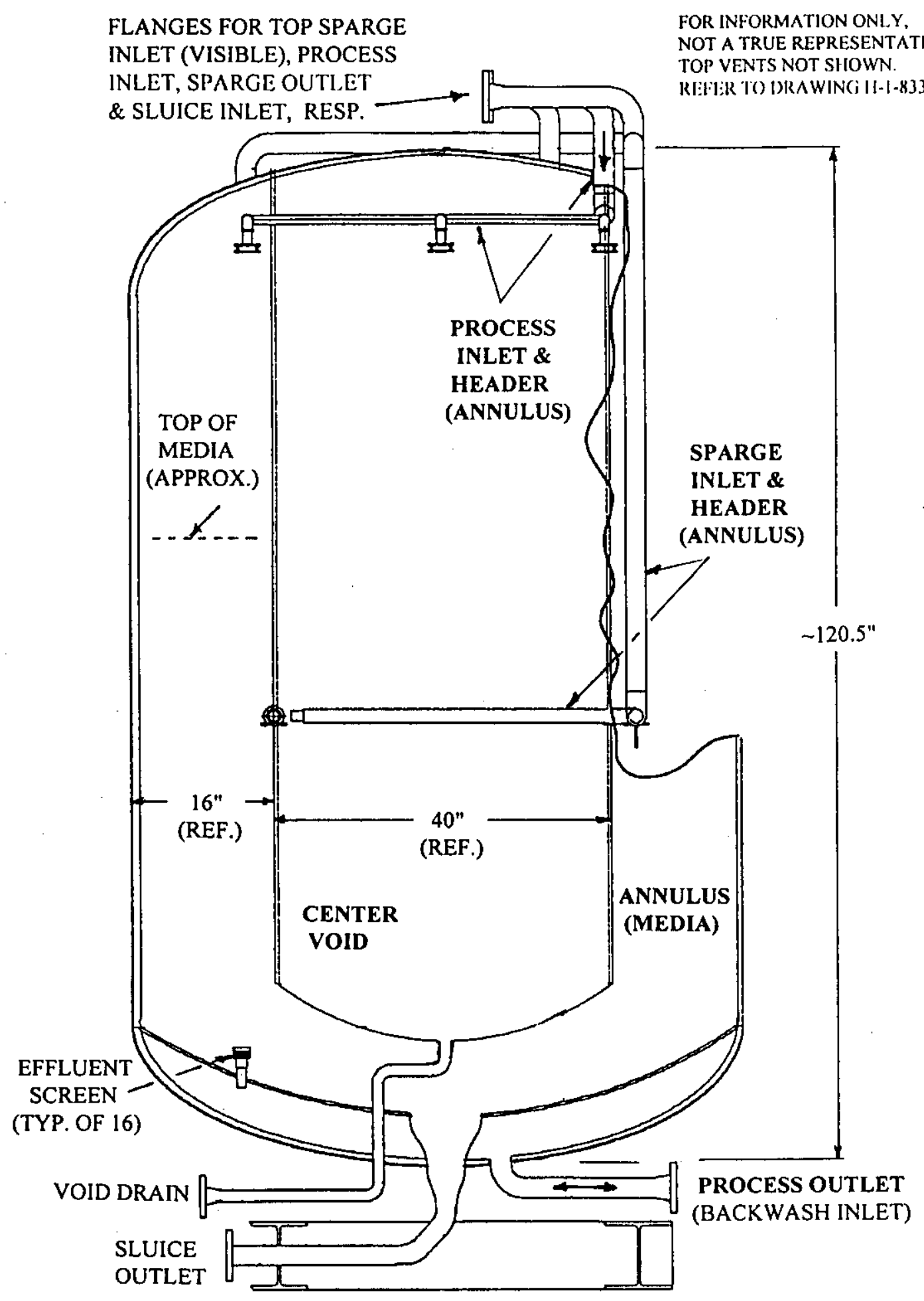

Figure 7-7 Garnet Filter Vessel Schematic 

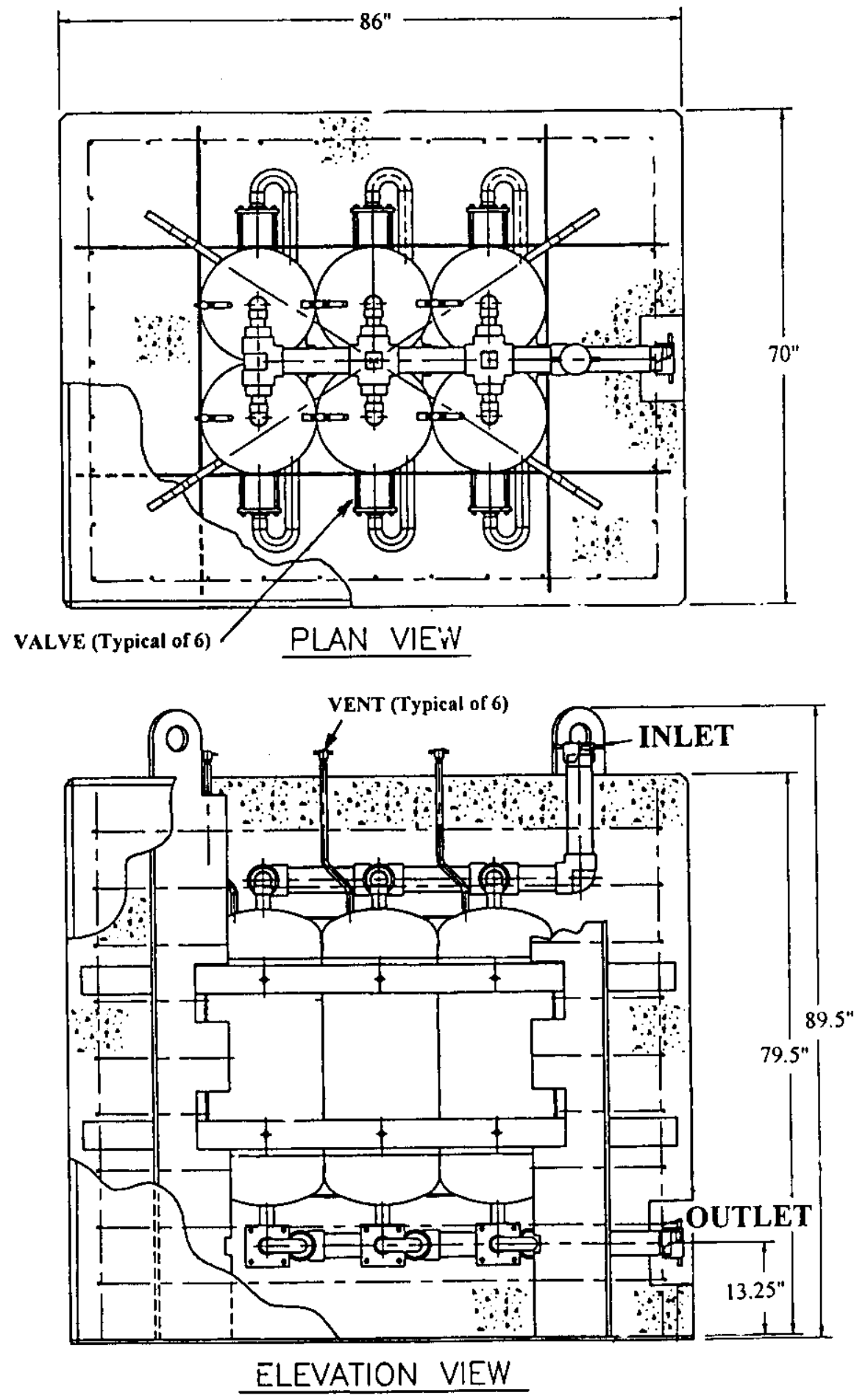

FOR INFORMATION ONLY, REFER TO DWG. H-1 -46279 .

Figure 7-8 Ion Exchange Module 
This page was intentionally left blank. 


\subsection{KW BASIN IWTS REFERENCES}

This section contains letters, professional standards, documents, specifications, drawings, CVI file numbers, and acknowledgment of trademark owners. The references are limited to those used in the SDD text and are not intended to be a complete list of IWTS documentation.

\subsection{DOCUMENTS}

\section{DOCUMENT NO.}

10CFR835

97-SPB-017

98-SFD-169

408

ASME B31.1

ASME N-509-1989

ASME N-510-1989

ASME Section VIII

DOE Order 6430.1A

DOE-RL-92-36

DOE/RL-97-28

DOE/RL-98-02

\section{DOCUMENT TITLE}

Code of Federal Regulations, Occupational Radiation Protection, Subpart K, Washington, D.C.

Letter, SP Burke to EJ Shen, "Evaluation of Houghto-Safe ${ }^{\circledR} 620$ Hydraulic Fluid," dated May 27, 1997.

Letter, CA Hansen (DOE) to RD Hanson (FDH), "Acceptance of the Safety Analysis Documents for the Fuel Retrieval System (FRS), HNF-2032, Revision (Rev.) 0, and K-West Integrated Water Treatment System (KW-IWTS), HNF-SD-SNF-SAD-002," Rev. 2, dated August 31, 1998.

SNF Project Process Standard 408, Environmental Safety Requirements, Rev. 1 (related to DOE Notice of Construction DOE/RL-97-28)

Power Piping Code, ASME (Historically ANSI B31.1)

Nuclear Power Plant Air-Cleaning Units and Components, ASME

Testing of Air Treatment Systems, ASME

Boiler and Pressure Vessel Code, Division 1, Unfired Pressure Vessels, ASME

General Design Criteria, U.S. DOE, Washington, D.C.

Hanford Site Hoisting and Rigging Manual (DOE, 1999)

Radioactive Air Emissions, Notice of Construction, Fuel Removal for 105-KE Basin, Rev. 0, DOE (DOE, 1997), UC-630

Radioactive Air Emissions, Notice of Construction for 105-KW Filter Vessel Sparging Vent, Rev. 0, DOE (DOE, 1998) 
ES-E-146

ES-E-152

GC-LOAD-01

HNF-1777

HNF-1914

HNF-2760

HNF-3165

HNF-4198

HNF-PRO-097

HNF-PRO-259

HNF-PRO-268

HNF-S-0461
Guidance for Procurement and Field Use of Process Hoses, Rev. 1, Chem-Nuclear Systems (C Wingard, 1997) with Appendices A, B, C, and D on different hose specifications

General Specification for US Government Water Treatment System for Hanford $K$ West Basin, Rev. 3, Chem-Nuclear Systems (WS Edwards, 1999) with the following Data Sheets:

ES-E-152-01: Hanford WTS Filter Vessel Assemblies

ES-E-152-02: Hanford WTS Knock Out Pot

ES-E-152-03: Hanford WTS Settler Tank System

ES-E-152-04: Hanford WTS Booster Pump (\&) Skid

ES-E-152-05: Hanford WTS Decapper Pump

ES-E-152-06: Hanford WTS Primary Cleaning Pump

ES-E-152-07: Hanford WTS Process Pump

Standard Architectural-Civil Design Criteria - Design Loads for Facilities, Rev. 12, FDH, (McGinley et al, 1998) - superseded by HNF-PRO-097

$K$ West Integrated Water Treatment System Annular Filter Vessel Accident Calculations, Rev. 5, FDNW (PD Rittmann, 2000) - to be released. HNF-1777 now includes HNF-1778 on spray leaks.

System Description - Cranes and Hoists Systems, (K Basins), Rev. 0, DESH (WA Frier, 1998)

Safety Analysis Report Packaging (Onsite) Ion Exchange Modules, Rev. 0-D, FDH (JH O'Brien, 1999)

$K$ West Basin Sludge Volume Estimates for Integrated Water Treatment System, Rev. 1, DESH (KL Pearce et al, 1998)

Procurement Specification for Ion Exchange Modules (IXM), Rev. 0, DESH (JR Cassidy, 1999) - was WHC-S-0142

Engineering Design and Evaluation, Rev. 0, FDH (TJ Conrads, 1997) - supersedes SDC 4.1 and GC-LOAD-01

Graded Quality Assurance, Rev. 0, FDH

Control of Purchased Items and Services, Rev. 5, FDH

Fuel Retrieval Subproject, Specification for Design of the SNF Project, Rev. 1, (BD Groth, 1998) - previously WHC-S-0461 
HNF-S-0564

HNF-SD-GN-DGS-30006

HNF-SD-SNF-CSER-011

HNF-SD-SNF-FDC-003

HNF-SD-SNF-RD-001

HNF-SD-SNF-RPT-007

HNF-SD-SNF-SAD-002

HNF-SD-SNF-SDD-014

HNF-SD-SNF-SDD-016

HNF-SD-SNF-TSR-001

NFPA 69

PF-001

SNF-4297
Specification for Design, Fabrication, Testing, and Technical Assistance for the $K$ West Basin Water Treatment System, Rev. 1A, DESH (KH Bergsman, 1998)

Guidelines for Assessing Seismic Adequacy of Existing Performance Category Equipment at the Hanford Site, Rev. 2, Numatec Hanford (TJ Conrads, 1997)

CSER 98-001: Criticality Safety Evaluation Report for the K West Basin Integrated Water Treatment System, Rev. 3, Fluor Daniel Northwest (DG Ericksen, 1999)

Functional Design Criteria for the $K$ West Basin Integrated Water Treatment System, Rev. 2, DESH (KH Bergsman, 1998), including ECN-641398

Spent Nuclear Fuel Project Standards/Requirements Identification Document, Rev. 2, FDH (SJ Dechter, 1999)

Application of the Office of Civilian Radioactive Waste Management $Q A$ Requirements to the Hanford Nuclear Fuel Project, Rev. 3, FDH (RL McCormack, 1999)

$K$ West Integrated Water Treatment System Subproject Safety Analysis Document, Rev. 2, FDNW (LS Semmens, 1998)

System Description for the K Basins Fuel Handling System, Rev. 0, DESH (MJ Langevin, 1997)

System Description - The Basin Water Systems, Rev. 0, DESH (JM Kurta, 1998)

K Basins Technical Safety Requirements, Rev. 1A, FDH

Explosion Prevention Systems, National Fire Protection Association

Calculation, "Hanford Pool Filtering System - Settler Size," Rev. 0, Chem-Nuclear Systems, (RT Anderson, 1997)

Human Factors Engineering (HFE) Report for the Safety Analysis Report (SAR), Rev. 0, DESH (LC Mauws, 1999) 
SNF-4331

SNF-4592

SNF-4670

SNF-4671

SNF-4729

SNF-4774

SNF-4913

SNF-4916

SNF-5153

SNF-5163

SNF-5244

SNF-5906

UBC -94

UNI-410
System Design Description for the Fuel Retrieval System, Rev. 0 , DESH (BD Groth, 1999)

Integrated Water Treatment System - K West Settler and Weasel Pit Seismic and Drop Analysis, Rev. 0, DESH (LC Mauws, 1999)

Integrated Water Treatment System - K West Knockout Pot Drop and Seismic Analysis, Rev. 0, DESH (LC Mauws, 1999)

Integrated Water Treatment System - $K$ West Basin Ladder Logic, Rev. 1, FDH (SA Najjar, 2000) - refer to latest revision

$K$ West Knockout Pot Screen Erosion and Impact Analysis, Rev. 0, DESH (LC Mauws, 1998)

Evaluation of Integrated Water Treatment System (IWTS)

Compliance to DOE Order 6430.1A, Rev. 0, FDH (KH Bergsman et al, 1999)

Integrated Water Treatment System Factory Acceptance Test Acceptance Report, Rev. 0, FDH (LC Mauws, 1999)

$105 \mathrm{~K}$ West Basin Water Treatment Report - $105 \mathrm{~K}$ West PLC 2 Program, Rev. 0, FDH (LC Mauws, 1999)

ALARA Report for the Integrated Water Treatment System (IWTS) - Project A.9, Rev. 0, FDH (DR Precechtel, 1999)

Integrated Water Treatment System Pump Lifter Strength Evaluation, Rev. 0, FDH (JS Huisingh, 1999)

Integrated Water Treatment System Knockout Pot Lifting Tool Assembly, Rev. 0, FDH (MA Islam, 1999)

105 KW SNF Basin Water Sample Analysis Plan, FDH, Rev. 0, (PE Stanley, 2000)

Uniform Building Code, 1994 Edition (or later), International Conference of Building Officials, Whittier, CA

Functional Design Criteria, Supplemental N Reactor Irradiated Fuel Storage, $105 \mathrm{KW}$, Rev. 0, United Nuclear Inc. 
WAC 296-104

WHC-EP-0063-4

WHC-SD-GN-ER-10006

WHC-SD-NR-CSER-011

WHC-SD-SNF-DGS-001

WHC-SD-WM-SAR-062

WMH-9852504
Washington Administrative Code, Board of Boiler Rules, Substantive

Hanford Site Solid Waste Acceptance Criteria, Rev. 1, WHC (NP Willis, 1996)

K Basins Floor Loads and Calculations, Rev. 0-A, WHC (RM McCoy, 1996)

Criticality Safety Evaluation of the $100 \mathrm{~K}$ Area Ion Exchange Modules and Ion Exchange Columns, Rev. 1, WHC (DG Erickson, 1994)

K Basins Design Guidelines, Rev. 0, WHC (Roe \& Wills, 1995)

K Basins Safety Final Analysis Report, Rev. 3L (FDH, 1999)

Letter, LG Irons (Waste Management Federal Services of Hanford) to DS Takasumi (DESH), "Revision of the Waste Disposal Plan for DE\&S Hanford, Inc. Integrated Water Treatment System Filter Media," dated March 19, 1998 (Attachment)

\subsection{H-1 AND VENDOR DRAWINGS}

\section{DWG NO. SHTS. TITLE}

\begin{tabular}{|c|c|c|}
\hline $\mathrm{H}-1-34736$ & 1 & Piping Plan VI (KW) \\
\hline H-1-46279 & $1-4$ & Ion Exchange Module \\
\hline $\mathrm{H}-1-46311$ & 1 & IXM Lifter, KE \& KW \\
\hline $\mathrm{H}-1-80550$ & 1 & Drawing Index and Legend (P\&IDs) \\
\hline $\mathrm{H}-1-80550$ & 2 & KW Fuel Storage Basin P\&ID Cooling Water System (skimmer) \\
\hline $\mathrm{H}-1-80550$ & 3 & KW Fuel Storage Basin P\&ID Water Cleaning System (recirc) \\
\hline $\mathrm{H}-1-80550$ & $8-11$ & KW Fuel Storage Basin IWTS P\&ID \\
\hline $\mathrm{H}-1-81198$ & 1 & Valve Stem Handling Tool Assembly \\
\hline $\mathrm{H}-1-83301$ & $1-2$ & KW Fuel Storage Basin WTS Process Flow Diagram \\
\hline H-1-83310 & $1-2$ & KW Fuel Storage Basin WTS General Arrangement (plan) \\
\hline H-1-83311 & 1 & KW Fuel Storage Basin WTS General Arrangement (elevation) \\
\hline H-1-83320 & $1-3$ & KW Fuel Storage Basin WTS Knock-Out Pot Assembly and Details \\
\hline $\mathrm{H}-1-83326$ & $1-2$ & IWTS In-Pool Equipment Submersible Pump Adaptor Assembly \\
\hline $\mathrm{H}-1-83330$ & $1-3$ & KW Fuel Storage Basin IWTS Settler System Assembly and Details \\
\hline H-1-83332 & $1-3$ & KW Fuel Storage Basin IWTS Settler Frame Assembly and Details \\
\hline H-1-83340 & $1-4$ & KW Fuel Storage Basin WTS Booster Pump Skid Assembly and Details \\
\hline H-1-83341 & $1-4$ & KW Fuel Storage Basin WTS Annular Filter Vessel Assembly and Details \\
\hline H-1-83342 & $1-3$ & KW Fuel Storage Basin WTS Filter Vessel Frame and Shielding \\
\hline
\end{tabular}




\section{DWG NO. SHTS. TITLE}

H-1-83343 $\quad 1 \quad$ KW Fuel Storage Basin IWTS Filter Vessel Inlet Baffle

H-1-83344 1 KW Fuel Storage Basin IWTS Filter Vessel Effluent Screen

H-1-83345 1 KW Fuel Storage Basin IWTS Filter Vessel Relief Screen

H-1-83346 1 KW Fuel Storage Basin IWTS Filter Vessel Top Sparger Screen

$\mathrm{H}-1-83400 \quad 1 \quad$ Drawing Index and Legend (electrical)

H-1-83401 1 Single Line Diagram MCC-8

H-1-83402 1-4 MCC 8480 V Power Distribution Wiring Diagrams

H-1-83403 1-15 PCL-2 Elementary Wiring Diagrams

H-1-83404 1-9 PCL-2 Panel, Terminal, and Junction Box Diagrams

H-1-83991 1 IWTS Pump FRW-P-1, 2 \& 3 Lifting Assembly

H-1-84014 1-2 IWTS KOP Lifting Tool Assembly

DW-213(1) 1-2 FRS In-Pool Equipment - Submersible Pump Stand Assembly (for FRW-P-1)

DAG-330 1-12 FRS Primary Clean Machine Base Assembly (for FRW-P-2)

DAG-356 ${ }^{(1)} \quad$ 1-2 FRS In-Pool Equipment - Submersible Pump Stand Assembly (for FRW-P-3)

Note (1): The above FRS DW drawing is from British Nuclear Fuels, Ltd., and the FRS DAG drawings are from Westinghouse Corporation. The drawings are found in FRS CVI 50062.

\subsection{VENDOR INFORMATION}

\subsubsection{Certified Vendor Information (CVI)}

CVI 50062 Specifications, Drawings, and Manuals Related to Procurement of the FRS In-Pool Equipment (includes submersible pump stands and PCM base for IWTS pumps FRW-P-1, 2, and 3)

CVI 50082 Vendor Data for the KW Basin Integrated Water Treatment System (Project A.9)

\subsubsection{Trademark Data}

Refer to the Trademark Disclaimer statement on the SDD cover sheet. Certain products were identified in the SDD with registered $\otimes$ or pending ${ }^{T M}$ trademarks, usually assuming the registration has been obtained if it cannot be proved otherwise. The following products and companies are mentioned in the SDD:

Acrobat Reader ${ }^{\circledR}$ is a registered trademark of Adobe Systems, Inc., of San Jose, CA. 
Ashcroft ${ }^{\circledR}$ is a registered trademark of Dresser Industries, Inc., of Dallas, Texas.

Check-All ${ }^{\circledR}$ and Check-All Valve ${ }^{\circledR}$ are registered trademarks of the International Valve Corporation of Des Moines, Iowa (previously Check-All Valve Company of Des Moines).

Chromalox $\otimes$ is the registered trademark of the Edwin L. Wiegand Company of Pittsburgh, PA. Previously was owned by the Emerson Electric Company of St. Louis, MO.

Duralife ${ }^{\circledR}$ is a registered trademark of Dresser Industries, Inc., of Dallas, TX.

Eberline No registered or pending trademark was found for Eberline.

Empro® is a registered trademark of the Empro Manufacturing Company, Inc., Indianapolis, ID.

Fisher $(B)$ is a registered trademark and the Rosemount ${ }^{\mathrm{TM}}$ line is a pending trademark of Fisher ${ }^{\circledR}$ Controls of Marshalltown, IA.

Flanders ${ }^{\circledR}$ is a registered trademark of Flanders ${ }^{\circledR}$ Filters, Inc., of Washington, NC.

Flotect $^{\text {TM }}$ is a pending trademark of Dwyer Instruments, Inc., of Michigan City, ID.

Flow-Tek refers to Flow-Tek, Inc. of Columbia, SC. No registered or pending trademark was found for this name.

Hawkeye ${ }^{\circledR}$ is a registered trademark of Veris Industries, Inc., of Wilsonville, OR.

Honeywell $\circledast$ is a registered trademark of Honeywell, Inc., of Minneapolis, MN.

Houghto-Safe $\circledast$ is a registered trademark of Houghton International, Inc., Valley Forge, PA.

Isolok $®$ is a registered trademark of the Bristol Equipment Company of Yorkville, IL.

Kamlok ${ }^{\circledR}$ is a registered trademark of OPW Corporation of Cinncinati, $\mathrm{OH}$; and previously it was Dover Corp. of New York, NY. The pseudo mark "Camlock" is sometimes erroneously used on the SNFP, but the term is registered by other companies for dis-similar products.

Kunkle $B$ is a registered trademark of Kunkle Industries, Inc., of Fort Wayne, Indiana (previously Keystone International Holdings Corp., Houston, Texas).

Magnehelic $®$ is a registered trademark of Dwyer Instruments, Inc., of Michigan City, ID.

Panasonic ${ }^{\circledR}$ is the registered trademark of Matsushita Electric Industrial Co., LTD., of Kadoma-shi, Osaka, Japan. 
ProMinent ${ }^{\circledR}$ is a registered trademark of the ProMinent Company of Pittsburgh, PA.

No specific trademark data was found for the Vario line of metering pumps.

Purolite ${ }^{\circledR}$ is a registered trademark for the Purolite Company which is a division of BroTech Corporation of Cynwyd, PA. No trademark was found for the NRW line of resins.

Reliance ${ }^{\circledR}$ is a registered trademark of the Reliance Electric \& Engineering Company of Cleveland, $\mathrm{OH}$, and Wilmington, Delaware.

RIS $®$ is a registered trademark of RIS Rochester Scientific Systems, Inc., Radiation Alarms Division, Rochester, NY. No trademark information was found for the MicroLarm product line.

R.S. Corcoran Corporation is located in New Lenox, IL. No registered or pending trademark data was found for this name.

SandPIPER ${ }^{\circledR}$ is a registered trademark of the Warren Rupp Company, Inc., which is now a unit of the IDEX Corporation, both headquartered in Mansfield, $\mathrm{OH}$.

Siemens ${ }^{\circledR}$ is a registered trademark representing the Siemens Group of companies headquartered in Munich, Germany.

Transmag( is a model line of Turbo Instruments, Inc., of Koln, Germany. Transmag has the registered symbol in the catalog cut; but no registered or pending US trademark was found for Transmag, Messtechnic, Turbo, or Turbo Instruments at the US Patent Office.

TRIAC $®$ is a registered trademark of Triac Controls, Inc., Cincinnati, OH.

Val-Matic ${ }^{\circledR}$ is a registered trademark of the Val-Matic Valve and Manufacturing Corp. of Elmhurst, IL.

Warterlink $\otimes$ is a registered trademark of Waterlink $®$ Barneby Suttcliffe, Inc., of Columbus, OH

Windows $®$ and $\mathbf{N T} \circledast$ are registered trademarks of Microsoft $®$ Corporation of Redmond, WA.

WONDERWARE ${ }^{\circledR}$ is a registered trademark of the Wonderware Software Development Corporation of Irvine, CA.

Yokogawa $\otimes^{8}$ is a registered trademark of the Yokogawa Electric Works, Limited, of Musashino-Chi, Tokyo, Japan. 


\section{CORRESPONDENCE DISTRIBUTION COVERSHEET}

Author

DeRusseau, R.R.

Addressee

Precechtel, D.R./Mauws, L.C

MSIN X4-01

Correspondence No.

SNF-4449

Subject: System Design Description for the KW Integrated Water Treatment System

\section{DISTRIBUTION}

Ard, K.E. $\quad$ X3-85

Call, Russ $\quad$ X4-01

Cassidy, J.R. X4-01

Chaffee, G.A. X3-79

Cleveland, K.J. X3-85

Colosi, K.A.(2) X3-85

DeRusseau, R.R.(6) X4-01

Eaton, G.L. $\quad$ S2-45

Fredrickson, J. X4-01

Frier, W.A. X4-01

Higgins, G.V. AB-39

Hunacek, G.S. X3-79

Irwin, J.J. R3-86

Knutson, B.J. $\quad$ X4-04

Kurta, J.M. X4-01

Kurtz, J.E. X3-68

Langevin, M.J. X4-01

Law, K.W. X3-85

Mathews, J.D. X3-65

Mauws, L.C. X3-85

Medford, D.W. R3-86

Moist, G.C. X3-80

Precechtel, D.R. X3-85

Semmens, L X3-79

Splett, D.H. S7-41

Stegen, G.E. X3-76

Watson, D.J. X3-79

K Basin

Proj Files A.9 X3-85

Document Control

(RMIS) 